\title{
Feasibility Study of
}

\section{Supercritical Light Water Cooled Fast Reactors for} Actinide Burning and Electric Power Production

Nuclear Energy Research Initiative Project 2001-001

Progress Report for Work Through June $2002-3^{\text {rd }}$ Quarterly Report

Philip MacDonald

Dr. Jacopo Buongiorno

Cliff Davis

Dr. Kevan Weaver

Professor Ron Latanision

Dr. Bryce Mitton

Professor Gary Was

Dr. Luca Oriani

Dr. Mario Carelli

Dmitry Paramonov

Lawerence Conway

June 2002

Idaho National Engineering and Environmental Laboratory

Bechtel BWXT Idaho, LLC 


\section{Feasibility Study of Supercritical Light Water Cooled Fast Reactors for Actinide Burning and Electric Power Production}

\section{Nuclear Energy Research Initiative Project 2001-001}

\section{Progress Report for Work Through June 2002 3rd Quarterly Report}

Principal Investigators: Philip MacDonald, Dr. Jacopo Buongiorno, Cliff Davis, and Dr. Kevan Weaver

Collaborating Organizations:

Massachusetts Institute of Technology

Principal Investigators: Professor Ron Latanision and Dr. Bryce Mitton

University of Michigan

Principal Investigator: Professor Gary Was

Westinghouse Electric Company

Principal Investigators: Drs. Luca Oriani, Mario Carelli, and Dmitry Paramonov, and Lawrence Conway

June 2002

Idaho National Engineering and Environmental Laboratory Idaho Falls, Idaho 83415

Prepared for the U.S. Department of Energy Under DOE Idaho Operations Office Contract DE-AC07-99ID13727 


\section{Table of Contents}

TABLE OF CONTENTS ................................................................................................................................................................. II

PROJECT DESCRIPTION …….......................................................................................................................................................

TASK 1 RESULTS: ASSESSMENT OF SOLID MODERATORS FOR THERMAL SPECTRUM SCWRS

(INEEL) .......................................................................................................................................................................................

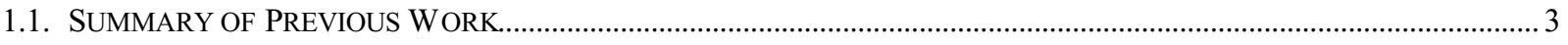

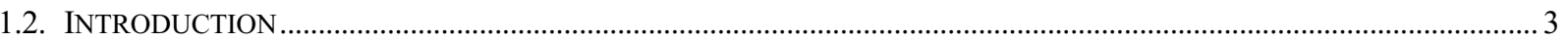

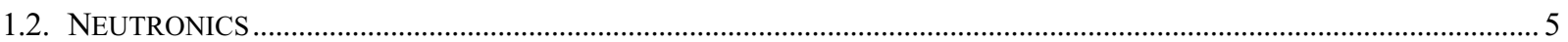

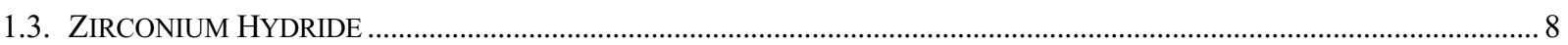

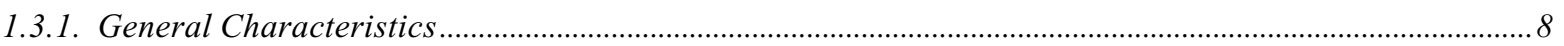

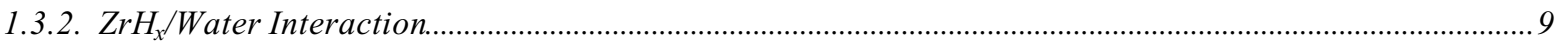

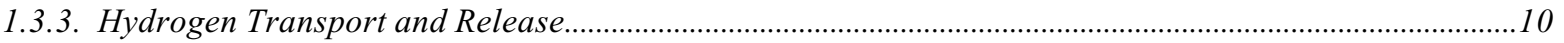

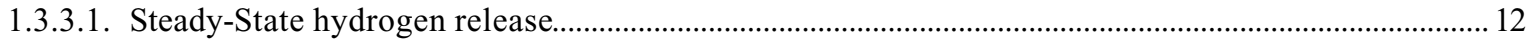

1.3.3.2. Hydrogen Release During Accident Conditions........................................................................... 13

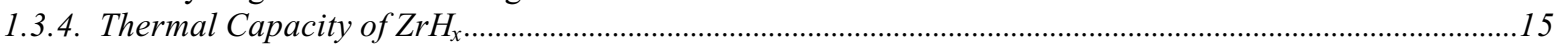

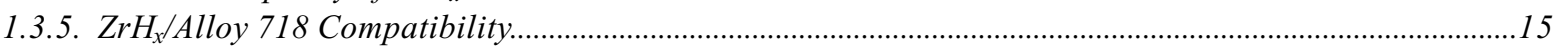

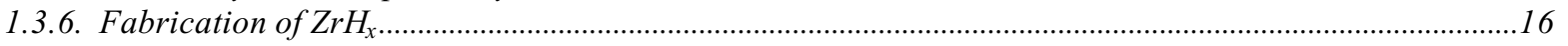

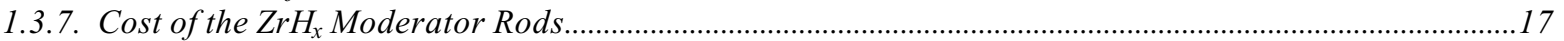

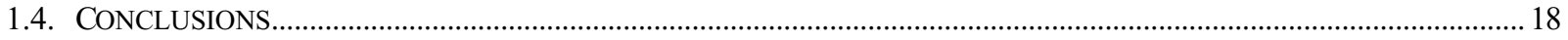

TASK 2 RESULTS: FUEL CLADDING AND STRUCTURAL MATERIAL CORROSIN AND STRESS

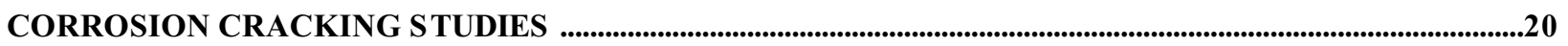

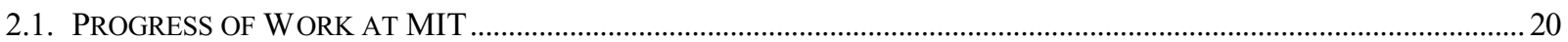

2.1.1. Identification of Most Promising Materials ..............................................................................................

2.1.2. Corrosion and Stress Corrosion Cracking of Candidate Materials.........................................................21

2.2. PROGRESS OF WORK AT THE UNIVERSITY OF MICHIGAN ………....................................................................22

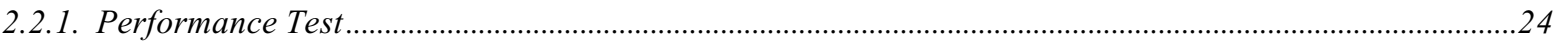

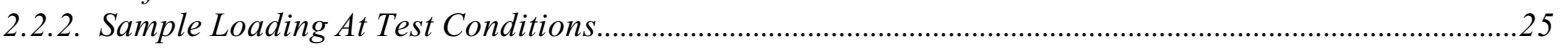

2.2.3. Influence Of A Pressure Change On Displacement And Load ...................................................................25

2.2.4. Estimation Of The Load And Lengthening Of The Sample ………………….........................................27

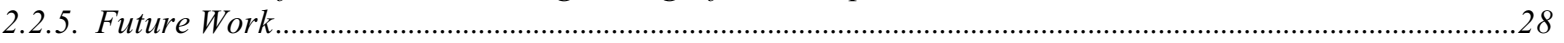

TASK 3 RESULTS: PRELIMINARY THERMAL HYDRAULIC CONSIDERATIONS AND CORE DESIGN CRITERIA ..........................................................................................................................................................................29

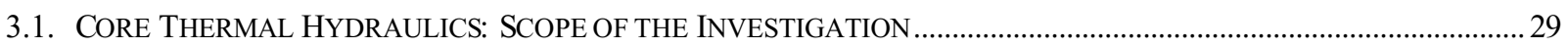

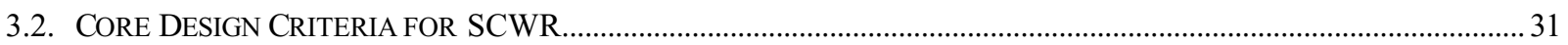

3.2.1. Temperature Limits For The Cladding And Fuel ................................................................................ 39

3.2.2. Calculation of the Cladding Temperature: a Critical Review of Supercritical Water Heat Transfer

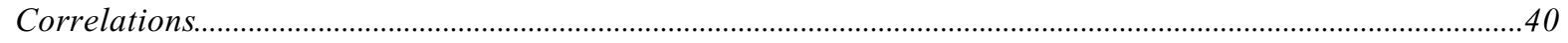

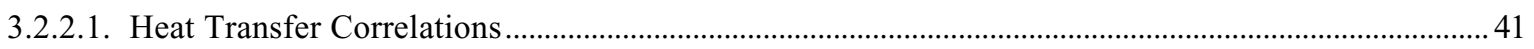

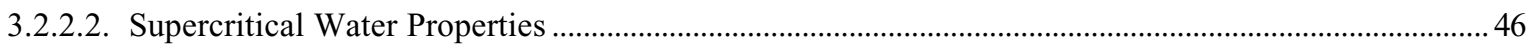

3.2.3. Hot Channel Factors and Implementation of the Design Criteria ............................................................49

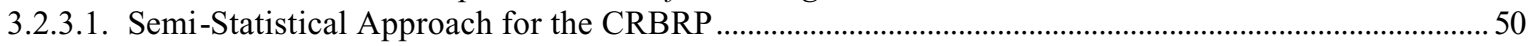

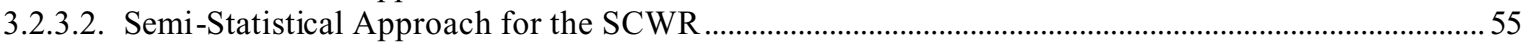

3.2.3.3. Direct (Non-Statistical) Hot Channel Factors for the SCWR …………............................................. 56

3.3. TeMPERATURE AND DENSITIES PROFILES In THE A VERAGE AND Hot CHANNELS For DifFERENT System

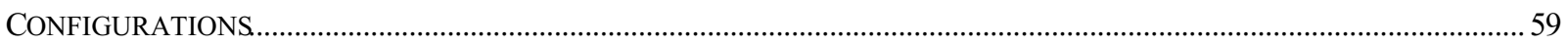

3.3.1. Case \#1 Direct/Indirect Cycle, Thermal Core, Inlet Core Temperature $280^{\circ} \mathrm{C}$.........................................60

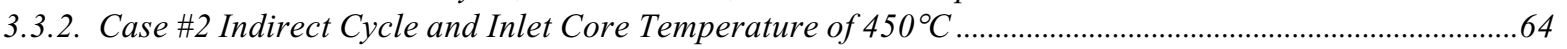

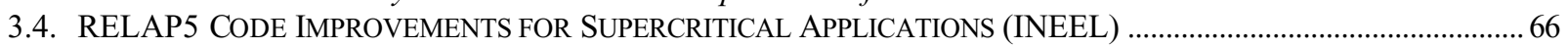




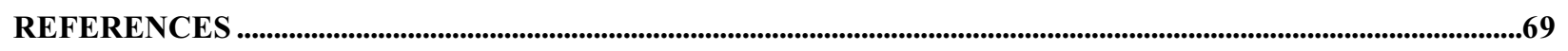

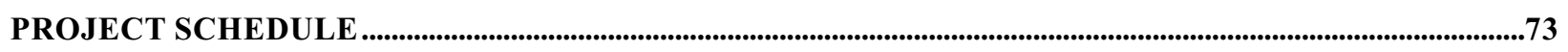

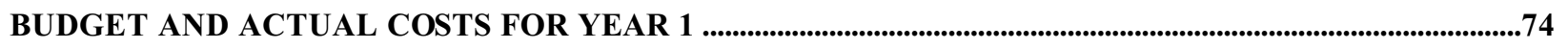

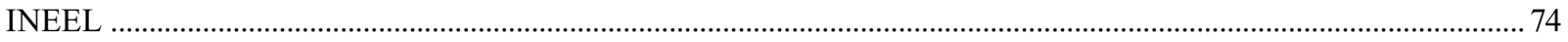

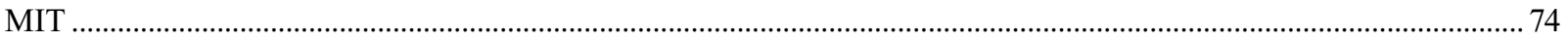

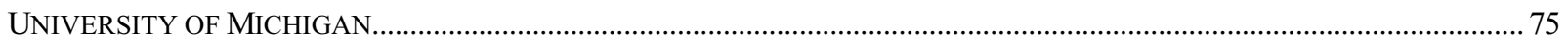

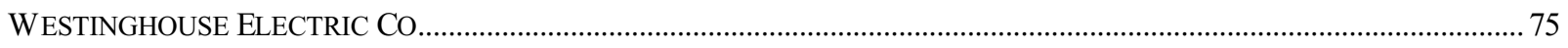

APPENDIX A - THERMAL-HYDRAULICS OF THE SCWR CORE WITH MODERATOR BOXES .........76

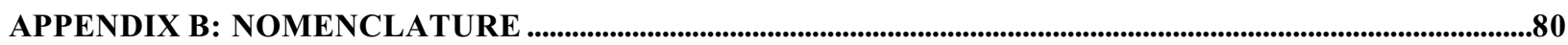




\section{Project Description}

The use of light water at supercritical pressures as the coolant in a nuclear reactor offers the potential for considerable plant simplification and consequent capital and O\&M cost reduction compared with current light water reactor (LWR) designs. Also, given the thermodynamic conditions of the coolant at the core outlet (i.e. temperature and pressure beyond the water critical point), very high thermal efficiencies of the power conversion cycle are possible (i.e. up to about 45\%). Because no change of phase occurs in the core, the need for steam separators and dryers as well as for BWR-type re-circulation pumps is eliminated, which, for a given reactor power, results in a substantially shorter reactor vessel and smaller containment building than the current BWRs. Furthermore, in a direct cycle the steam generators are not needed.

If no additional moderator is added to the fuel rod lattice, it is possible to attain fast neutron energy spectrum conditions in a supercritical water-cooled reactor (SCWR). This type of core can make use of either fertile or fertile-free fuel and retain a hard spectrum to effectively burn plutonium and minor actinides from LWR spent fuel while efficiently generating electricity. One can also add moderation and design a thermal spectrum SCWR that can also burn actinides. The Generation IV Roadmap effort has identified the thermal spectrum SCWR (followed by the fast spectrum SCWR) as one of the advanced concepts that should be developed for future use. Therefore, the work in this NERI project is addressing both types of SCWRs.

This reactor concept presents several technical challenges. The most important are listed below.

\section{1) Fuel and Reactor Core Designs:}

- Local or total coolant voiding in the fast-spectrum SCWRs increases leakage, but hardens the neutron energy spectrum and decreases parasitic absorption. The net effect can be a reactivity increase. The core must be designed to ensure that the overall reactivity coefficient is negative.

- The thermal-spectrum SCWRs require additional moderation, water rods can be used but one has difficult design problems to control the heat transfer from the coolant to the moderator rods, especially during off-normal and accident situations. A solid moderator would be better.

- A low conversion ratio fuel rapidly loses reactivity with burnup, thus requiring a large excess reactivity at beginning-of-life to operate continuously for an acceptably long time. Therefore, a control system must be designed that safely compensates for reactivity changes throughout the irradiation cycle, or the spectrum must be hardened to increase the conversion ratio.

- The Doppler feedback in the fast-spectrum SCWRs will be much smaller than that found in typical LWRs.

2) Fuel Cladding and Structural Material Corrosion and Stress Corrosion Cracking:

- Because of the oxidizing nature of high temperature water, corrosion and stress corrosion cracking of the fuel cladding and core internals materials are expected to be major concerns for this reactor concept.

- Radiolysis of the water coolant in the fast-spectrum SCWRs may take place at a higher rate than in traditional LWRs. In addition, the radicals formed by the radiolytic decomposition of the water (both fast and thermal versions) are highly soluble in supercritical water and may not recombine as well as in an LWR.

- The hard neutron spectrum in the fast-spectrum SCWRs makes the irradiation damage of the fuel cladding and core structural materials more pronounced than in traditional LWRs. Also, highenergy neutrons work as catalysts for the oxidation and stress corrosion cracking of the structural materials (irradiation assisted stress corrosion cracking). 


\section{3) Plant Engineering and Reactor Safety Analysis:}

- Depending on its mission (e.g. electricity generation, co-generation of steam and electricity, desalinization), the plant will exhibit different optimal configurations and operating conditions.

- Because no change of phase occurs in the reactor vessel, the need for a pressurizer to maintain the operating pressure has to be assessed.

- The implications of utilizing supercritical water on the design of the reactor containment need to be evaluated.

- Because of the significant coolant density variation along the core, the supercritical water reactor might be susceptible to coupled neutronic/thermathydraulic instabilities.

- The response of the plant to design and anticipated accidents and transients might differ significantly from that of LWRs and needs to be evaluated.

- The relative benefits of direct versus indirect cycle reactor coolant system designs need to be assessed.

The project is organized into three tasks, reflecting the three technical challenges above.

Task 1. Fuelcycle Neutronic Analysis and Reactor Core Design (INEEL). For the fast-spectrum SCWR, metallic, oxide, and nitride fertile fuels will be investigated to evaluate the void and Doppler reactivity coefficients, actinide burn rate, and reactivity swing throughout the irradiation cycle. Although metallic alloy fuels are incompatible with the water coolant, we envision the use of a dispersion type of metallic fuel, which will be compatible with water. Included in the fertile options will be the use of thorium. The main variables are the core ge ometry (e.g. fuel rod length, pitch-to-diameter ratio, assembly configuration) and the fuel composition. For the thermalspectrum SCWR, a variety of fuel and moderator types will be assessed. The MCNP code will be utilized for instantaneous reactivity calculations and the MOCUP code for burnup calculations and isotopic content.

Task 2. Fuel Cladding and Structural Material Corrosion and Stress Corrosion Cracking (University of Michigan and MIT). The existing data base on the corrosion and stress-corrosion cracking of austenitic stainless steel and nickelbased alloys in supercritical water is very sparse. Therefore, the focus of this work will be corrosion and stress corrosion cracking testing of candidate fuel cladding and structural materials. In Year 1 of the project MIT will use an existing supercriticalwater loop to conduct initial corrosion experiments on a first set of candidate alloys in flowing supercritical water, and will identify promising candidate alloys classes for core internal components and fuel cladding based on existing data on the alloys radiation stability and resistance to both corrosion and stresscorrosion cracking. A high temperature autoclave containing a constant rate mechanical test device will be built in Year 1 and operated in Years 2 and 3 at the University of Michigan. The resulting data will be used to identify promising materials and develop appropriate corrosion and stress corrosion cracking correlations.

Task 3. Plant Engineering and Reactor Safety Analysis (Westinghouse and INEEL). The optimal configuration of the power conversion cycle will be identified as a function of the plant mission (e.g. pure electricity generator, co-generation plant, hydrogen generator). Particular emphasis will be given to the applicability of current supercritical fossil-fired plant technology and experience to a directcycle nuclear system. A steady-state sub-channel analysis of the reactor core will be undertaken with the goal of establishing power limits and safety margins under normal operating conditions. Also, the reactor susceptibility to coupled neutronic/thermathydraulic oscillations will be evaluated. The response of the plant to accident situations and anticipated transients without scram will be assessed. In particular the following transients and accidents will be analyzed: start-up, shut-down, load change and load rejection; LOCAs and LOFAs. As part of this analysis, a suitable containment design will be explored to mitigate the consequences of LOCA accidents. 


\section{Task 1 Results: Assessment of Solid Moderators for Thermal Spectrum SCWRs (INEEL)}

\subsection{Summary of Previous Work}

During the $1^{\text {st }}$ quarter, a qualitative analysis was performed to determine which fuel form would support the highest reactivity-limited burnup in a fast-spectrum SCWR, and would have the most proliferation resistant isotopics at a particular burnup. A relatively long core life and a modest reactivity swing are possible in fast-spectrum SCWRs with most fuels. However, the uranium-based fuel types had the highest beginning-of-life reactivity, and the best reactivity-limited burnup, whereas the thorium-based fuels had the best spent-fuel isotopics. Therefore, the most appropriate fuel for fast-spectrum SCWRs appears to be a mixture of thorium and uranium to balance long core life with proliferation resistant isotopics.

The small effective delayed neutron fraction $\left(\beta_{\text {eff }}\right)$ associated with fast-spectrum reactors can make reactor control problematic, especially for fuels that contain large quantities of minor actinides. To help overcome this challenge, and remain within the current knowledge of thermal spectrum reactor control, work was started during Quarter 2 to assess the design of a thermal-spectrum SCWR. In order to thermalize the neutron spectrum in a supercritical pressure water reactor, one can increase the pin pitch or introduce moderator rods to increase the moderator to fuel ratio. While increasing the pin pitch would be the simplest approach, the large hydraulic diameter would result in very low coolant velocities and unacceptable cladding temperatures. Therefore, one must employ moderator rods or cans and initial calculations were performed to verify the moderating power of several different moderators including $\mathrm{H}_{2} \mathrm{O}, \mathrm{D}_{2} \mathrm{O}$, graphite $(\mathrm{C}), \mathrm{BeO}$, and $\mathrm{ZrH}_{2}$. This work was continued in the $3^{\text {rd }}$ Quarter as discussed below.

\subsection{Introduction}

The characteristics of supercritical water that most affect the thermathydraulic and neutronic design of a thermal-spectrum supercriticalwater-cooled reactor (SCWR) core are the large enthalpy rise and the low average density. Typical values for the enthalpy rise and density drop along the axis of a SCWR core are shown in Figures 1 and 2.

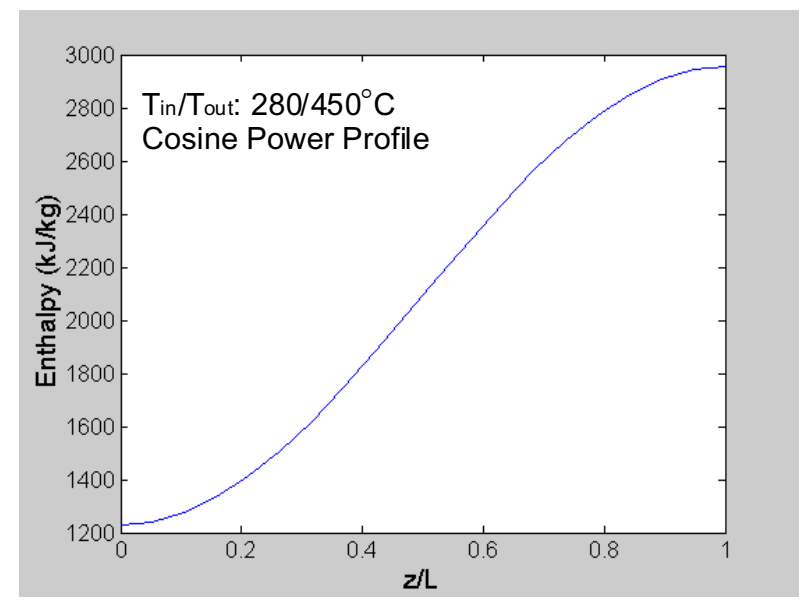

Figure 1. Typical enthalpy rise in the SCWR core.

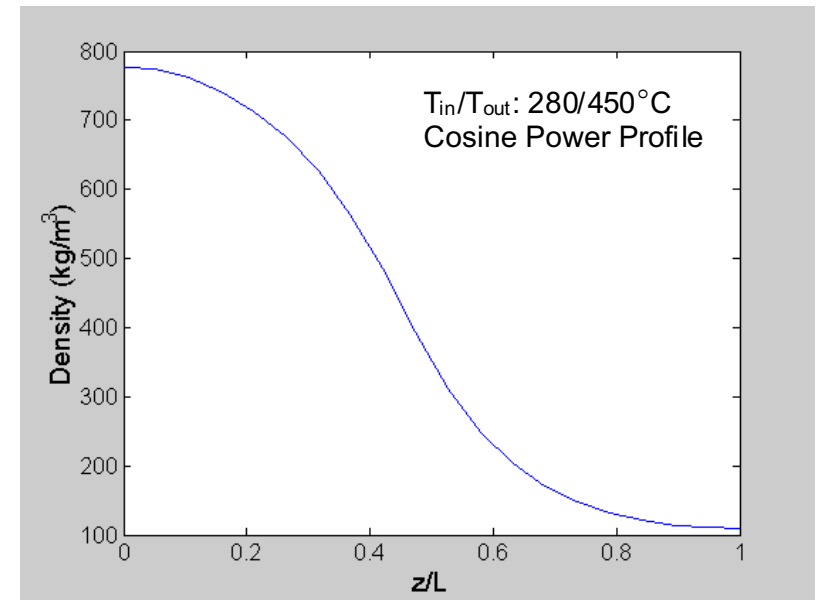

Figure 2. Typical coolant density drop in the SCWR core. 
Note that the enthalpy rise is about an order of magnitude larger than for an LWR. Correspondingly, for given thermal power, the core flow rate is an order of magnitude smaller. This requires that the core flow area (i.e., the coolant-to-fuel ratio) be considerably reduced compared with an LWR, to maintain high coolant velocities and ensure proper cooling of the fuel. However, the low coolant-to-fuel ratio, combined with the low average coolant density, makes it impossible to design a thermal-spectrum core without the addition of a dedicated moderator.

In Japan, where the SCWR concept has been studied for over a decade, this issue has been addressed by the introduction of water rods into the fuel assemblies [Okano et al. 1994]. More recently a similar approach has been adopted in Europe as well [Cheng et al. 2002]. The water-rod concept is based on the coolant flow path illustrated in Figure 3. The feedwater flow splits into two streams, one of which is directed to the lower plenum at the bottom of the reactor pressure vessel (RPV), the other is directed to cool the RPV upper head, from where it flows downward into water filled moderator rods and through the core, mixes with the other feedwater stream in the lower plenum, flows back up into the core as coolant and finally goes to the turbine. This flow path is necessary to prevent a significant reduction of the outlet core temperature by mixing hot coolant with cold moderator in the upper plenum. Although it was demonstrated that this approach does provide adequate moderation, its practical realization relies on complicated plumbing extending above the core to convey the moderator from the RPV upper head to the water filled moderator rods in the fuel assemblies. Further, the moderator coolant piping above the core may make refueling more cumbersome.

Therefore, we have evaluated alternative solutions in an effort to simplify the RPV internals and attain some capital cost savings. The use of a solid moderator in lieu of water rods deserves attention, as it would eliminate

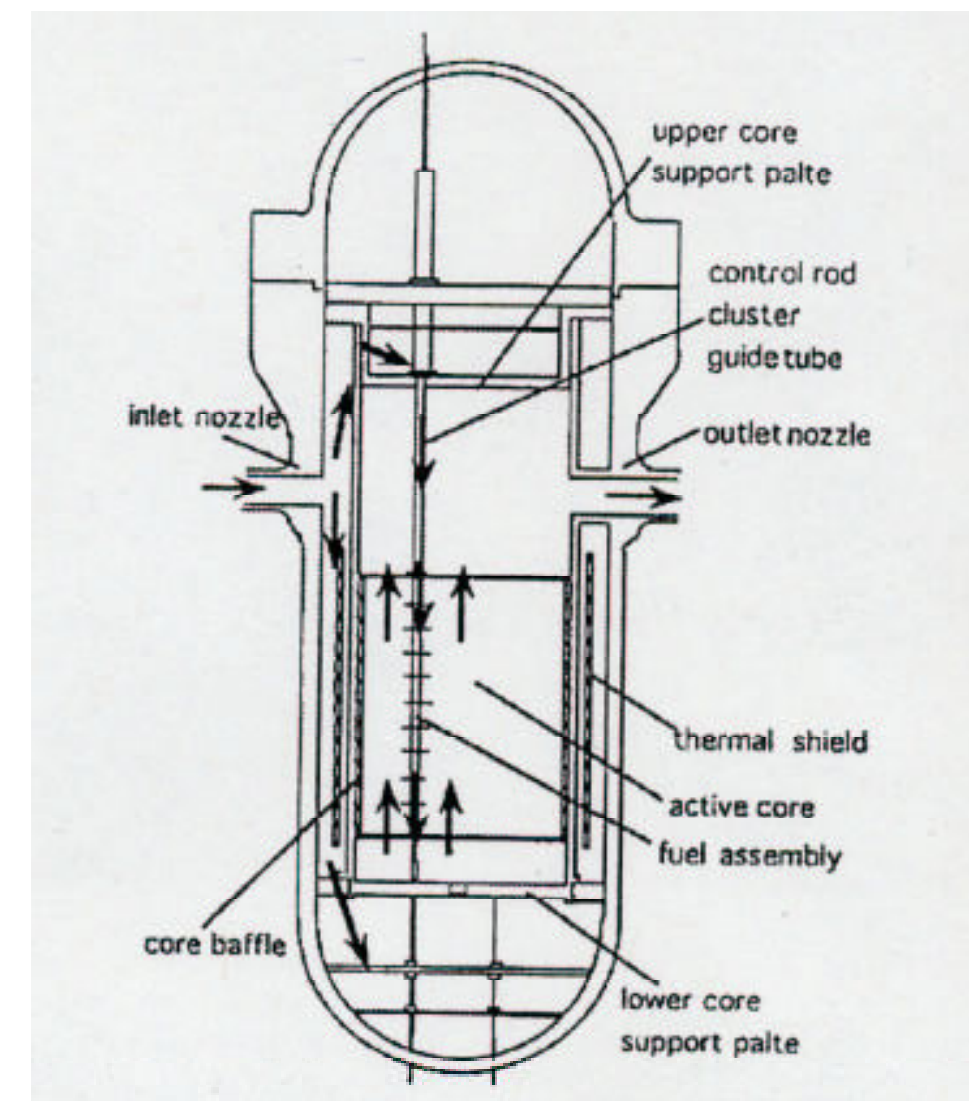

Figure 3. Flow path in the SCWR with water rods (from Ishiwatari et al., 2002).

the need for the involved coolant flow path within the RPV and the associated plumbing. Other advantages of this approach include a reduction of the coolant worth and an increase of the core thermal capacity, both of which might result in significant safety improvements.

Obviously, if the technical feasibility of the solid moderator approach is demonstrated, its ultimate selection or rejection will be determined mostly by an economic trade-off. It will be necessary to establish if the savings from elimination of the water filled moderator rod plumbing justifies the cost increase deriving from the use of more expensive materials for moderation in the core. Assessment of such trade-off is beyond the scope of this study at this point in time. However, a rough estimate of the 
impact of using a solid moderator on the electricity production costs of a SCWR is presented in Section 3.7 .

\subsection{Neutronics}

In this section the neutronic performance of 6 moderators is assessed (some of this information was presented last Quarter). The moderators are: water rods, zirconium hydride $\left(\mathrm{ZrH}_{1.6}\right), \mathrm{Be}, \mathrm{BeO}, \mathrm{C}, \mathrm{SiC}$. (The choice of $\mathrm{ZrH}_{1.6}$ instead of stochiometric zirconium hydride, $\mathrm{ZrH}_{2}$, will be clarified in Section 1.3.1.) In addition to $\mathrm{Be}$ and $\mathrm{C}$, the chemically more stable $\mathrm{BeO}$ and $\mathrm{SiC}$ are analyzed. The general neutronic characteristics of these materials are reported in Table 1. The most important parameter is the scattering density, which is proportional to the neutron slow-down energy deposited in the unit volume of the material. It should be noted that $\mathrm{ZrH}_{1.6}$ actually has a somewhat better scattering density than water, and much better than all other moderators, while its absorption cross section is higher.

Table 1. General characteristics of neutron moderators.

\begin{tabular}{|c|c|c|c|c|}
\hline \multirow{2}{*}{$\begin{array}{c}\text { Material / Density } \\
\left(\mathrm{g} / \mathrm{cm}^{3}\right)\end{array}$} & \multicolumn{3}{|c|}{ Moderating Element } & \multirow{2}{*}{$\begin{array}{c}\text { Thermal capture cx } \\
(1 / \mathrm{cm})\end{array}$} \\
\hline & Element / Mass \# & $\begin{array}{c}\text { Number Density } \\
\left(10^{22} / \mathrm{cm}^{3}\right)\end{array}$ & $\begin{array}{c}\text { Scattering Density* } \\
(1 / \mathrm{cm})\end{array}$ & \\
\hline $\mathrm{H}_{2} \mathrm{O} / 0.78$ & $\mathrm{H} / 1$ & 5.22 & 0.205 & 0.015 \\
\hline $\mathrm{ZrH}_{1.6} / 5.64$ & $\mathrm{H} / 1$ & 5.85 & 0.230 & 0.023 \\
\hline $\mathrm{Be} / 1.85$ & $\mathrm{Be} / 9$ & 12.38 & 0.119 & 0.0008 \\
\hline $\mathrm{BeO} / 3.01$ & $\mathrm{Be} / 9$ & 7.25 & 0.070 & 0.0005 \\
\hline $\mathrm{C} / 2.00$ & $\mathrm{C} / 12$ & 10.04 & 0.067 & 0.0003 \\
\hline $\mathrm{SiC} / 3.16$ & $\mathrm{C} / 12$ & 4.75 & 0.032 & 0.007 \\
\hline
\end{tabular}

* The scattering density is defined as $(1-\alpha) \Sigma_{\mathrm{s}}$ where $\Sigma_{\mathrm{s}}$ is the fast elastic scattering cross section and $\alpha=[(\mathrm{A}-$ $1) /(\mathrm{A}+1)]^{2}$ with $\mathrm{A}$ being the mass number.

The cell geometry for the neutronic calculations is illustrated in Figure 4. It is demonstrated in Appendix A that this geometry enables achievement of a high power density while meeting the

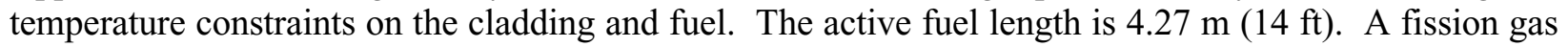
plenum of about $40 \mathrm{~cm}$ is provided at the top of the fuel pins. The fuel is $\mathrm{UO}_{2}$ with uniform 4 at $\%$ U-235 enrichment and $95 \%$ theoretical density $\left(-10.42 \mathrm{~g} / \mathrm{cm}^{3}\right)$. The fuel cladding and moderator box wall are made of Alloy 718 with 8.19 $\mathrm{g} / \mathrm{cm}^{3}$ density. The nominal composition of Alloy 718 is (in wt\%) Ni=52.90, $\mathrm{Cr}=19.08, \quad \mathrm{Fe}=18.122, \quad \mathrm{Nb}=5.05$, $\mathrm{Mo}=3.01, \mathrm{Ti}=0.91, \mathrm{Al}=0.49, \mathrm{Mn}=0.20$, $\mathrm{Si}=0.19, \mathrm{C}=0.038, \mathrm{~V}=0.01$. The lower and upper reflectors of $3 \mathrm{~cm}$ thickness each are also made of Alloy 718. The lower and upper coolant plena are modeled as semi-infinite volumes filled with coolant of density corresponding to

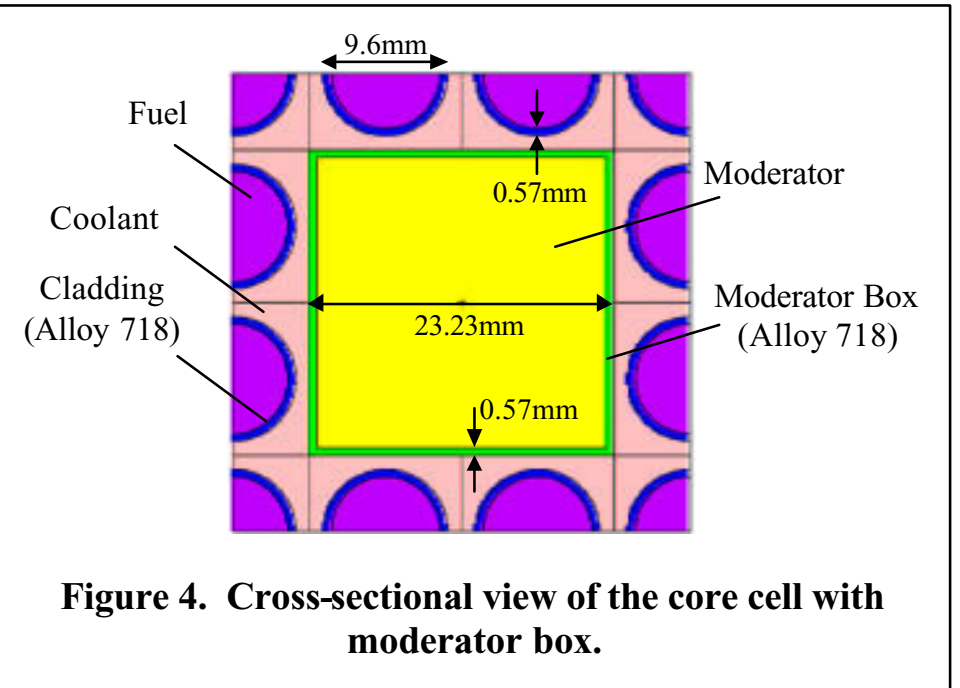
the core inlet and outlet temperature, respectively. Therefore, axial leakage is accounted for. On the other hand, the cell vertical boundaries are modeled as perfectly reflective. The calculations are performed with the Monte Carlo code MCNP4B. The number of neutron histories followed for each case is $10^{5}$ resulting in an uncertainty of about \pm 0.002 
on the value of the multiplication factor. In order to input the coolant density profile and calculate the axial power profile, the coolant and fuel pin regions are divided into 20 axial zones each. The axial profile of the coolant density is that of Figure 2.

The reactivity results are illustrated in Figure 5 in terms of the multiplication factor, $\mathrm{k}_{\mathrm{eff}}$. The multiplication factor for a PWR fuel pin with Zircaloy-4 cladding and for a fictitious PWR pin with Alloy 718 cladding are also reported for reference ${ }^{1}$. Figures 6 and 7 show the normalized neutron spectra in the upper core region (where virtually no moderation is provided by the coolant) and the axial power profiles, respectively. From Figure 5 it is apparent that among the SCWR moderators water performs best reactivity-wise, closely followed by $\mathrm{ZrH}_{1.6}$. The other solid moderators exhibit significantly lower reactivity, with $\mathrm{BeO}$ and $\mathrm{SiC}$ performing worse than $\mathrm{Be}$ and $\mathrm{C}$, respectively. Also, a comparison of the two PWR cases suggests that the reactivity penalty associated with the use of Alloy 718 instead of the low-absorbing Zircaloy-4 is significant ${ }^{2}$. However, this penalty is an intrinsic characteristic of the SCWR (for which zirconium alloys cannot be used because of their low strength at high-temperature) and thus is not instrumental in discriminating between moderators.

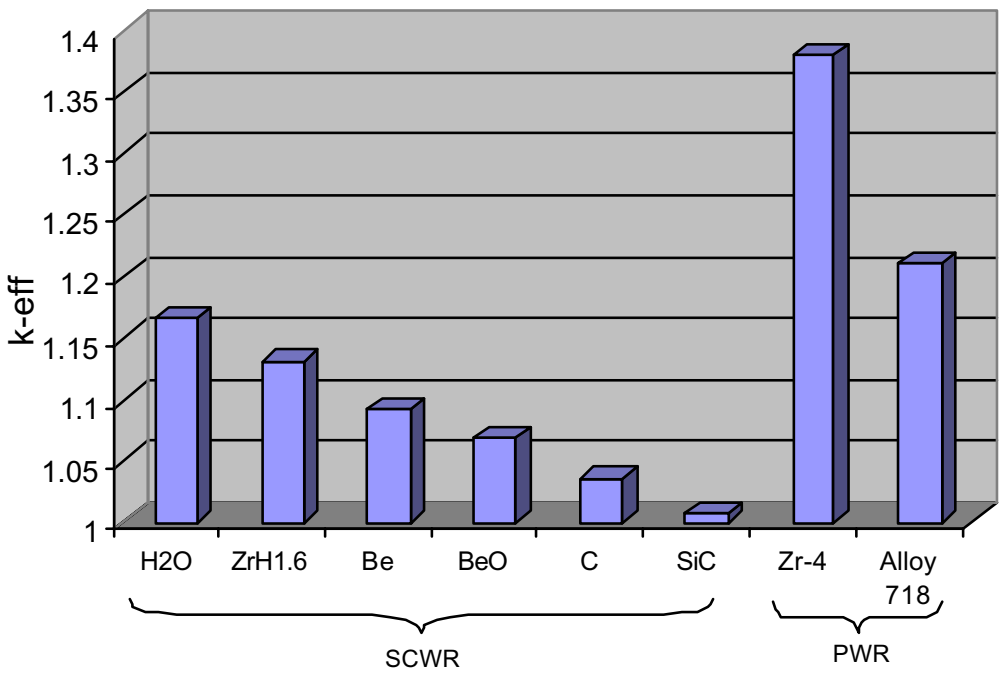

Figure 5. Reactivity performance.

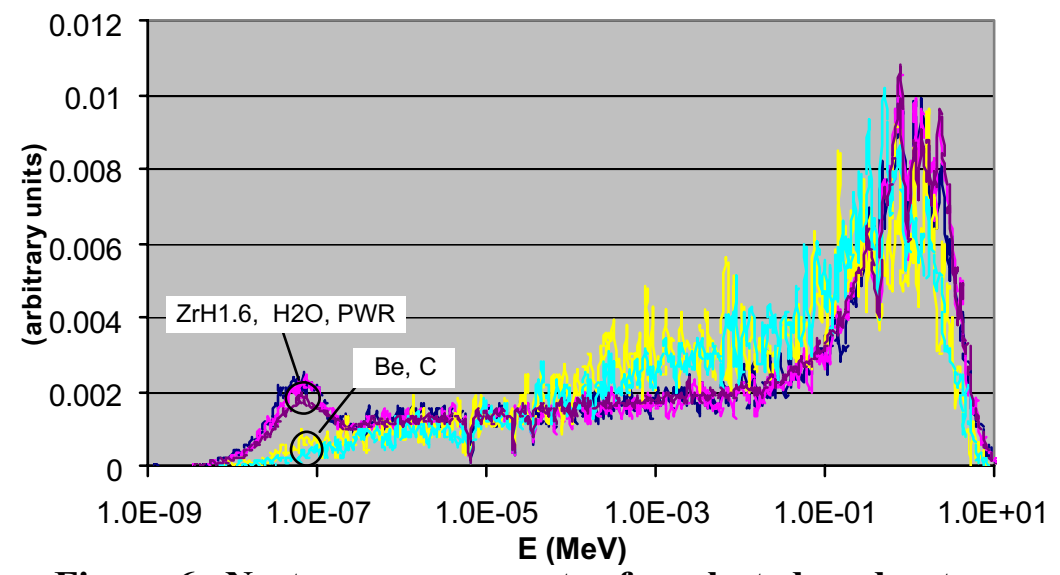

Figure 6. Neutron energy spectra for selected moderators. Figure 6 confirms that $\mathrm{ZrH}_{1.6}$ is an excellent material to moderate neutrons, while the other solid moderators fail to generate a significant thermal component. This was expected on the basis of the scattering density data. This observation is corroborated by Figure 7 where it is shown that for Be and $\mathrm{C}$ the fission power is very low in the upper half where all moderation is due to the moderator. Note that the axial power profiles in Figure 7 should be regarded only as qualitative for two reasons. First, the reactivity feedback on the coolant density axial profile was not accounted for; second, the profiles are not optimized because uniform enrichment was assumed. One might design the axial enrichment distribution to flatten the power peaking.

\footnotetext{
${ }^{1}$ The geometry and fuel composition for the PWR pin calculations are the same as for the SCWR cell, but with a typical PWR pitch-to-diameter ratio of 1.33 , an average coolant density of $0.712 \mathrm{~g} / \mathrm{cm}^{3}$ and without the moderating box.

${ }^{2}$ It should be emphasized that the difference between the PWR case with Alloy 718 and the SCWR cases with Alloy 718 and water or $\mathrm{ZrH}_{1.6}$ as the moderator is due to the parasitic captures in the moderator box wall.
} 
These results clearly indicate that the only neutronically acceptable moderators for the SCWR geometry of Figure 4 are water and $\mathrm{ZrH}_{1.6}$. To make the other solid moderators more effective, larger moderator boxes would have to be used (with three, four or even five fuel pins per side), but this would drastically reduce the core power density, thus negatively affecting costs. Therefore, the only solid moderator that will be further explored is $\mathrm{ZrH}_{1.6}$. The reactivity gap between water rods and $\mathrm{ZrH}_{1.6}$ can be closed with a modest enrichment increase of about $11 \%$, i.e., the multiplication factor for $\mathrm{ZrH}_{1.6}$ at 4.45 at $\%$ U-235 enrichment is equal to the multiplication factor for water rods at 4.0 at $\%$ U-235 enrichment.

We conclude the neutronic section of this study by noting that the SCWR core with $\mathrm{ZrH}_{1.6}$ moderator boxes maintains the important LWR safety characteristic of having a negative coolant void reactivity coefficient. To demonstrate this, a series of calculations have been performed in which the core power-toflow ratio $(\mathrm{Q} / \mathrm{M})$ was varied (while keeping the inlet temperature at $280^{\circ} \mathrm{C}$ and the cosine axial power profile) to simulate under- and over-cooling transients. The coolant axial density profile was generated for each case (Figure 8) and was fed to MCNP to calculate the multiplication factor. The results are illustrated in Figure 9. It can be seen that the reactivity monotonically decreases with the power-to-flow ratio (i.e., with decreasing average coolant density). Flooding the core $(\mathrm{Q} / \mathrm{M}=0)$ results in a reactivity insertion of 0.01 or about $\$ 1.4$ (assuming a 0.007 delayed neutron fraction) with respect to the nominal conditions. On the other hand, voiding the core $(\mathrm{Q} / \mathrm{M}=\infty)$ results in a reactivity decrease of 0.01 or again about $\$ 1.4$.

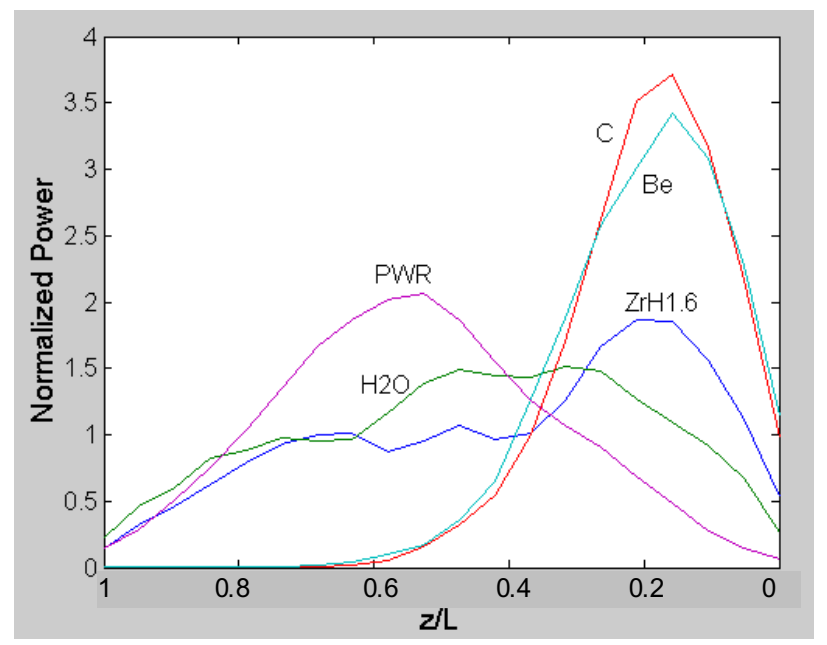

Figure 7. Axial power profiles for selected moderators.

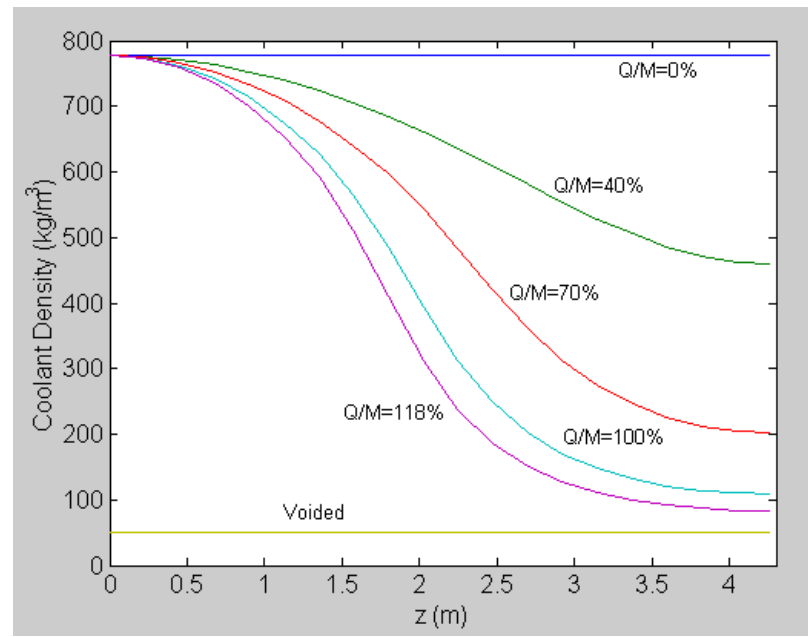

Figure 8. Coolant density distribution in the SCWR core at different power levels.

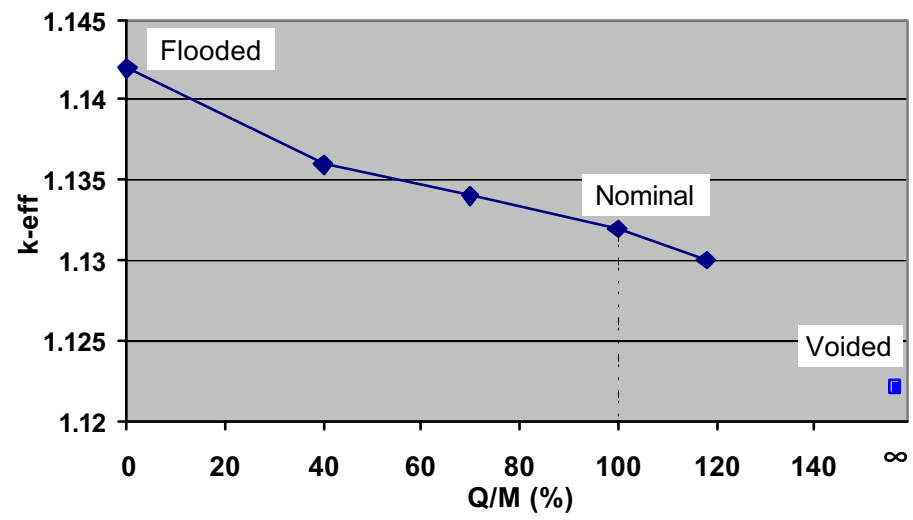

Figure 9. Reactivity of the SCWR core with $\mathrm{ZrH}_{x}$ moderator at different power levels. 


\subsection{Zirconium Hydride}

\subsubsection{General Characteristics}

Zirconium hydride is not new to the nuclear industry. Various nuclear applications were considered in the past including moderator for thermal reactors, control material for fast reactors, and shielding material [Van Houten 1974]. Hexagonal bars of zirconium hydride moderator were successfully utilized in the Heat Transfer Reactor Experiment-3 (HTRE-3) within the Aircraft Nuclear Propulsion Program in the late 50s and early 60s [Mueller 1968a]. Zirconium hydride was used as a moderator also in the Systems for Nuclear Auxiliary Power (SNAP) reactors for spacecraft and satellite applications [Huffine 1968]. Furthermore, a thorough investigation of zirconium hydride was performed for application as a moderator in a maritime carbon-dioxide-cooled reactor using a closed-cycle gas turbine [Mueller 1968a]. However, perhaps most importantly, a dispersion of enriched uranium in a matrix of zirconium hydride has been developed and used as the fuel for the General Atomics TRIGA research reactor (a mature and popular product worldwide) for over 40 years [Simnad 1981]. Therefore, considerable information on the thermodynamic, transport, mechanical, and irradiation properties of zirconium hydride is available in the literature.

A phase diagram of the zirconium-hydrogen binary system (or $\mathrm{ZrH}_{\mathrm{x}}$, with $\mathrm{x}$ being the hydrogen-tozirconium ratio) is illustrated in Figure 10. There are four phases: the $\alpha$ phase has the hexagonal closepacked (hcp) lattice typical of zirconium metal, the $\beta$ phase has the body-centered cubic (bcc) lattice also typical of zirconium metal, while the $\delta$ phase and the $\varepsilon$ phase have a face-centered cubic (fcc) and a facecentered tetragonal (fct) lattice, respectively. At relatively low hydrogen contents (e.g., $\mathrm{x}<1.4$ ) zirconium hydride is a solid solution of hydrogen in a zirconium metal lattice. At higher hydrogen contents actual hydride phases are formed.

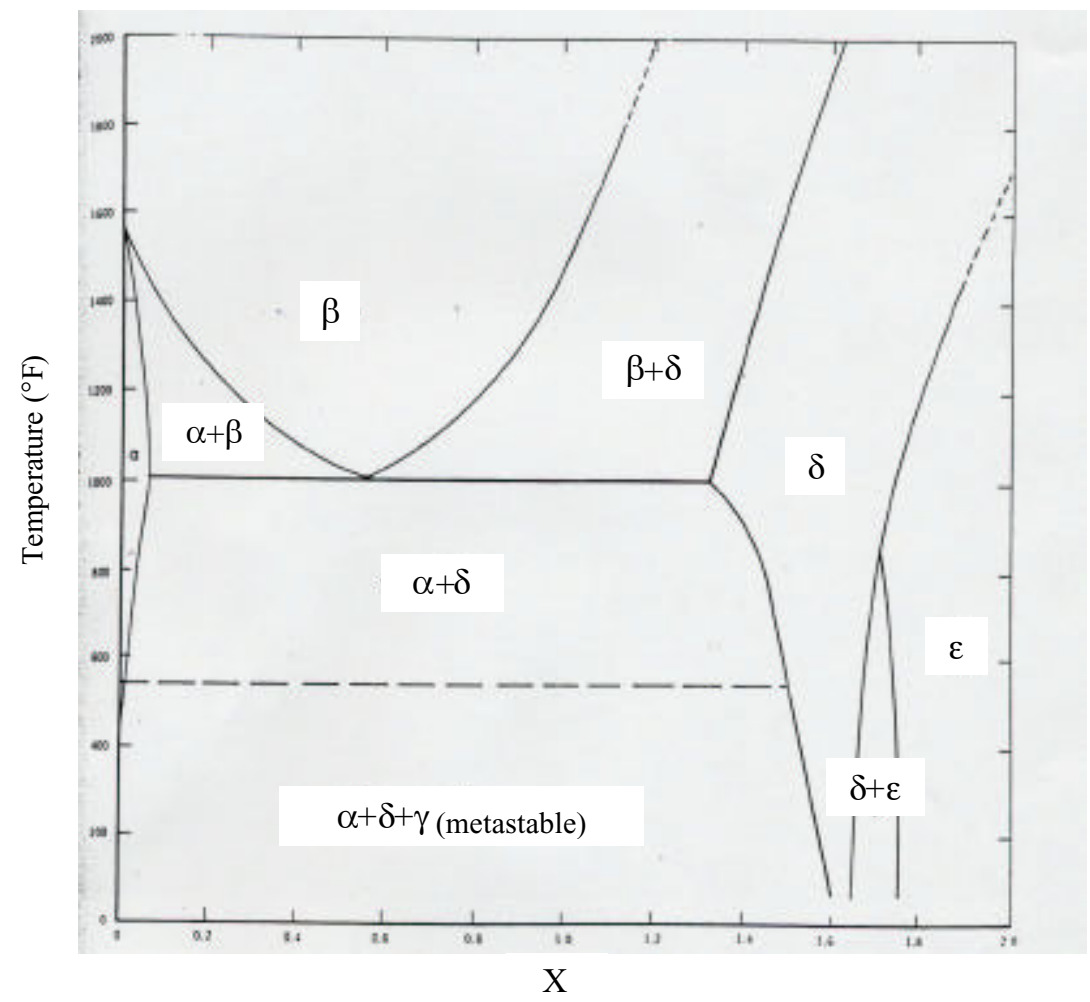

Figure 10. Phase diagram for zirconium hydride. 
The phases of interest to our application are the ones rich in hydrogen, i.e., the $\delta$ and $\varepsilon$ phases. We select $\delta$-phase zirconium hydride (with $\mathrm{x}=1.6$ ) as the moderator for the SCWR core for the following reasons:

1) The $\delta$ phase exhibits better irradiation stability than the $\varepsilon$ phase. The experiments reported by Paetz and Lucke [1972], Shcherbak et al. [1991], and Primakov et al. [1999] show that the $\delta$ phase does not swell under neutron irradiation while the $\varepsilon$ phase swells by $0.5 \mathrm{vol} \%$ at a fast fluence of $1.3 \times 10^{21} \mathrm{n} / \mathrm{cm}^{2}$ and up to $5 \mathrm{vol} \%$ at $6 \times 10^{22} \mathrm{n} / \mathrm{cm}^{2}$.

2) For $\mathrm{x}=1.6$ the $\delta$ phase is stable up to a temperature of at least $1040^{\circ} \mathrm{C}$, while for $\mathrm{x}=2$ the $\varepsilon$ phase is stable only up to $903^{\circ} \mathrm{C}$ where a $\varepsilon \rightarrow \delta$ transition occurs. Given the relatively high temperatures expected during transients/accidents in the SCWR, this phase transition could occur, resulting in a significant density change of the moderator with undesirable consequences on core reactivity and integrity of the moderator box.

3) Use of the hydrogen-richer $\delta$ phase would result in only a modest neutronic improvement. The $\mathrm{k}_{\text {eff }}$ for the SCWR cell of Section 2 with $\mathrm{ZrH}_{2}$ moderator is $1.136 \pm 0.002$ vs $1.132 \pm 0.002$ with $\mathrm{ZrH}_{1.6}$.

The room temperature density of $\mathrm{ZrH}_{\mathrm{x}}$, is [Simnad 1981]:

$$
\begin{array}{ll}
?_{\mathrm{ZrHx}} & =\frac{1}{0.1541+0.0145 \mathrm{x}} \text { for } \mathrm{x}<1.6 \\
?_{\mathrm{ZrHx}} & =\frac{1}{0.1706+0.0042 \mathrm{x}} \text { for } \mathrm{x} \geq 1.6
\end{array}
$$

where $\rho_{\mathrm{ZrHx}}$ is in $\mathrm{g} / \mathrm{cm}^{3}$. The linear thermal expansion coefficient of $\delta$-phase $\mathrm{ZrH}_{\mathrm{x}}$ in the $25-300^{\circ} \mathrm{C}$ temperature range varies between $6.7 \times 10^{-6}$ and $10.0 \times 10^{-6} 1 /{ }^{\circ} \mathrm{C}$ [Yamanaka et al. 1999]. The melting point of zirconium hydride was estimated by Pinchuck et al. [1976] at $1882 \pm 75^{\circ} \mathrm{C}$, i.e., somewhat higher than that of pure zirconium. Measurements of the specific heat for $\delta$-phase $\mathrm{ZrH}_{\mathrm{x}}$ were correlated by the following expression [Yamanaka et al. 1999]:

$$
c_{p}=25.02+4.746 x+\left(3.103 \times 10^{-3}+2.008 \times 10^{-2} x\right) T-\left(1.943 \times 10^{5}+6.358 \times 10^{5} x\right) / T^{2}
$$

where $c_{p}$ is in $\mathrm{J} / \mathrm{mol} \cdot \mathrm{K}$ and $\mathrm{T}$ is in $\mathrm{K}$. This expression can be used in the $25-730^{\circ} \mathrm{C}$ temperature range. For $\mathrm{x}=1.5-1.7$ and $\mathrm{T}=25-430^{\circ} \mathrm{C}$ the thermal conductivity of $\delta$-phase $\mathrm{ZrH}_{\mathrm{x}}$ ranges from 15 to $20 \mathrm{~W} / \mathrm{m} \cdot \mathrm{K}$ with a weak dependence on composition and temperature [Yamanaka et al. 2001]. The lower bound (15 $\mathrm{W} / \mathrm{m} \cdot \mathrm{K}$ ) will be assumed for design calculations.

\subsection{2. $\mathrm{ZrH}_{\mathrm{x}} /$ Water Interaction}

Compatibility with the coolant is a key feasibility issue for a moderator material. Under normal operating conditions any interaction between $\mathrm{ZrH}_{\mathrm{x}}$ and water is prevented because the two materials are physically segregated by the moderator box. In case of failure of the moderator box, the reaction of interest is:

$$
\mathrm{ZrH}_{2}+2 \mathrm{H}_{2} \mathrm{O} \rightarrow \mathrm{ZrO}_{2}+3 \mathrm{H}_{2}
$$

which has the following calculated Gibbs free energy: 
where $\Delta \mathrm{G}$ is in $\mathrm{kJ} / \mathrm{mol}_{\mathrm{ZrH} 2}$ and $\mathrm{T}$ is in $\mathrm{K}$. Therefore, the reaction is exothermic, thermodynamically favored at all temperatures and generates hydrogen. However, numerous experiments have shown that zirconium hydride has excellent corrosion resistance in water and steam also at very high temperature because it rapidly forms a protective zirconium oxide film, which prevents further oxidation [Simnad 1981]. Bare zirconium hydride specimens were exposed to water at $300^{\circ} \mathrm{C}$ and $8.5 \mathrm{MPa}$ for $400 \mathrm{hrs}$ in an autoclave during TRIGA fuel testing. The maximum extent of corrosion penetration was less than $50 \mu \mathrm{m}$. Further, water quench tests were performed from elevated temperatures. $\mathrm{ZrH}_{\mathrm{x}}$ rods of $25 \mathrm{~mm}$ diameter were heated to $800^{\circ} \mathrm{C}$ and then quenched with water. No corrosion was observed. Later these tests were extended to $900^{\circ} \mathrm{C}$ and $1200^{\circ} \mathrm{C}$. The only effect observed at $900^{\circ} \mathrm{C}$ was a slight surface discoloration, while at $1200^{\circ} \mathrm{C}$ the rod cracked but no massive oxidation could be detected. While not conclusive, these observations clearly indicate that the problem of $\mathrm{ZrH}_{\mathrm{x}} /$ water interaction is much less intractable than suggested by equations 4 and 5 .

Experiments in air at $760^{\circ} \mathrm{C}$ did not result in massive oxidation of the zirconium hydride either. The oxidation front penetrated into the specimens only $0.5 \mathrm{~mm}$ after $100 \mathrm{hrs}$, thus confirming the benign nature of the $\mathrm{ZrH}_{\mathrm{x}} /$ air interaction as well [Blackledge 1968].

\subsubsection{Hydrogen Transport and Release}

A more challenging issue associated with the use of $\mathrm{ZrH}_{\mathrm{x}}$ is that of hydrogen release. At all compositions and temperatures $\mathrm{ZrH}_{\mathrm{x}}$ dissociates until an equilibrium hydrogen pressure is established. In the case of the SCWR core, the $\mathrm{ZrH}_{\mathrm{x}}-\mathrm{H}_{2}$ equilibrium would exist within the moderator box. Hydrogen is hard to contain and will diffuse through the moderator box thus progressively reducing moderation in the core. At the relatively low temperatures of steady-state operation for the moderator $\left(<500^{\circ} \mathrm{C}\right)$, this is a fairly slow phenomenon. However, given the time scale of the moderator residence in the core (i.e., up to $4 \mathrm{yrs}$ ), it is a phenomenon that needs to be considered. At the higher temperatures typical of accident events $\left(\geq 850^{\circ} \mathrm{C}\right)$ an additional concern is that hydrogen can excessively pressurize the moderator box. If this causes extensive failure of the moderator boxes throughout the core, large amounts of hydrogen will be released into the RPV and containment. In this section we will evaluate the importance of these phenomena. To do so, two properties are needed: the equilibrium $\mathrm{ZrH}_{\mathrm{x}}-\mathrm{H}_{2}$ pressure as a function of temperature and $\mathrm{x}$, and the hydrogen permeability for the moderator box material.

Three correlations for the equilibrium hydrogen pressure are reported in the literature [Wang and Olander 1995, Namba et al. 1984, Simnad 1981]. Figure 11 shows the predictions of the three correlations over a wide range of temperatures and for three different values of the hydrogen content, $\mathrm{x}$. As expected, the equilibrium hydrogen pressure increases with $\mathrm{x}$ and temperature. Incidentally we shall emphasize that $\delta$-phase $\mathrm{ZrH}_{1.6}$ has a significantly lower equilibrium hydrogen pressure than $\varepsilon$-phase $\mathrm{ZrH}_{2}$ resulting, for given temperature, in lower pressurization of the moderator box and lower diffusion of hydrogen through the moderator box wall, which further strengthens the rationale for selecting the $\delta$ phase over the $\varepsilon$ phase. The agreement among the three correlations is fairly good. However, we recommend the use of the Wang and Olander's correlation, which was derived from a theoretical model for the $\delta$ phase and shows remarkable agreement with the experimental data. The Wang and Olander correlation is:

$$
\ln \mathrm{P}_{\mathrm{H} 2}=2 \ln \frac{\mathrm{x}}{2-\mathrm{x}}+8.01+5.21 \mathrm{x}-\frac{2.07 \times 10^{4}}{\mathrm{~T}}
$$


where the units for $\mathrm{P}_{\mathrm{H} 2}$ and $\mathrm{T}$ are atm and $\mathrm{K}$, respectively.

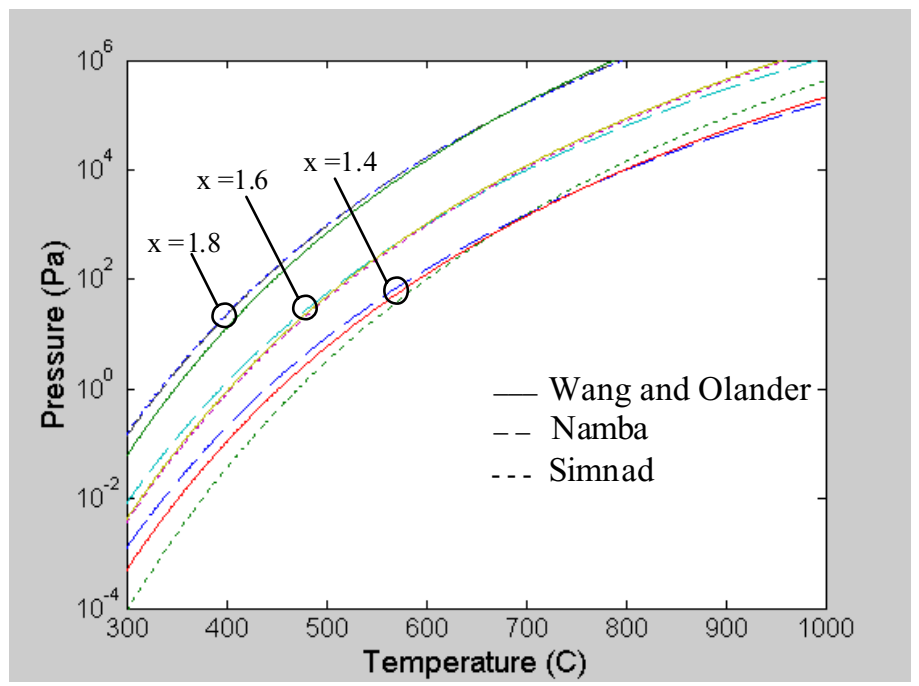

Figure 11. Equilibrium hydrogen pressure for $\mathrm{ZrH}_{\mathrm{x}}$.

Figures 12 and 13 (from EG\&G [1989]) illustrate the hydrogen permeability as a function of temperature for several different materials.

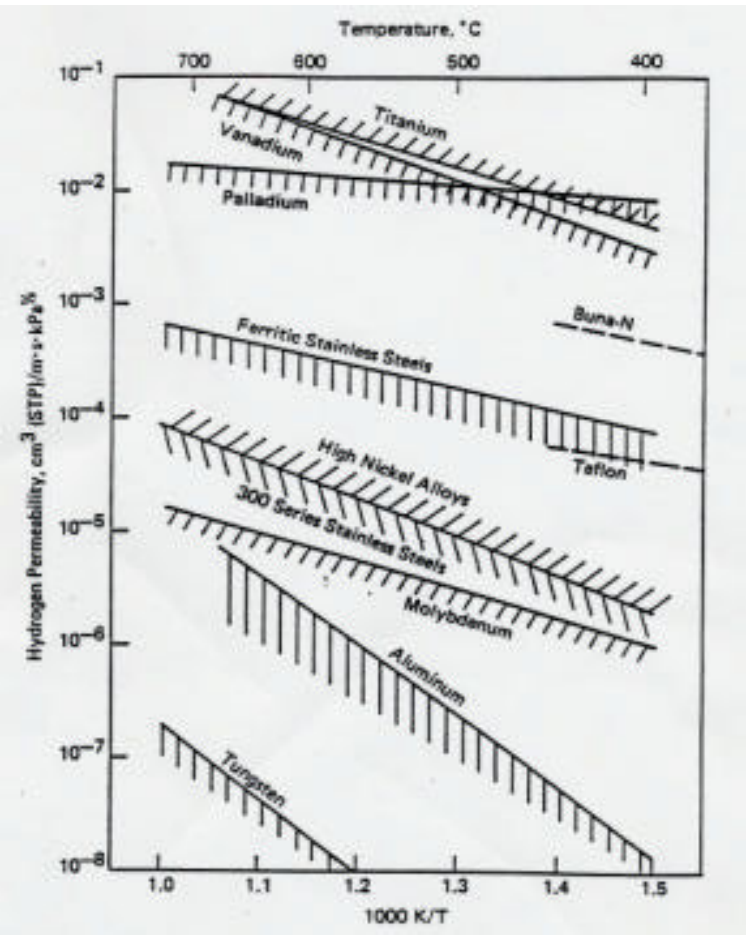

Figure 12. Hydrogen permeability (1).

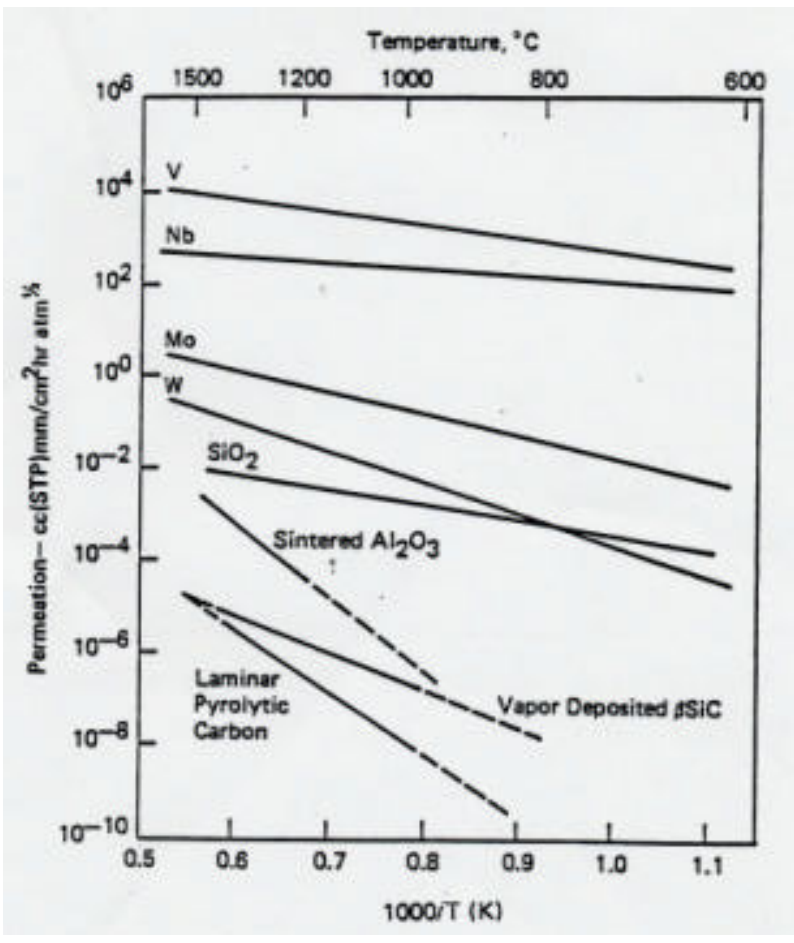

Figure 13. Hydrogen permeability (2).

The hydrogen permeability for high nickel alloys (e.g., Alloy 718) was evaluated from Figure 12 as:

$$
?_{\mathrm{H} 2}=10^{-6.7549-3193.28 / \mathrm{T}}
$$


where $\Pi_{\mathrm{H} 2}$ is in mol.m $\mathrm{m}^{-1} \mathrm{~s}^{-1} \mathrm{~Pa}^{-1 / 2}$ and $\mathrm{T}$ is in $\mathrm{K}$.

\subsubsection{Steady-State hydrogen release}

To calculate the release of hydrogen from the moderator box, we assume that the $\mathrm{ZrH}_{\mathrm{x}}-\mathrm{H}_{2}$ equilibrium exists within the moderator box at the operating temperature of the moderator box inner surface. Then, by definition of permeability, the hydrogen flux through the moderator box wall can be calculated as:

$$
\mathrm{J}=?_{\mathrm{H} 2}(\mathrm{~T}) \frac{\sqrt{\mathrm{P}_{\mathrm{H} 2}(\mathrm{x}, \mathrm{T})}}{\mathrm{t}_{\mathrm{w}}}
$$

where, $\mathrm{J}$ is in $\mathrm{mol} / \mathrm{m}^{2} \mathrm{~s}$ and $\tau_{\mathrm{w}}=0.57 \mathrm{~mm}$ is the wall thickness. The hydrogen balance for the moderator box is:

$$
\mathrm{S}^{2} \mathrm{~N}_{\mathrm{Zr}} \frac{\mathrm{dx}}{\mathrm{dt}}=-4 \mathrm{SJ} \quad \Rightarrow \quad \frac{\mathrm{dx}}{\mathrm{dt}}=-\frac{4 \mathrm{~J}}{\mathrm{SN}_{\mathrm{Zr}}}
$$

where $t$ is time, $S=23.232 \mathrm{~mm}$ is the moderator box side length and $\mathrm{N}_{\mathrm{Zr}}=0.061 \mathrm{~mol} / \mathrm{cm}^{3}$ is the number of moles of zirconium atoms per unit volume of zirconium hydride. Because $\mathrm{J}$ is a function of $\mathrm{x}$ and $\mathrm{T}$, equation 9 is an ordinary differential equation for the unknown function $\mathrm{x}(\mathrm{t})$ with $\mathrm{T}$ as a parameter. This equation can be readily solved with standard techniques. The decrease of hydrogen content in $\mathrm{ZrH}_{\mathrm{x}}$ is illustrated in Figure 14 for an expected moderator box lifetime of 4 yrs (i.e., two refueling cycles of 2 yrs each) and for several different operating temperatures of the moderator box inner surface. The maximum temperature of $490^{\circ} \mathrm{C}$ was estimated at the end of Appendix A under very conservative assumptions for the hottest fuel assembly. In reality most moderator boxes will perate at temperatures close to the coolant temperature (i.e., 280$450^{\circ} \mathrm{C}$ ). However, it can be seen that, even at the high temperature, the hydrogen content drops by only $2.5 \%$ over 4 yrs of operation (i.e., $x=1.56$ at end-of-life). Conservatively assuming that the $2.5 \%$ hydrogen drop is uniform throughout the core, the loss of neutron reactivity associated with the decrease of moderation was calculated by MCNP to be only 0.002 or less than $30 \propto$. Such a minute decrease of reactivity over a

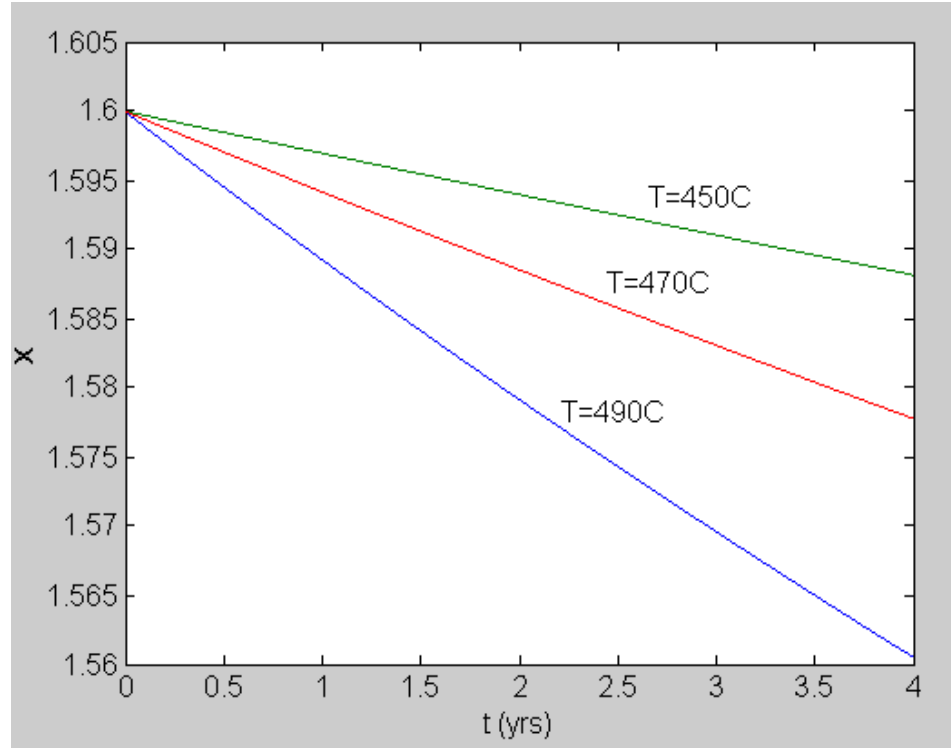

Figure 14. Long-term hydrogen depletion in the $\mathrm{ZrH}_{x}$ moderator. period of 4 yrs is negligible if compared with the reactivity drop associated with fuel burnup, and thus can be readily handled by the control system. Also, note that the drop in hydrogen content is not sufficient to cause a phase transition in the $\mathrm{ZrH}_{\mathrm{x}}$ (see Figure 10), so dimensional stability of the moderator is ensured.

The average rate of hydrogen release from a single moderator box corresponding to a $2.5 \%$ hydrogen content drop over 4 yrs lifetime would be about $1.6 \times 10^{-4} \mathrm{~mol} / \mathrm{hr}$ or 4 orders of magnitude lower than the 
estimated hydrogen generation by radiolysis of the coolant surrounding the moderator box (i.e., roughly $1.4 \mathrm{~mol} / \mathrm{hr}$ ). Therefore, steady-state hydrogen release from the moderator boxes represents no additional burden on the reactor off-gas system.

It is reported by Huang et al. [2000] that redistribution of hydrogen within $\mathrm{ZrH}_{\mathrm{x}}$ occurs in presence of a temperature gradient. Diffusion of a gas within a solid is described by the following equation [Olander 1976]:

$$
\overrightarrow{\mathrm{J}}=-\mathrm{D}\left\{\nabla \mathrm{x}+\mathrm{x} \frac{\mathrm{Q}}{\mathrm{RT}^{2}} \nabla \mathrm{T}\right\}
$$

where $\mathrm{J}$ is the hydrogen flux, $\mathrm{D}$ is the diffusion coefficient, $\nabla$ is the gradient operator, $\mathrm{R}$ is the gas constant and $\mathrm{Q}$ is the heat of transportation. Equation 10 indicates that a temperature gradient can induce hydrogen diffusion, even if a concentration gradient is not initially present. Diffusion continues until the following equilibrium condition is achieved:

$$
\frac{\nabla \mathrm{x}}{\mathrm{x}}=-\frac{\mathrm{Q}}{\mathrm{RT}^{2}} \nabla \mathrm{T}
$$

Equation 11 indicates that hydrogen tends to diffuse down the temperature gradient. It also suggests that at equilibrium the deviation from the initial hydrogen concentration $\left(\Delta \mathrm{x} / \mathrm{x}_{0}\right)$ is proportional to the temperature gradient and inversely proportional to the square of the mean temperature $\left(\Delta \mathrm{T} / \mathrm{T}^{2}\right)$ :

$$
\frac{? \mathrm{x}}{\mathrm{x}_{0}}=\mathrm{C} \frac{? \mathrm{~T}}{\mathrm{~T}^{2}}
$$

where $\mathrm{C}$ is a proportionality constant. This trend is confirmed by Huang et al.'s calculations for $\delta$-phase $\mathrm{ZrH}_{\mathrm{x}}$, from which the value of $\mathrm{C}$ is estimated to be around $642 \mathrm{~K}$.

In the SCWR case a temperature gradient is generated within the $\mathrm{ZrH}_{\mathrm{x}}$ moderator because of neutron and gamma heating. In Appendix A the maximum operating temperatures of the moderator in the hottest fuel assembly are estimated to be $490^{\circ} \mathrm{C}$ (moderator surface) and $620^{\circ} \mathrm{C}$ (moderator centerline). Thus, $\Delta \mathrm{T}=130 \mathrm{~K}, \mathrm{~T}=828 \mathrm{~K}, \mathrm{x}_{0}=1.6 \mathrm{and}$, from equation $12, \Delta \mathrm{x} \sim 0.2$. This means that the local value of $\mathrm{x}$ in the moderator box can be as high as $x_{\theta}+\Delta x / 2=1.7$ (at the moderator box inner surface) and as low as $x_{0}$ $\Delta x / 2=1.5$ (at the moderator centerline). This introduces some uncertainty on the value of $\mathrm{x}$ to be used in the hydrogen release calculations. To bound the SCWR behavior, the hydrogen release was recalculated assuming $x=1.7$. In this case the hydrogen content over 4 yrs of operation drops by about $3.5 \%$, larger than for $\mathrm{x}=1.6$, but again with negligible consequences on the core reactivity.

Finally it should be emphasized that redistribution of hydrogen within the moderator does not cause a phase transition, i.e., the $x=1.5-1.7$ range estimated for the SCWR is well within the field of stability of $\delta$ phase $\mathrm{ZrH}_{\mathrm{x}}$ at the temperatures of interest.

\subsubsection{Hydrogen Release During Accident Conditions}

We shall now analyze the issue of moderator box pressurization by hydrogen at the high temperatures typical of accident conditions. Note that, if the reactor has not depressurized, compressive stresses will exist in the moderator box wall due to the high external pressure of the coolant. However, the most 
severe conditions for failure of the moderator box are ones in which the reactor has depressurized, e.g., during a LOCA. Under such conditions (i.e., low external pressure and high temperature) tensile stresses are generated in the moderator box wall due to the internal surge of hydrogen pressure. A simple static equilibrium analysis provides an expression for the tangential membrane stress in the moderator box wall:

$$
\mathrm{S}_{\mathrm{t}}=\mathrm{P}_{\mathrm{H} 2} \frac{\mathrm{S}}{2 \mathrm{t}_{\mathrm{w}}}
$$

where $\mathrm{P}_{\mathrm{H} 2}$ depends on $\mathrm{x}$ and $\mathrm{T}$ as per equation for two values of the hydrogen content, and is compared with the yield stress of Alloy 718 . Unfortunately the mechanical properties of Alloy 718 could only be found for temperatures up to $870^{\circ} \mathrm{C}$ [ASM 1990]. Therefore, for the purpose of this calculation the yield stress had to be linearly extrapolated resulting in a zero value at $930^{\circ} \mathrm{C}$. Figure 15 shows that the maximum allowable temperature for the moderator box is about $925^{\circ} \mathrm{C}$. However, we recommend a value of $900^{\circ} \mathrm{C}$ for which a very large safety margin to failure $(>5)$ is provided even for the case with hydrogen redistribution $(x=1.7)$. Note that the use of the yield stress as the failure criterion is justified by the expected low frequency of LOCA events.

We shall now assess the hydrogen release through the moderator box wall at the established limit of $900^{\circ} \mathrm{C}$. Equations 8 and 9 still hold for this calculation. The decrease in hydrogen content during a transient for which the moderator box is held at $900^{\circ} \mathrm{C}$ for $24 \mathrm{hrs}$ is shown in Figure 16. The hydrogen content drop over this period of time is signific ant. Assuming a core of 1,000 MWth with $10^{4}$ fuel pins and 2,000 moderator boxes, the total release of hydrogen during such accident would be about $22,000 \mathrm{~mol}$ or $45 \mathrm{~kg}$. If this amount of hydrogen cannot be handled by the recombiners in the containment, two possible solutions are envisioned: i) an inert containment could be adopted to eliminate the risk of hydrogenoxygen explosion, or ii) a coating of

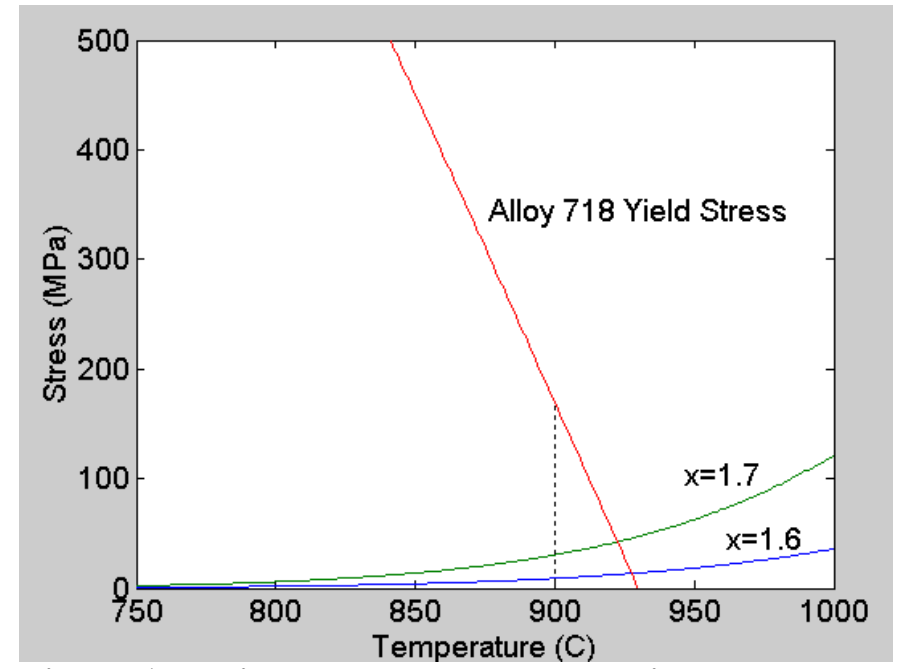

Figure 15. High-temperature stresses in the moderator box wall.

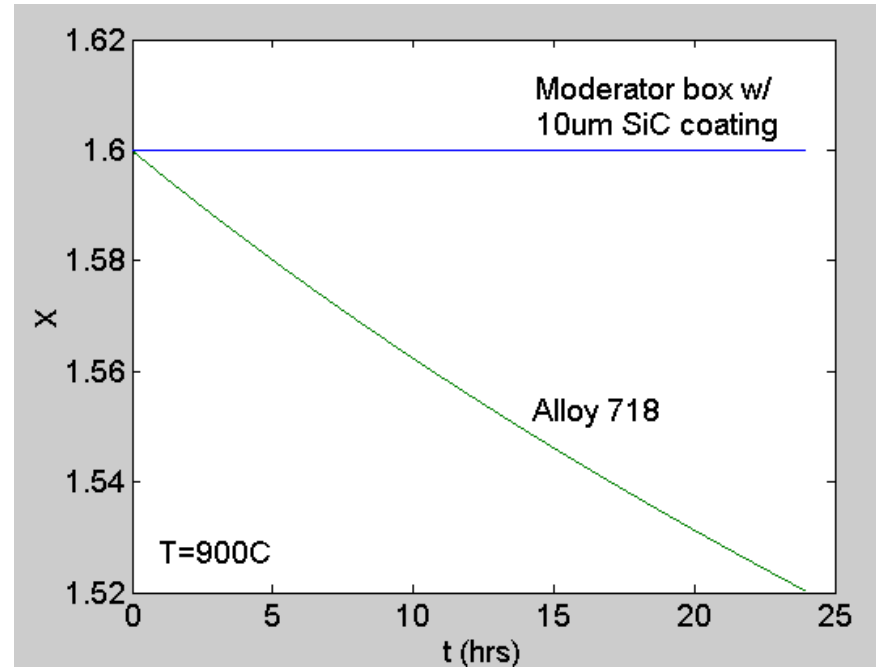

Figure 16. High-temperature hydrogen depletion in the $\mathrm{ZrH}_{\mathrm{x}}$ moderator.

hydrogen-impermeable material could be deposited on the inner surface of the moderator box to reduce hydrogen release in the first place. Figures 12 and 13 show that aluminum, SiC, and pyrolytic carbon have a much lower permeability to hydrogen than nickel alloys. For example, it is estimated by means of equations 8 and 9 that a $10 \mu \mathrm{m} \mathrm{SiC} \mathrm{coating} \mathrm{layer} \mathrm{on} \mathrm{the} \mathrm{inner} \mathrm{surface} \mathrm{of} \mathrm{the} \mathrm{moderator} \mathrm{box} \mathrm{would}$ 
practically eliminate hydrogen release at $900^{\circ} \mathrm{C}$ (Figure 16). Aluminide coatings on stainless steel have been shown to significantly reduce tritium permeability (Apley 1992, Marschman et al. 1991, Lanning et al. 1992).

\subsubsection{Thermal Capacity of $\mathrm{ZrH}_{x}$}

The use of a solid moderator affords some benefits in terms of thermal performance of the core during an event in which the coolant is rapidly lost (e.g., a large-break LOCA). The amount of $\mathrm{ZrH}_{1.6}$ in a single moderator box is about $13 \mathrm{~kg}$ or $140 \mathrm{~mol}$. Assuming an average value of $50 \mathrm{~J} / \mathrm{mol} \cdot \mathrm{K}$ for the specific heat (as per equation 3 for $\mathrm{T}=600^{\circ} \mathrm{C}$ and $\mathrm{x}=1.6$ ) the thermal capacity of the moderator box is $7000 \mathrm{~J} / \mathrm{K}$. Because there are 5 fuel pins for each moderator box, the moderator adds $7000 / 5=1400 \mathrm{~J} / \mathrm{K}$ of extra thermal capacity per fuel pin. Considering that for a $\mathrm{UO}_{2}$ specific heat of $450 \mathrm{~J} / \mathrm{kg} \cdot \mathrm{K}$ the estimated thermal capacity of a fuel pin is about $1140 \mathrm{~J} / \mathrm{K}$, it can be concluded that the $\mathrm{ZrH}_{\mathrm{x}}$ moderator effectively more than doubles the thermal capacity of the core.

\subsection{5. $\mathrm{ZrH}_{\mathrm{x}} /$ Alloy 718 Compatibility}

The three main constituents of Alloy 718 (i.e., nickel, chromium, and iron) do not form stable hydrides at the hydrogen pressures and temperatures of interest to our application [Siegel and Libowitz 1968]. Therefore, massive hydriding of the moderator box is not a concern. Among the other constituents of Alloy 718, only titanium (nominally present at $0.9 \mathrm{wt} \%$ ) forms stable hydrides (i.e., $\mathrm{TiH}_{\mathrm{x}}$ ). However, note that, for any given temperature and composition, the dissociation pressure of $\mathrm{TiH}_{\mathrm{x}}$ is higher than that of $\mathrm{ZrH}_{\mathrm{x}}$. Therefore, in our system (where the hydrogen pressure is set by the $\mathrm{ZrH}_{\mathrm{x}}-\mathrm{H}_{2}$ equilibrium) the value of $\mathrm{x}$ for $\mathrm{TiH}_{\mathrm{x}}$ at any given temperature will always be lower than 1.6, i.e., the value of $\mathrm{x}$ for $\mathrm{ZrH}_{\mathrm{x}}$. On the basis of the temperature-pressure-composition $\left(\mathrm{P}_{\mathrm{H} 2}-\mathrm{T}-\mathrm{x}\right)$ diagrams for $\mathrm{TiH}_{\mathrm{x}}$ reported by Mueller [1968b], we estimate that less than 5\% of the titanium in the Alloy 718 (or about $450 \mathrm{wt}$ ppm of the whole alloy) will react to form hydrides over the $280-470^{\circ} \mathrm{C}$ temperature range of normal operation for the moderator box. At this point it is hard to tell if such a minute amount of titanium hydride will have some effect on the strength or corrosion performance of the Alloy 718. This can be further reduced by the use of an aluminide coating on the inside surface as discussed above.

Like most high-strength alloys, Alloy 718 is susceptible to hydrogen embrittlement. Nevertheless, it has been extensively and successfully used as a structural material in hydrogen environments from cryogenic to elevated temperatures [He et al. 1994, Lenhart et al. 1992, Gross 1990]. Furthemore, there are two mitigating factors suggesting that hydrogen embrittlement should not be a serious problem in our case: i) embrittlement becomes important when plastic stresses are present, but the moderator box operates well below the yield point even at high temperature, and ii) embrittlement is mostly a concern at low temperatures (i.e., room temperature and below), while the moderator box operates at relatively-high temperatures $\left(>280^{\circ} \mathrm{C}\right)$.

A third issue to consider is that of diffusion of zirconium into the moderator box at high temperature. If intermetallic compounds are possible (as is the case for the $\mathrm{Zr}-\mathrm{Ni}$ couple [Elliott 1965]), zirconium diffusion can result in the formation of a weak and brittle interaction layer, which can lead to failure of the moderator box. For this reason Huffine [1968] states that nickel alloys are not suitable for cladding of zirconium hydrides without a protective coating acting as a barrier to zirconium diffusion. However, contrary to Huffine, Van Houten [1974] reports that nickel alloys are routinely used for cladding of zirconium hydrides. If in fact a protective coating is needed, Huffine [1968] recommends molybdenum, which has been used successfully, either plasma sprayed or in thin foils. Only few microns of material are needed to arrest zirconium diffusion. Incidentally, we shall note that a thin molybdenum layer, 
although helpful, would not solve the problem of hydrogen release at high temperature discussed at the end of Section 1.3.3.2, so that a coating of hydrogen-impermeable material would still be needed.

\subsubsection{Fabrication of $\mathrm{ZrH}_{\mathrm{x}}$}

Huffine [1968] and Van Houten [1974] provide good reviews (albeit relatively old) of the fabrication technology for metal hydride components. Zirconium hydride is best produced by direct exposure of zirconium metal to hydrogen gas in a furnace of controlled temperature and hydrogen pressure. Hydrogen diffuses within the metal matrix until equilibrium is achieved. This process is called metal hydriding. The desired phase (or value of $\mathrm{x}$ ) can be produced by selecting the process temperature and the hydrogen pressure as per the $\mathrm{P}_{\mathrm{H} 2}-\mathrm{T}-\mathrm{x}$ relation of Equation 6. For example, hydriding with a hydrogen pressure of $0.01 \mathrm{~atm}$ at a temperature of $600^{\circ} \mathrm{C}$ would produce $\delta$-phase zirconium hydride with $\mathrm{x}=1.6$. Obviously, if the $\delta$ phase is to be preserved during cooldown to room temperature, the pressure of hydrogen must be continuously adjusted to follow an isocore (i.e., a curve of given $\mathrm{x}$ value). Oxygen and nitrogen impurities in the hydrogen gas must be minimized, as they would cause formation of oxide and/or nitride films on the metal surface, thus impairing hydrogen diffusion during the hydriding process. Also, oxygen affects the phase stability of the zirconium hydride, i.e., it shifts the $\delta \rightarrow \varepsilon$ transition to lower hydrogen contents. However, at the specified low levels of oxygen impurities in reactor-grade zirconium $(<1000 \mathrm{wt}$ ppm or $<1$ at. \%) this effect is expected to be negligible [Beck and Mueller 1968]. Finally, it should be emphasized that uniform and cost effective hydriding of zirconium parts with cross sections as wide as $7 \mathrm{~cm}$ has been successfully performed in the past; the proposed moderator rods for the SCWR fall well within this established range.

In principle, once the hydriding process is complete, there are two approaches to proceed on to the final product:

1) Grinding of the hydride and then powder compaction and sintering to the desired geometry,

2) Direct machining of the hydride.

The first approach presents several disadvantages. When the $\mathrm{ZrH}_{\mathrm{x}}$ powder is handled in air, the importance of oxidation and the effect of oxygen contamination on phase stability are higher because of the large surface-to-volume ratio. This might require performing fabrication in boxes with an inert atmosphere, which negatively affects costs. Also, the sintering step would be considerably complicated because of the need to maintain extremely high hydrogen equilibrium pressures $(>300 \mathrm{MPa}$ for $\mathrm{x}=1.6$ and $\mathrm{T}=1600^{\circ} \mathrm{C}$ ) in order to prevent massive de-hydriding. Finally, the sintered material would have worse thermo-mechanical properties (e.g., thermal conductivity and strength) than the original as-hydrided material because of the lower-than-theoretical density.

With the second approach the initial zirconium metal part must possess roughly the final geometry of the $\mathrm{ZrH}_{\mathrm{x}}$ part so that machining of the hydride can be minimized. Informal talks with zirconium specialists at Allegheny Technologies [2002] indicated that fabrication of solid square rods of nucleargrade zirconium metal with the dimensions of interest to our application (i.e., $\sim 2 \times 2 \mathrm{~cm}$ cross section, $\sim 430 \mathrm{~cm}$ length) is a straightforward process comprising the following steps: a large forged zirconium slab (10 cm thick, $60 \mathrm{~cm}$ wide, $500 \mathrm{~cm}$ long) is hot rolled to produce a plate of $2 \mathrm{~cm}$ thickness. The plate is then quenched at $870^{\circ} \mathrm{C}$ to stabilize the $\alpha$ phase and eliminate any grain orientation resulting from hot rolling. Finally, the plate is cut in $2-\mathrm{cm}$ wide strips to realize the $\sim 2 \times 2 \mathrm{~cm}$ square cross section rods that will be hydrided.

The integrity of the as-hydrided metal with the first approach (i.e., grinding and sintering) is not important because the material is to be ground anyway. However, the main issue with the second 
approach is that of producing a crack-free hydride. This requires accurate control of the heating and cooling rates during hydriding, i.e., too quick a hydrogen pick-up or depletion can cause cracking of the material. Another issue is that of expansion during hydriding, which usually occurs anisotropically along the three directions of the metal grains, hence in general requiring that the part be machined to its final geometry. Huffine [1968] reports that zirconium hydride is a brittle material with machining properties between those of graphite and gray cast iron, and thus all machining operations are possible and relatively easy, including internal and external threading. In fact, zirconium hydride rods of much greater geometric complexity than the ones analyzed in this report were successfully machined for the HTRE-3 project [Huffine 1968]. However, Van Houten later reported that, if the anisotropy of the initial zirconium metal is well characterized and the hydriding cycle is carefully controlled, the geometry of the as-hydrided expanded part can be predicted within $0.1 \%$ of the desired dimension, which may eliminate the need for machining [Van Houten 1974]. Because of the very simple geometry of the SCWR moderator rods and because accurate characterization of zirconium anisotropy is common practice in the nuclear industry, it is likely that the machining step could be avoided in our case.

Once the zirconium hydride rod is fabricated, it needs to be inserted in the moderator box, or cladding. One end of the moderator box is welded shut leaving the other open for insertion of the moderator rod. Once the hydride is in, inert-gas-shielded arc welding is used, which is a rapid welding technique giving minimal heating of the area adjacent to the weld. This is important to prevent localized de-hydriding of the hydride rod. The residual gases in the box are removed through an evacuation tube connected to a vacuum pump. Then the box can be re-pressurized with a proper cover gas (e.g., helium) and checked for leaks [Huffine 1968].

\subsubsection{Cost of the $\mathrm{ZrH}_{\mathrm{x}}$ Moderator Rods}

In this section we estimate the cost of the $\mathrm{ZrH}_{\mathrm{x}}$ moderator rods and its impact on the cost of electricity generated by the SCWR. The cost of nuclear-quality zirconium square rods (i.e., the starting point for the hydriding process) was estimated by Allegheny Technologies [2002] to be in the $\$ 90-110 / \mathrm{kg}$ range. In our calculations we will assume the upper limit. Also, Allegheny Technologies routinely conducts hydriding of zirconium for powder metallurgy purposes. On the basis of their experience they estimate the hydriding process will increase the cost of the final product by $20-30 \%$. However, here we will assume that hydriding will double the cost of the product. This is because, while in powder metallurgy the hydriding process does not have to be carefully controlled to avoid cracking of the initial zirconium, in our case it would. Thus, considering that there is a mass of $13 \mathrm{~kg}$ of $\mathrm{ZrH}_{1.6}$ in each moderator rod, the cost of an unclad rod is $\$ 110 / \mathrm{kg} \times 13 \mathrm{~kg} \times 2=\$ 2860$. As for the moderator box, the cost of Alloy 718 was obtained from Dynamic Metal Forming [2002] at about $\$ 62$ per $\mathrm{kg}$ of Alloy 718 ingot. We shall assume that the cost of the end product (i.e., the actual box) is 10 times higher than that of the raw material. Therefore, considering that the mass of Alloy 718 in one moderator box is about $1.9 \mathrm{~kg}$, the cost of the moderator box is estimated as $\$ 62 / \mathrm{kg} \times 1.9 \mathrm{~kg} \times 10=\$ 1178$. Finally, we assume that inserting the zirconiumhydride in the moderator box, plus sealing and testing will double the cost of the final product. Then the cost of a clad zirconium-hydride rod ready to go into a fuel assembly is $(\$ 2860+\$ 1178) \times 2=\$ 8076$. We shall indicate this cost as $\mathrm{C}_{\mathrm{M}}$.

To calculate the impact on the cost of electricity, we have to account for several factors including the amount of electricity generated per rod of solid moderator, the payment of interest during in-reactor residence, and the depreciation of the asset. We will make use of the following assumptions:

- $\mathrm{M}_{\mathrm{UO} 2}$ is the mass of $\mathrm{UO}_{2}$ fuel associated with a single moderator rod. Because there are 5 fuel rods for each moderator rod, and each fuel rod contains about $2.5 \mathrm{~kg}$ of $\mathrm{UO}_{2}$, the total mass of fuel is $\mathrm{M}_{\mathrm{UO} 2}=12.5 \mathrm{~kg}$

- $\quad$ The discharge burnup for the SCWR is assumed to be $\mathrm{B}=45,000 \mathrm{kWD} / \mathrm{kg}$ 
- $\quad$ The reactor thermal efficiency is $\eta=0.42$

- The in-reactor residence time is $\mathrm{N}=4$ yrs

- The marginal tax rate is $\tau=30 \%$

- The after-tax averaged cost of capital is $\mathrm{i}=10 \%$

- $\quad$ The salvage value of the moderator is $\$ 0$

- A linear depreciation schedule is assumed.

Then the cost of the solid moderator, c $(\$ / \mathrm{kWh})$, levelized over the in-reactor residence time is:

$$
\mathrm{c}=\frac{\mathrm{C}_{\mathrm{M}}}{24 \cdot \mathrm{M}_{\mathrm{UO} 2} \cdot \mathrm{B} \cdot ?} \Phi
$$

where the factor 24 accounts for the conversion of days to hours, and $\Phi$ is the levelized annual capital carrying charge factor, calculated as follows:

$$
\mathrm{F}=\frac{\left[(\mathrm{A} / \mathrm{P}, \mathrm{i}, \mathrm{N})-\frac{\mathrm{t}}{\mathrm{N}}\right]}{1-\mathrm{t}} \approx 34 \%
$$

where $(\mathrm{A} / \mathrm{P}, \mathrm{i}, \mathrm{N})$ is the capital recovery factor [Park 1990]:

$$
(A / P, i, N)=\frac{i(1+i)^{N}}{(1+i)^{N}-1} \approx 32 \%
$$

Equation 14 yields a value of $\$ 0.005 / \mathrm{kWh}$ or $0.5 \mathrm{mills} / \mathrm{kWh}$. Therefore, assuming a target total cost of electricity of $30 \mathrm{mills} / \mathrm{kWh}$, the use of zirconium hydride moderator rods in the core would represent an estimated increase of less than $2 \%$. This increase is negligible if compared with more important factors in determining the total cost of electricity like plant capital cost, effective maintenance, and outage duration, which, incidentally, would be made relatively easier with a solid moderator than with water rods.

\subsection{Conclusions}

The neutronic performance of several solid moderators for the SCWR core was evaluated and compared to that of water rods. It was found that the only acceptable solid moderator is $\delta$-phase zirconium hydride $\left(\mathrm{ZrH}_{1.6}\right)$, which generates a relatively high multiplication factor and a negative coolant void reactivity coefficient. Several issues key to the chemical and thermo-mechanical feasibility of $\mathrm{ZrH}_{1.6}$ were assessed including zirconium-hydride/water interaction, hydrogen release, hydrogen redistribution, pressurization of the moderator box at high temperature, phase stability, and compatibility of zirconium hydride with the moderator box material. It was found that:

1) The chemical reaction of zirconium hydride with water is thermodynamically favored but kinetically impaired even at high temperatures.

2) Hydrogen release is low at steady-state, while the use of a hydrogen-impermeable coating on the inner surface of the moderator box might be required at higher temperatures.

3) The moderator-box wall temperature during a LOCA should be limited to $900^{\circ} \mathrm{C}$ to prevent failure from internal hydrogen pressure.

4) Hydrogen redistribution and release do not threaten the stability of $\delta$-phase zirconium hydride. 
5) The use of a solid moderator greatly enhances the thermal capacity of the SCWR core.

6) The issues of hydriding and hydrogen embrittlement of the moderator box material, Alloy 718, appear of little concern, while high-temperature diffusion of zirconium into Alloy 718 might have to be prevented by means of a thin molybdenum protective coating.

7) Finally, fabrication of the SCWR moderator rods appears feasible within the envelope of existing technology.

In the cost area a simple analysis indicated that the use of zirconium-hydride moderator will not result in significant economic penalization of the SCWR.

At this point no insurmountable difficulties have been identified in the development of zirconium hydride moderator rods for SCWR thermalspectrum cores, and thus this approach will be further pursued in the project. 


\section{Task 2 Results: Fuel Cladding and Structural Material Corrosion and Stress Corrosion Cracking Studies}

\subsection{Progress of Work at MIT}

\subsubsection{Identification of Most Promising Materials}

A formal literature survey has been initiated and preliminary results follow. Hattori et. al. [2000] investigated the oxidation resistance in high pressure superheated steam of several candidate materials: austenitic steels, nickel base alloys, Ti alloys, and high $\mathrm{Cr}$ ferritic steels.

The high Cr ferritic steels, Mod 9Cr-Mo steel, and 12Cr-1Mo steel are commonly used as heat resistant tubes in fossil power plants. Austenitic type SUS316 stainless steels is generally used in many industries in addition to nuclear power plants. Type SUS310 is also corrosion resistant because of the high Cr content. The high Ni alloys, Alloy 690 and Alloy 718, have been used in light water reactors as steam generator tube and leaf spring materials, respectively. Ti-3 Al-2.5V alloy is a representative $\alpha-\mathrm{Ti}$ alloy mainly used for tube material in airplanes. Ti-15V-3Al-3Sn-3Cr alloy was selected as a $\beta$-Ti alloy because of corrosion resistance and formability at room temperature.

Autoclave tests were carried out in $\mathrm{SCW}$ at $566^{\circ} \mathrm{C}, 25 \mathrm{MPa}$, and superheated steam at $566^{\circ} \mathrm{C}, 12 \mathrm{MPa}$. The test duration was 2000 hours (deaerated) and 750 hours (aerated). The relative corrosion rates of the test specimens (normalized by the corrosion rate of SUS310 in the deaerated superheated steam) were compared. The corrosion rates were calculated based on the reduction of the thickness of the specimens after descaling, except for the $\mathrm{Ti}$ alloys. In the latter case, the corrosion rate was calculated from the weight gains.

For the deaerated condition, the corrosion rate of the high $\mathrm{Cr}$ ferritic steels was about $10-20$ times higher than that of SUS310. The high Ni alloys and SUS310 showed the highest corrosion resistance for this condition. In deaerated superheated steam, the oxide thickness of SUS316 was a few microns after 2000 hours. The experimental results suggest that, for the materials tested, austenitic stainless steels, and the high nickel alloys were likely to be more promising for SCR cladding material.

Kondo et al. [1998] report the results of corrosion tests for low activation ferritic/martensitic steel (F82H) and several boiler steels (HCM12A, NF616, HCM2S, STBA24). Of these materials, STBA24 has been widely used for heat exchanger tubes in conventional boilers, and has a service temperature around $560^{\circ} \mathrm{C}$. $\mathrm{HCM} 12 \mathrm{~A}, \mathrm{NF} 616$, and $\mathrm{HCM} 2 \mathrm{~S}$ are the current candidate materials for advanced boilers. The expected service temperature for HCM12A and NF616 is $600^{\circ} \mathrm{C}$ to $610^{\circ} \mathrm{C}$. Both $\mathrm{HCM} 12 \mathrm{~A}$ and NF616 have a ferritic/martensitic microstructure. The tests were carried out for up to 300 hours at $650^{\circ} \mathrm{C}$ and $8.6 \mathrm{MPa}$.

The corrosion behavior of conventional steels are known to depend mainly on $\mathrm{Cr}$ content. The low activation ferritic/martensitic steel, $\mathrm{F} 82 \mathrm{H}$, which contains $7.6 \% \mathrm{Cr}$ showed corrosion resistance similar to the series of boiler tubing materials consistent with $\mathrm{Cr}$ content. From their results, a double-layered oxide film with an iron-rich outer layer and $\mathrm{Cr}$ enrichment in the inner layer were formed on $\mathrm{F} 82 \mathrm{H}$. It is known that the separation of the Fe-rich outer layer and Cr-rich inner layer is due to higher diffusion rate of the $\mathrm{Fe}$ ions with respect to $\mathrm{Cr}$ ions and that the inner layer is a better diffusion barrier, and it mainly contributes to the oxidation resistance of the steels. Consequently, the anodic dissolutions of F82H and several boiler-tubing materials is controlled by the $\mathrm{Cr}$-rich inner layer. 


\subsubsection{Corrosion and Stress Corrosion Cracking of Candidate Materials}

Figure 17 presents a schematic representation of the current SCW facilities at MIT. (This facility was described in more detail in the first two quarterlies of this project.) The exposure facility incorporates a relatively large autoclave with an internal volume of approximately $860 \mathrm{mls}$. It is large enough to expose a rack of weight loss, welded, and ubend samples for extended times.

At the culmination of the meeting in Ann Arbor, it was decided that initial experiments should be carried out using 316L, and Inconel-625 as baseline materials. Preparations are currently underway to conduct instrumented-tube experiments with these materials. The samples

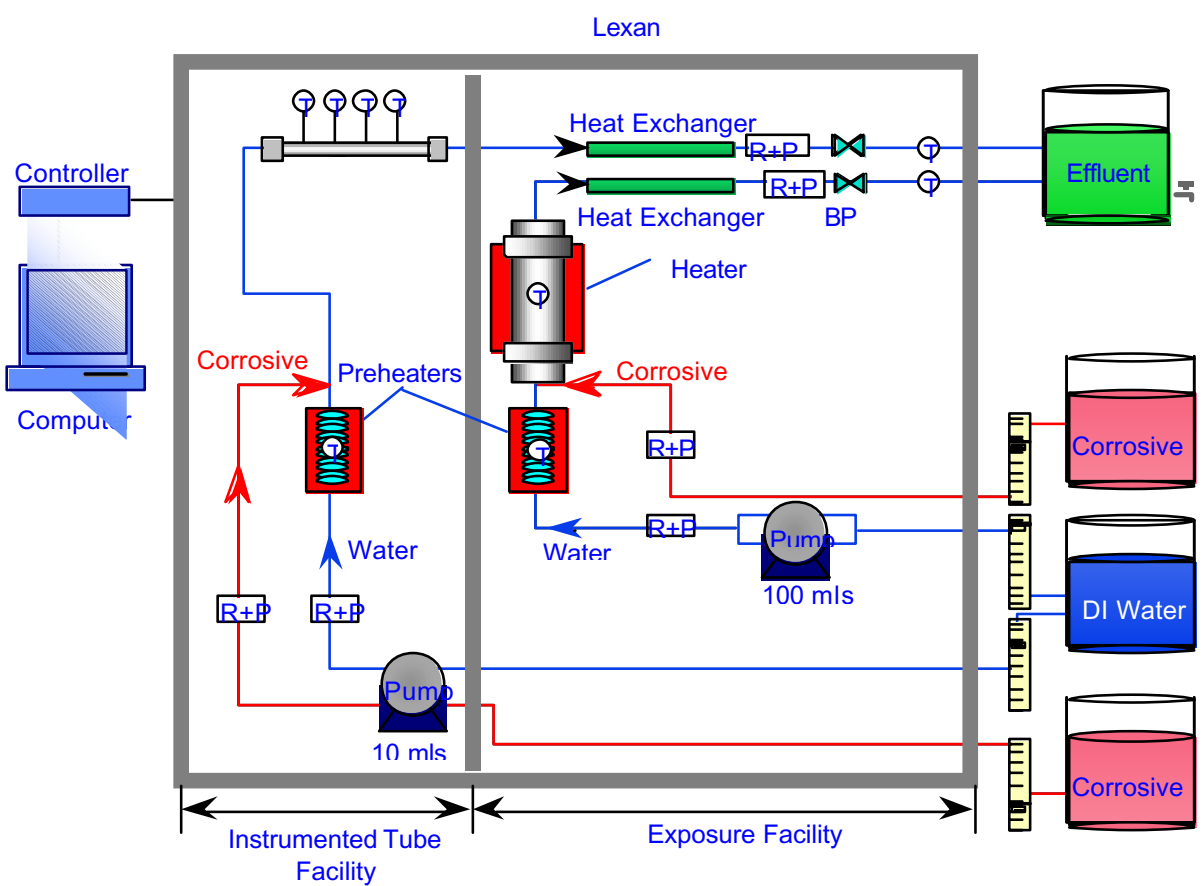

Figure 17. Schematic of the MIT SCW loop. will be exposed to 15 mega ohm water over a temperature range encompassing both sub- and supercritical conditions.

Preliminary data from Inconel-625 suggest the potential for localized breakdown both for exposed and occluded regions. Figure 18 presents a scanning confocal laser micrograph of the surface of an Inconel-625 sample exposed at MIT to 15-mega ohm water at a temperature of $300^{\circ} \mathrm{C}$ for 240 hours. The surface profile (uneven white line) represents the situation along the length of the solid white line positioned over the pit. This indicates that the pit has a depth of $4.46 \mu \mathrm{m}$ and a diameter of $19.3 \mu \mathrm{m}$.

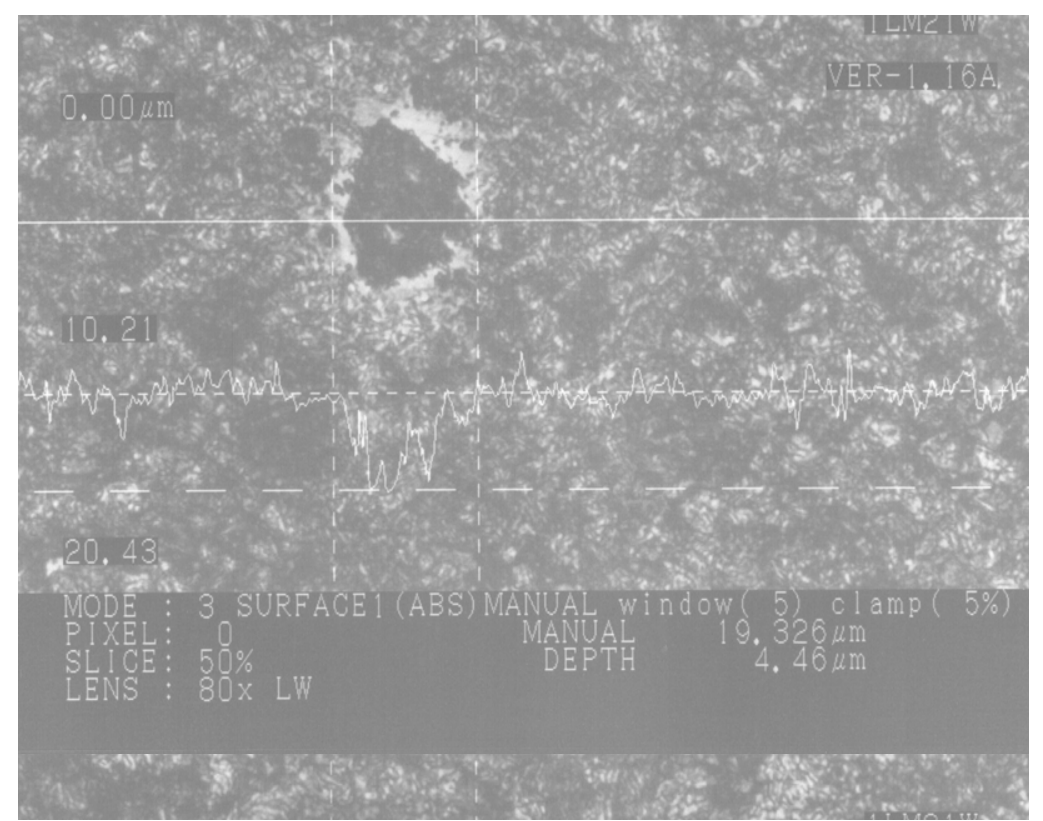

Figure 18. The exposed surface of an alloy 625 sample after 240 hours at $300^{\circ} \mathrm{C}$ in 15 mega ohm water. 
Figure 19 reveals pitting within the occluded region formed by an alumina spacer for the same Inconel-625 sample presented in Figure 18. In this case, however, a corrosion product cap has formed over a portion of the pit, likely suggesting a different microenvironment within the occluded region. The pit diameter is approximately $12 \mu \mathrm{m}$ and the depth of the open portion of the pit is about $2 \mu \mathrm{m}$.

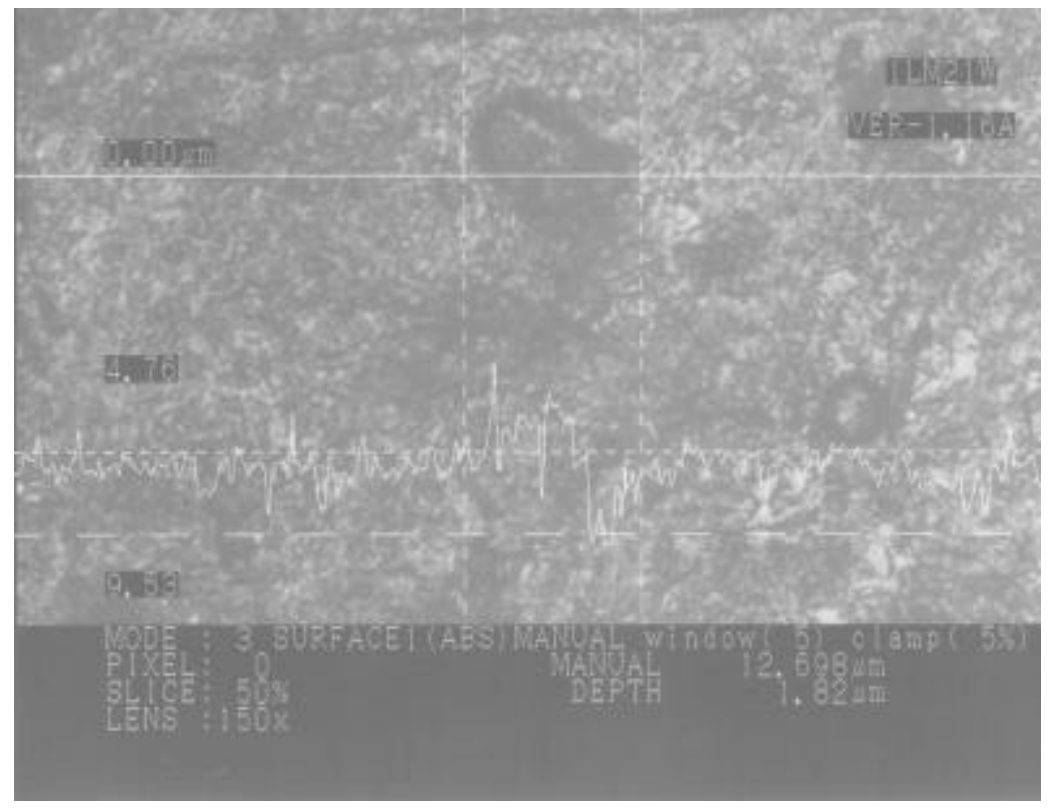

Figure 19. The shielded surface of an Alloy-625 sample exposed to 15 mega ohm water at $300^{\circ} \mathrm{C}$ for 240 hours.

\subsection{Progress of Work at the University of Michigan}

The design and fabrication of the University of Michigan supercritical water loop system for stress corrosion cracking tests was completed during the first two quarters of this NERI project. In this loop system, one tensile sample can be tested in various loading modes such as constant extension rate tension (CERT), constant load, ramp and hold, low cycle fatigue, etc. Additionally, 6 U-bend samples can be loaded into the test vessel, using sample holders secured to the vessel internal support plate. The system provides proper test conditions for stress-corrosion-cracking tests such as environmental and loading conditions. The main loop components are the test vessel, loading frame, main pump, heating elements, back pressure regulator, and water columns. Figure 20 shows a schematic of the water loop. Figures 21 and 22 show the overall view of the loop system and the load frame and loading elements.

During this quarter, the Supercritical Water Test Facility was evaluated. The test conditions have been reached and a dummy sample has been strained in these conditions. Several tests have been performed with the goal of determining the influence of pressure variation on load and LVDT displacement and the relationship between the load detected by the load cell and the load actually experienced by the sample. Also, the chemical environment has been surveyed and new steps have been taken for safety purposes. 


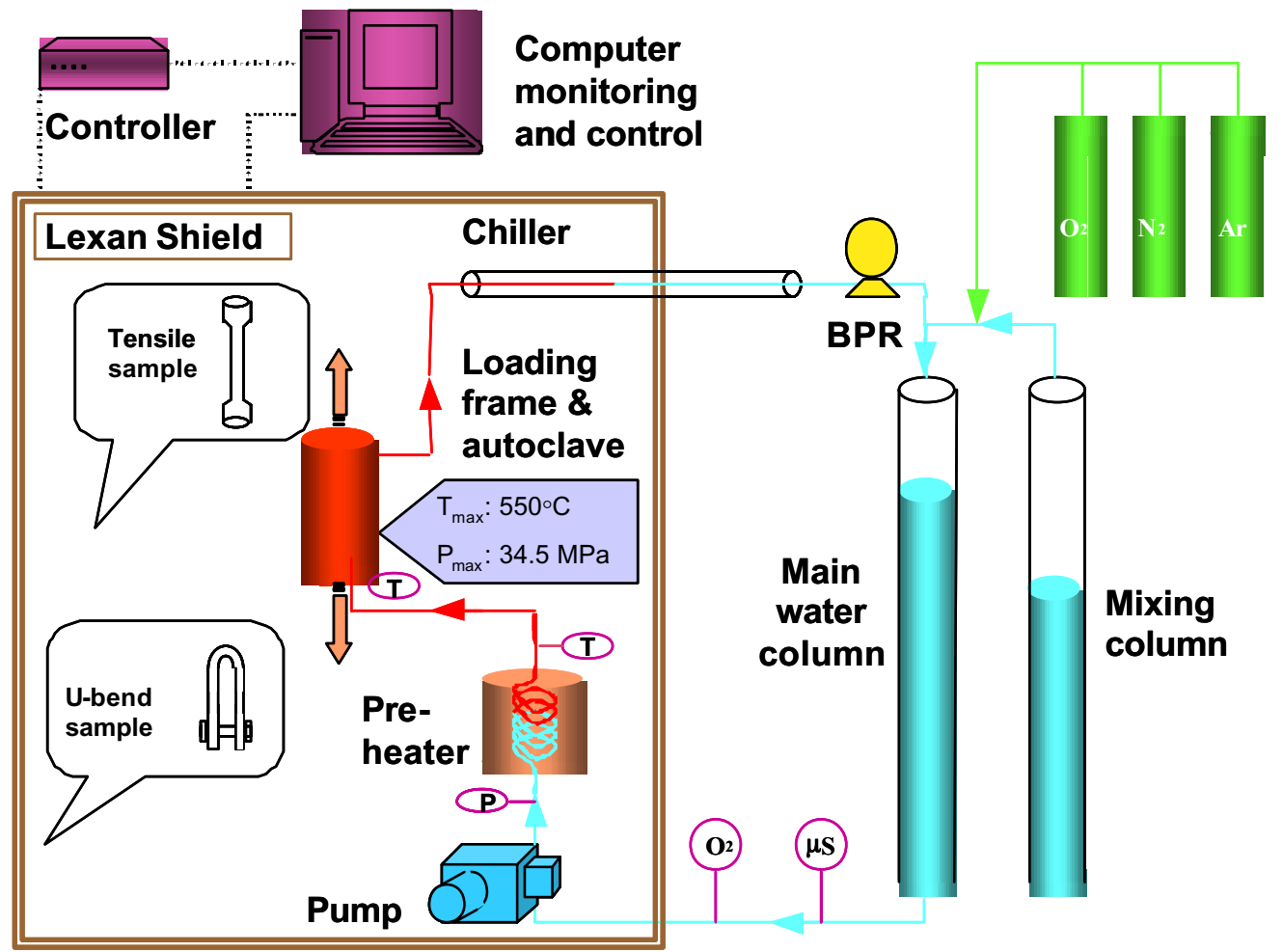

Figure 20. Schematic of the Supercritical water loop for stress corrosion cracking tests at the University of Michigan.

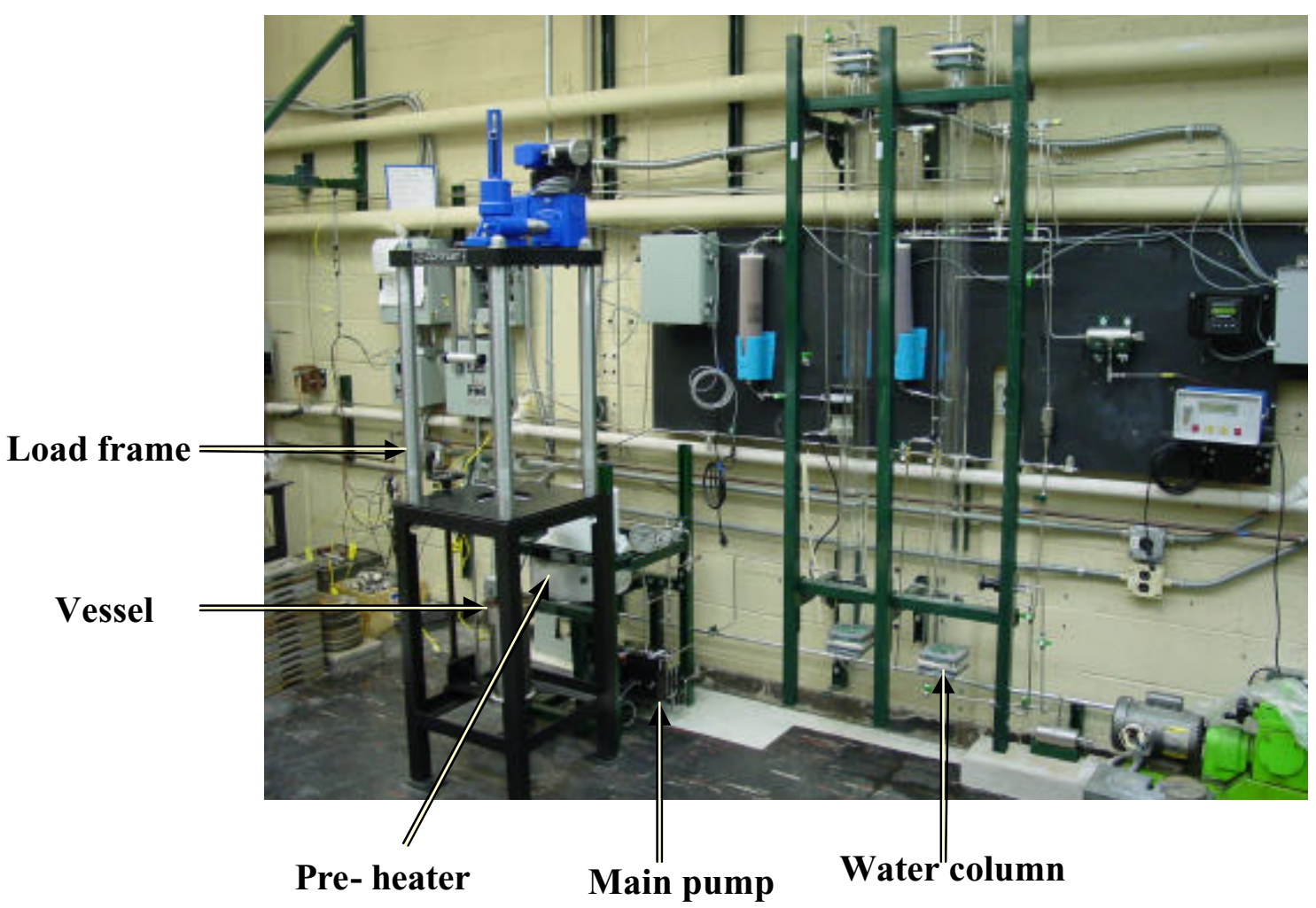

Figure 21. Overall view of the University of Michigan supercritical water loop system. 


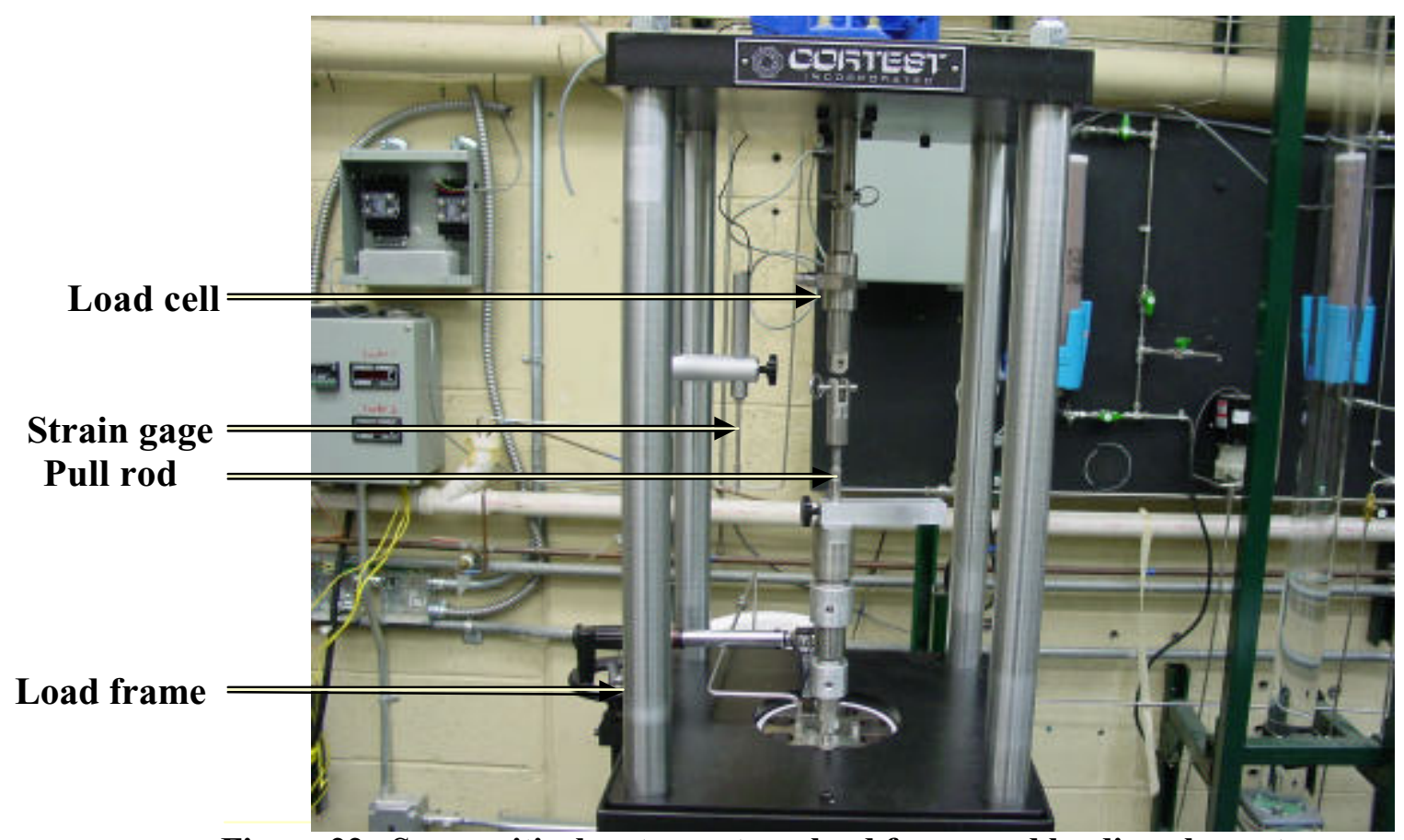

Figure 22. Supercritical water system: load frame and loading elements

\subsubsection{Performance Test}

Test conditions (25.5 MPa (3700 psig), $550{ }^{\circ} \mathrm{C}$ ) were reached and maintain for a period of 20 hours for the first time on June 14, 2002. Figure 23 shows the temperature and pressure history for the performance test. The first graph shows that the temperature was quite stable with a variation of around $\pm 2{ }^{\circ} \mathrm{C}$. The second graph shows the pressure variation during the increase in temperature to the set-point of $550^{\circ} \mathrm{C}$. The pressure varied by around $0.7 \mathrm{MPa}(100 \mathrm{psig})$ during the temperature rise. Once the temperature had stabilized, the variation of pressure was reduced to only about $\pm 0.14 \mathrm{MPa}$ (20 psig).

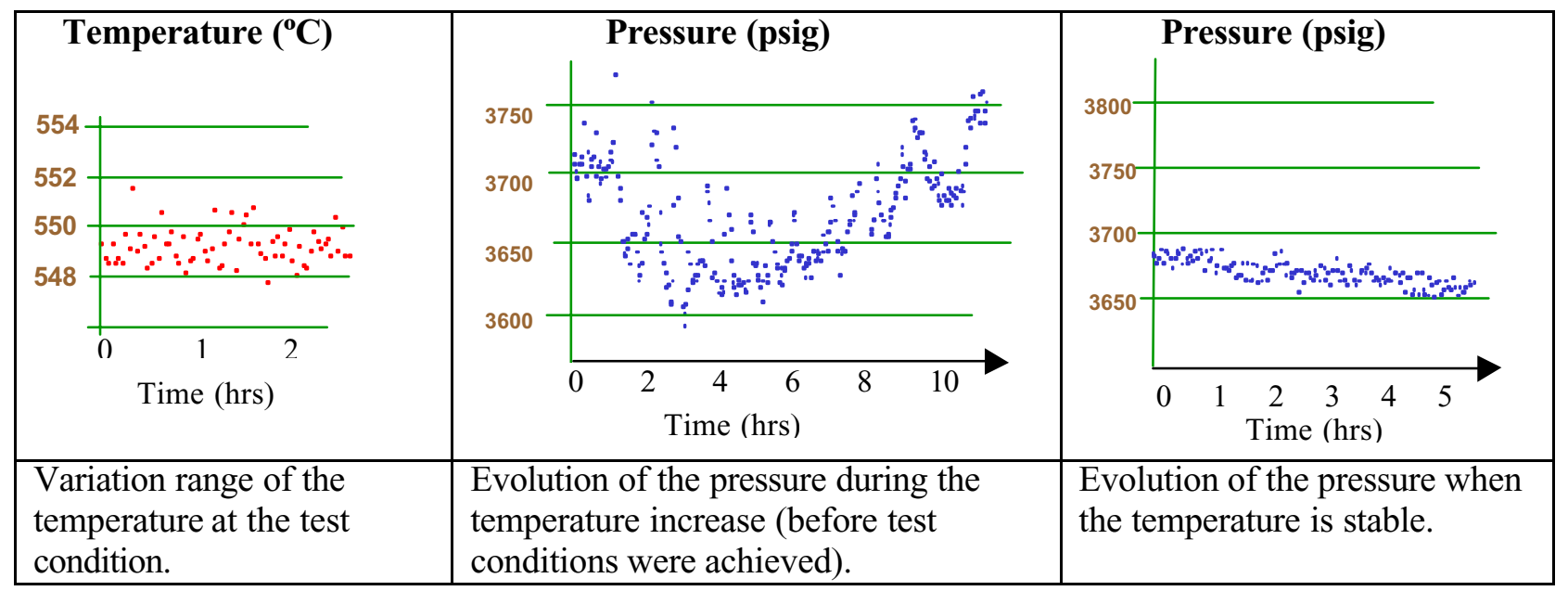

Figure 23. Performance test at $550^{\circ} \mathrm{C}$ and $25.5 \mathrm{MPa}(3700 \mathrm{psi})$. 


\subsubsection{Sample Loading At Test Conditions}

A dummy sample was strained in supercritical water $\left(25.5 \mathrm{MPa}, 550{ }^{\circ} \mathrm{C}\right)$ to about $6 \%$ strain. On the load versus time curve shown in Figure 24, the load cell records an increase of load, whereas the pull rod doesn't move until a load of $80 \mathrm{lbs}$ is reached. Then the load drops before increasing again. This behavior during the period of elastic deformation is probably due to friction between the bal seals and the pull rod. When the sample is strained, the load recorded by the bad cell is less stable $( \pm 15 \mathrm{lbs}$ of variation) than it was during the test performed at $20^{\circ} \mathrm{C}$ and $0 \mathrm{MPa}(0 \mathrm{psig})$. In order to capture the actual stress-strain behavior, a series of tests were performed to determine the relationship between the pressure and recorded load.

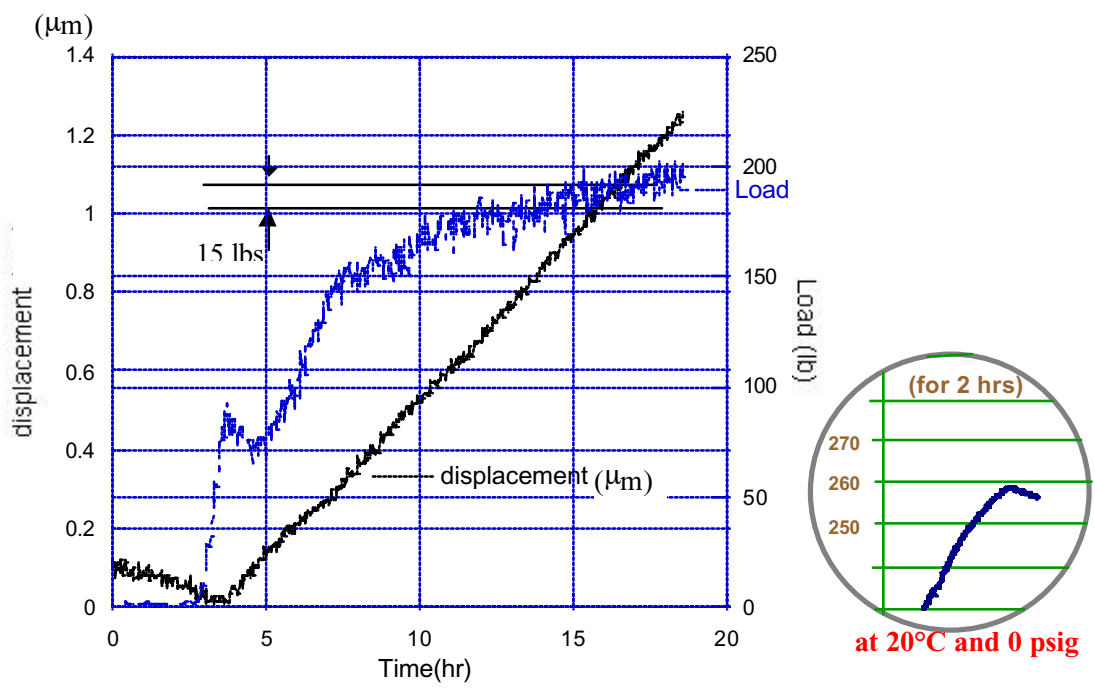

Figure 24. Load and displacement versus time obtained with a dummy sample in test conditions $\left(25.5 \mathrm{MPa}, 550^{\circ} \mathrm{C}\right)$. The inset to the right shows the load versus time taken from a sample strained in air. The drop in load during the period of elastic deformation is due to friction between the bal seals and the pull rod.

\subsubsection{Influence Of $A$ Pressure Change On Displacement And Load}

To determine if either the variation of pressure during a test (in supercritical water) or the increase of pressure at the beginning of the test can have any effect on the load and extension of the sample, several tests were performed. As shown in Figure 25, at the supercritical condition, there is no correlation between a pressure change of around 1.4 $\mathrm{MPa}(200 \mathrm{psig})$ and the variation range of the load (15 lb).

At room temperature, pressure changes were observed to affect load

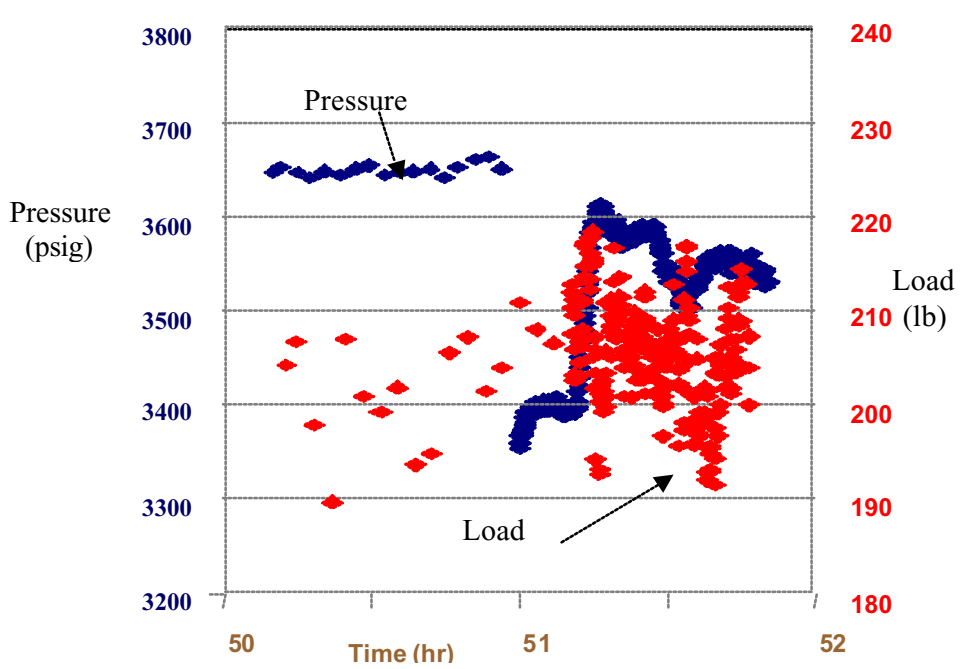

Figure 25. Response of load to a change in pressure at supercritical water condition $\left(25.5 \mathrm{MPa}, 5^{\circ} 0^{\circ} \mathrm{C}\right)$. 
and displacement. Figure 26 plots the response of load and displacement to a pressure change at room temperature. To be able to read the response of load during the test, the initial load was set as $240 \mathrm{lb}$. First the pressure was increased from 0 to 2000 psig in 2 steps of 1000 psig each. Then the pressure was dropped to zero in the same step-wise manner. Each pressure change implies a response of load and displacement. An increase of pressure causes a decrease in load, and vice-versa. This behavior is somewhat puzzling since with a pressure balance system, the load should be insensitive to changes in pressure as in the supercritical condition shown in Figure 25.

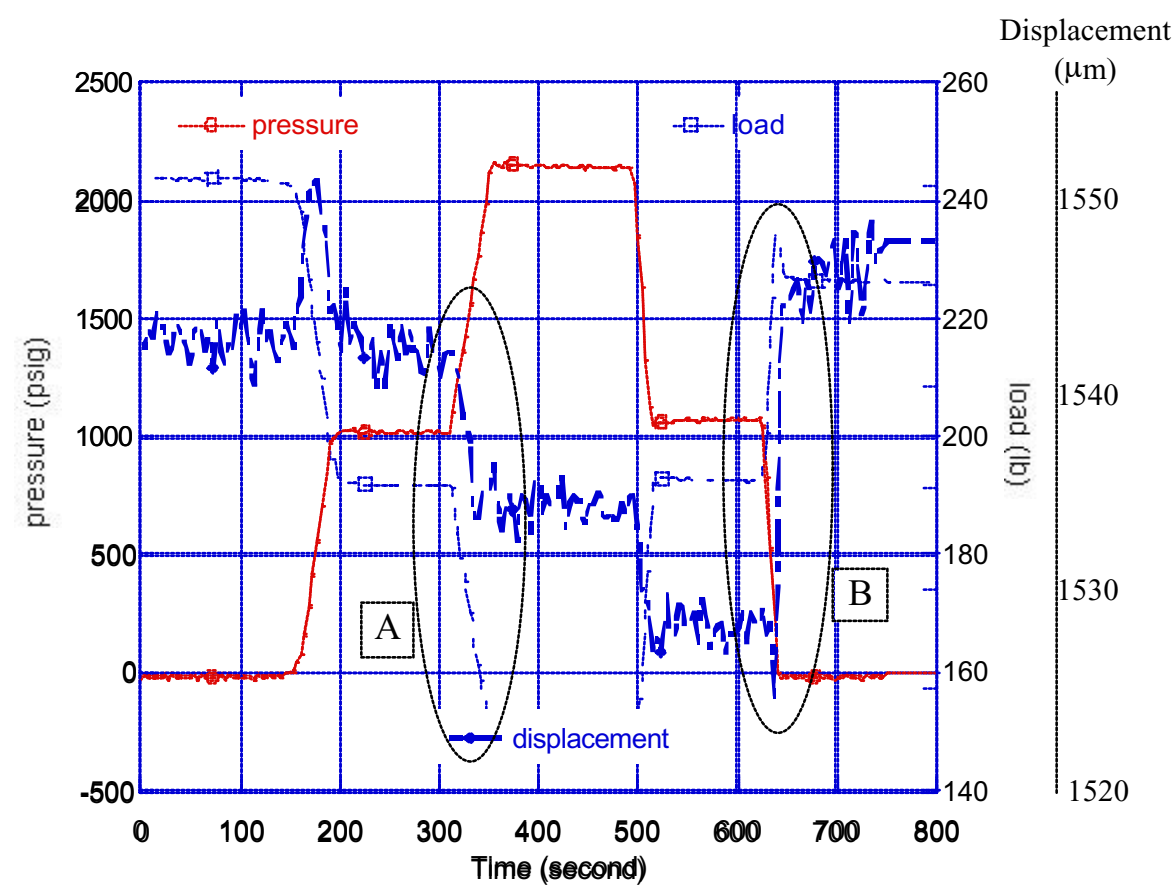

Figure 26. Response of load and displacement to a change in pressure at room temperature. Each change of pressure causes an opposite reaction to the load.

The response of displacement is also not well understood. Some unanticipated behavior, such as a drop in displacement related to a drop of load (A), or an increase in displacement related to an increase of load (B) was recorded. The effects of these results on the actual behavior on the sample is still not clear, but as the peculiar behavior takes place while the sample was being strained elastically, they are not expected to adversely affect a constant extension rate experiment that is typically taken to several tens of percent plastic strain.

Figure 27 shows the effect of pressure changes on the measured load at room temperature, when pressure is increased from $0 \mathrm{MPa}$ to $25.5 \mathrm{MPa}(3700$ psig). The graph shows that the

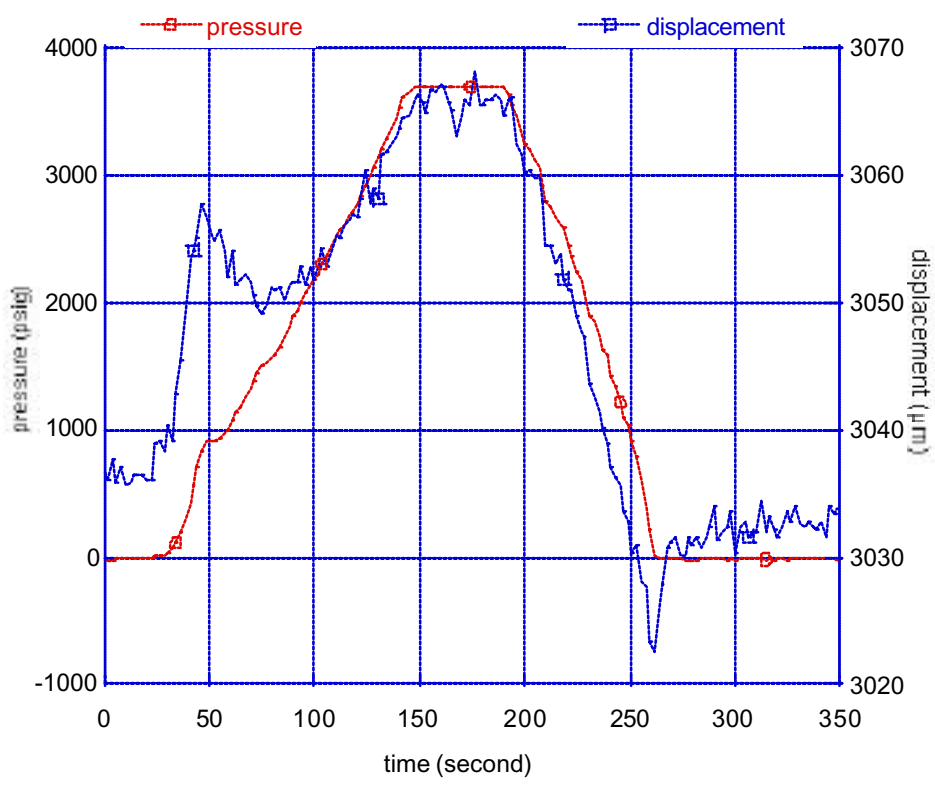

Figure 27. Change in displacement during an increase in pressure at room temperature. 
displacement changes by about $30 \mu \mathrm{m}$. (The pull rod contracts around $30 \mu \mathrm{m}$ when the pressure is increased from 0 to $25.5 \mathrm{MPa}$ ). Such a small displacement should not impact the sample strain, particularly if there is play in the load-train.

\subsubsection{Estimation Of The Load And Lengthening Of The Sample}

The general shape of the load versus time plot recorded during a straining test performed in our facility is plotted in Figure 28. This shape can be divided in 3 regimes. In the first, the load reaches the maximum static friction due to the bal seals on the pull rod. When the load exceeds the static friction force, the rod starts to move (Regime 2). As there is some play in the load-train, the load doesn't increase immediately because the only force on the load cell is due to the dynamic friction of the bal seals on the rod. In the $3^{\text {rd }}$ regime, the entire pull rod line is tight and the sample is strained. So, when a sample is strained, the recorded load includes the contribution of dynamic friction.

To determine the friction force, a sample of 316 steel was strained to just above the yield stress at room temperature in air and in highpressure (25.5 MPa) water, Figure 29. Curve A, taken from the test performed in air, shows that the load reaches $12 \mathrm{lbs}$ before it decreases somewhat and then maintains a steady value for 2000 seconds until the sample begins to strain. This test allowed us to determine that the friction on the pull rod is around 12 lbs at $0 \mathrm{MPa}$. If this factor is taken into account, the yield stress of the sample becomes $225 \mathrm{MPa}$, which is in agreement with the value given by the supplier $(220 \mathrm{MPa})$.

Curve $\mathrm{B}$, taken from the test performed at $25.5 \mathrm{MPa}$, shows that the static friction in the system is 77 $\mathrm{lbs}$ and the dynamic friction is $33 \mathrm{lbs}$. This data allows us to determine the

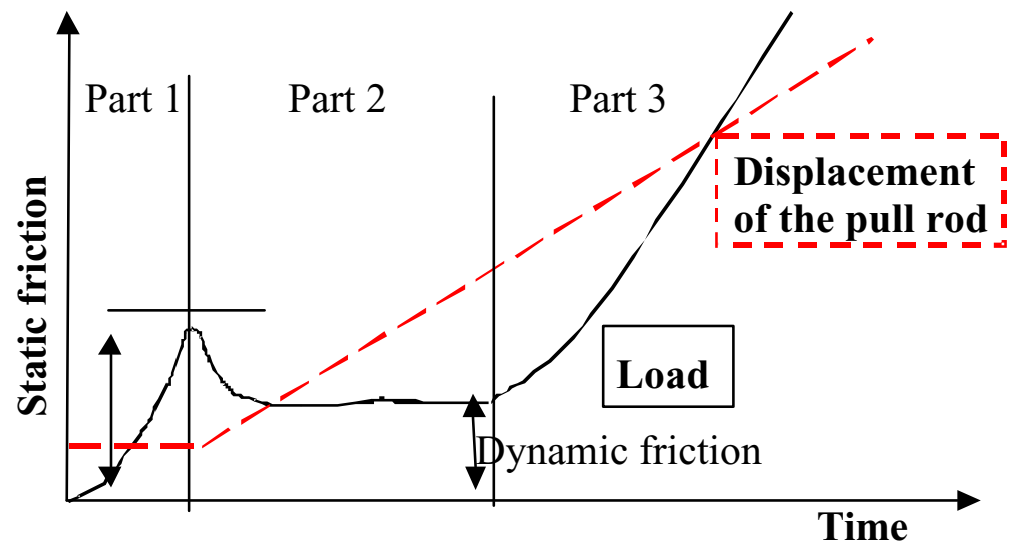

Figure 28. General shape of load versus time and displacement versus time curves. The static stress and the dynamic friction of the bal seals on the pull rod affect the load recorded by the load cell.

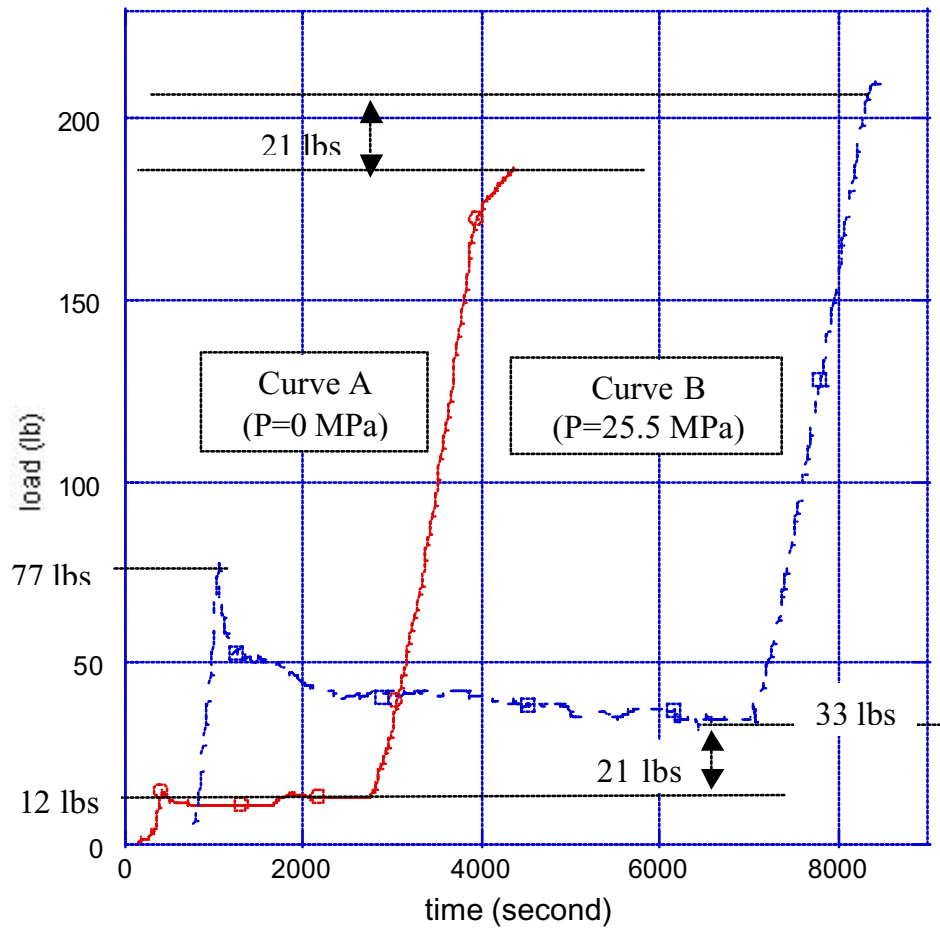

Figure 29. Load versus time curves of a sample strained in air (0 MPa) and then in high-pressure (25.5 MPa) water. The increase in pressure directly affects the load recorded by the load cell through its effect on the dynamic friction. 
true load and lengthening of the sample from the recorded data.

After the test, the sample was removed and the plastic deformation was determined by measuring the length change of the sample. The measured elongation was $90 \pm 25 \mu \mathrm{m}$. The displacement recorded by the LVDT during the test was $110 \mu \mathrm{m}$. This value is within the error range of the sample elongation measured directly on the sample after the test and as such, the two readings are reasonably consistent.

\subsubsection{Future Work}

The objective for this task over the next quarter is threefold: completion of the load-displacement performance characterization of the system, control of the water chemistry for the system, and the development of a safety system that permits the operation of the system overnight.

The remaining work to be done on the mechanical behavior of the system includes the determination of the static and dynamic friction of the bal seals on the pull rod pressure at supercritical water condition $\left(25.5 \mathrm{MPa}, 550{ }^{\circ} \mathrm{C}\right)$. It then will be possible to relate the load recorded by the load cell to the load experienced by the sample.

Regarding the water chemistry control, the main column is currently contaminated and needs to be cleaned. In the outlet line, the minimum conductivity recorded at room temperature is higher than the desired conditions so the loop needs to be cleaned and tests need to be performed that ensure that the outlet conductivity remains low during an experiment.

A safety program is being developed to allow the operation of the system 24 hours per day. This system is located in a laboratory with four other autoclaves and multiple users. Due to the temperatures and pressures used in this loop, a monitoring system needs to be developed that watches the temperature and pressure and alerts the operator when either exceed preset limits. We will accomplish this with a pager system that is linked to the Labview software to maintain contact between the person in charge and the system 24 hours a day. A temperature control system using the computer recording data is also being developed to replace the temperature controllers that are currently being used. 


\section{Task 3 Results: Preliminary Thermal Hydraulic Considerations and Core Design Criteria (Westinghouse Electric Company)}

This section of the quarterly report contains our preliminary design criteria and thermathydraulic analyses for the SCWR. Some preliminary considerations on the system that help define the space of the analysis, and provide some preliminary dimensions for the fuel lattice, are discussed in Section 3.1. Then the design criteria for the system will be defined and the correlations (for heat transfer in supercritical water), and the methods (for hot channel factors) that will be used to verify the proposed design criteria for the fuel system, will be discussed (Section 3.2). Once the criteria, tools, and methods for the thermat hydraulic analysis of the core have been introduced, a preliminary investigation will discuss the different options available and study the temperature and density profiles in the hot and average channels of the system. The nomenclature, subscripts, and acronyms used in this section are defined in Appendix B.

\subsection{Core Thermal Hydraulics: Scope of the Investigation}

The definition of a preliminary core layout (geometric dimensions, core configuration) and thermat hydraulic design (temperature, pressure, flow rates) is required to start the detailed neutronic design of the core for the supercritical reactor. Following the neutronic analyses, the core thermathydraulic design will be reviewed to take into consideration neutronic issues and optimization. The core outlet conditions have been preliminarily selected (MacDonald 2002) based on overall design and performance goals as:

Core Outlet Temperature:

Core Outlet Pressure: $550^{\circ} \mathrm{C} / 1040^{\circ} \mathrm{F}$

$25 \mathrm{MPa} / 3625 \mathrm{psia}$

To be able to compare the SCWR with similar Japanese/European studies, a lower core outlet temperature $\left(510^{\circ} \mathrm{C} / 950^{\circ} \mathrm{F}\right)$ has been considered in this investigation (with the option of increasing it if results of the analysis will allow it). The purpose of these analyses is to verify whether these high performance design data are obtainable, or if any core design concern will require a change in this design point.

For the core geometry, a tentative configuration has been selected based on preliminary studies by INEEL. For a thermal spectrum core, the square lattice with solid moderator "rod" arrangement shown in Figures 30 and 31 has been selected. Given the layout of the moderator box, two different fuel assembly configurations could have been considered: $16 \times 16$ and $19 \times 19$. For this preliminary analyses a 19x19 fuel assembly was selected (19x19 assemblies are currently foreseen for the APWR). Given the very low

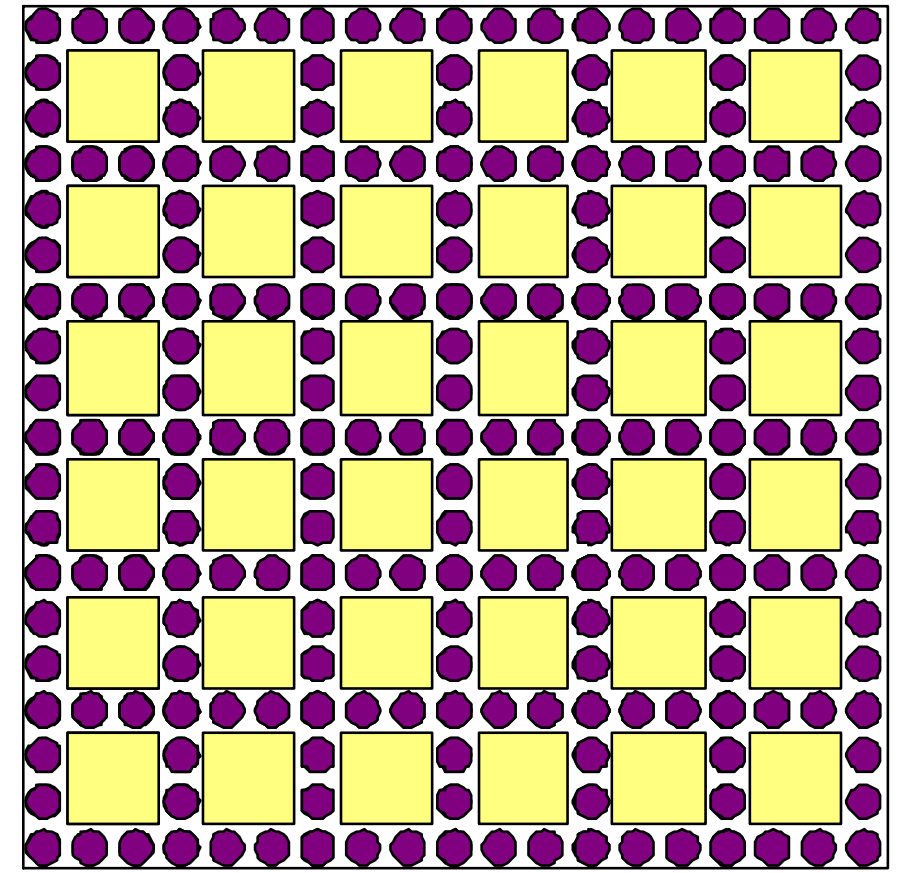

Figure 30. Preliminary Fuel Element Design Assembly (19x19). 
flow rate in the system due to the large enthalpy rise in the core, 14-foot fuel rods (similar to the AP1000 design) have been assumed as they allow for somewhat higher velocities given the same power density.

Fuel rods dimensions typical of PWRs have been assumed, so that the main geometrical innovation between the SCWR and a conventional PWRs is in the reduced pitch to diameter ratio: against a typical PWR value of 1.33 , the pitch to diameter ratio selected for the SCWR is 1.21 to reduce the flow area and allow for an increase in flow

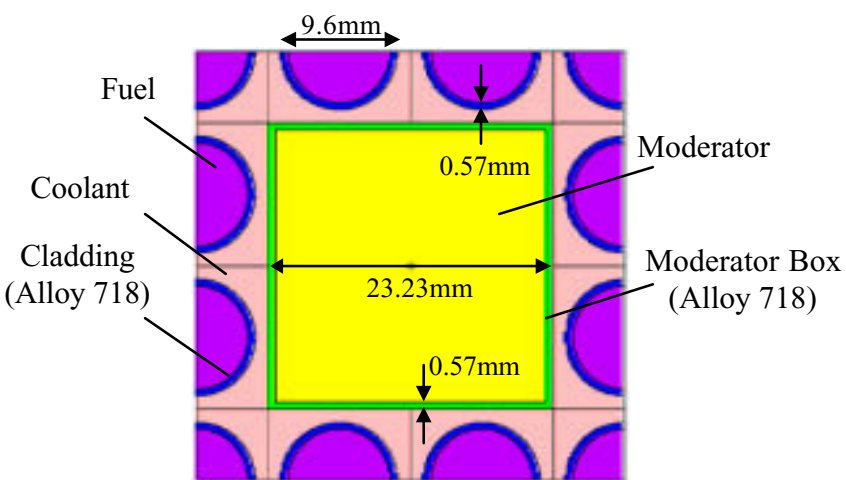

Figure 31. Preliminary Fuel Element Design

Detail.

velocity and a more compact and therefore economical core layout.

The following geometrical dimensions have been estimated for the fuel assembly and element:

Fuel rod outer diameter
Fuel pitch/diameter ratio
Pitch
Moderator box length
Fuel rod length
Fuel assembly pitch
Interassembly pitch
assembly)
Fuel rods per assembly
Flow area (assembly)

$$
\begin{aligned}
& 0.374 \text { in. }(9.50 \mathrm{~mm}) \\
& 1.21^{3} \\
& 0.452 \text { in }(11.48 \mathrm{~mm}) \\
& 0.905 \mathrm{in} .(22.99 \mathrm{~mm}) \\
& 14 \mathrm{ft}(4.27 \mathrm{~m}) \\
& 8.598 \text { in }(0.2184 \mathrm{~m}) \\
& 0.040 \text { in (open lattice) - } 0.40 \text { in (canned } \\
& 217 \text { (out of } 361 \text { positions) } \\
& 20.6 \text { sq-in }\left(0.0133 \mathrm{~m}^{2}\right)
\end{aligned}
$$

Some other parameters have been estimated on the basis of conventional experience:

$\begin{array}{ll}\text { Core inlet pressure drop coefficient } & 14^{4} \\ \text { Core outlet pressure drop coefficient } & 14^{4} \\ \text { Power profiles } & \text { See section } 2.3 \\ \text { Fraction of power generated in the fuel } & 97.4 \%\end{array}$

It may be worth stressing that for the scope of this analysis the choice of a square versus hexagonal lattice is not important: what matters is the channel flow area for different configurations, or even better the moderator to fuel ratio in the core.

Based on the three plant configurations: Direct Cycle, Integral Indirect Cycle, Loop Indirect Cycle, selected for further investigation (MacDonald et al. 2002), three different sets of inlet conditions have been considered for the core inlet temperature:

\footnotetext{
${ }^{3}$ The P/D ratio has been calculated based to have a sufficient distance between rods for the fabrication of grid spacers, according to INEEL indication.

${ }^{4}$ For the purpose of the present investigation and lacking a fuel assembly design, pressure losses have been concentrated at the core inlet (support plate, nozzles, lower grids) and core outlet (upper support plate, upper nozzle, upper grids, IFMs) and values based on common experience have been selected.
} 
- Core Inlet Temperature of $280^{\circ} \mathrm{C}$. This value represents a typical value for a direct cycle with a reasonable number of preheating stages. It also allows for the severe density change connected to the transition to above critical temperatures $\left(374^{\circ} \mathrm{C}\right)^{5}$ to be relatively far away from the channel inlet (however, the transition will be located in the core lower half even for the average channel). Note that it is not possible to push the pseudo-critical transition into the upper half of the core (as is done for BWRs for the transition from water to steam).

- Core Inlet Temperature $280-350^{\circ} \mathrm{C}$. Adoption of somewhat higher temperatures is possible for a direct cycle (where the in let temperature is not defined by preheating stages). This would allow slightly higher flow rates with all the associated benefits (better heat transfer coefficients, more margin to $\mathrm{DHF}^{6}$ conditions). However, this advantage is anticipated to be small, and there might be concerns of moving the transition region too near to the core inlet. For these reasons the analyses of this option will not be performed in this stage of the study.

- Core Inlet Temperature $450-500^{\circ} \mathrm{C}$. The adoption of a very high temperature in a direct cycle is possible. "Skipping" the pseudo-critical transition will allow achieving higher flow rates and more uniform flow conditions (the density changes will be much smaller). The very low density of the moderator also makes the adoption of a fast core possible and further studies will be devoted to analyze this solution. Even for a thermal core, the more uniform coolant density might help in the core design. The drawbacks of this solution are 1) poorer heat transfer coefficients that will limit the linear power, and 2) the very low density of the fluid in the primary system that will increase the concern for LOCAs events.

\subsection{Core Design Criteria for SCWR}

As discussed in our last quarterly (MacDonald et al. 2002), the Core Design Criteria for the SCWR are significantly different from those of a PWR, and in some aspects will be more similar to the criteria for liquid metal reactors. Design requirements are defined for PWRs on the basis of the ANSI N18.2 (ANSI 1973), and are summarized in Table 2:

Table 2. ANSI Plant Conditions

\begin{tabular}{|c|c|c|}
\hline $\begin{array}{l}\text { ANSI plant } \\
\text { conditions. }\end{array}$ & Description & Effect on the Plant \\
\hline $\begin{array}{l}\text { Condition I : } \\
\text { Normal } \\
\text { Operation }\end{array}$ & $\begin{array}{l}\text { Conditions accommodated with } \\
\text { margins between plant parameters and } \\
\text { values of parameters that would require } \\
\text { automatic/manual protective actions }\end{array}$ & $\begin{array}{l}\text { No fuel damage expected (MDNBR within 95/95 } \\
\text { rule). Limited fuel damage within capability of } \\
\text { plant cleanup system. Plant capable of operation } \\
\text { after limited corrective actions. }\end{array}$ \\
\hline $\begin{array}{l}\text { Condition II: } \\
\text { Incident of } \\
\text { Moderate } \\
\text { Frequency }\end{array}$ & $\begin{array}{l}\text { Conditions of moderate frequency that } \\
\text { can be accommodated, at worst, with } \\
\text { reactor shutdown. }\end{array}$ & Same as condition I \\
\hline $\begin{array}{l}\text { Condition III: } \\
\text { Infrequent } \\
\text { Faults }\end{array}$ & $\begin{array}{l}\text { Conditions of low frequency that will } \\
\text { not, by themselves, generate a } \\
\text { Condition IV fault }\end{array}$ & $\begin{array}{l}\text { Small fraction of fuel rods can be damaged. } \\
\text { Immediate resumption of operation may be } \\
\text { precluded. Release of radioactive materials should } \\
\text { not be sufficient to interrupt or restrict public use } \\
\text { of those areas beyond the exclusion radius }\end{array}$ \\
\hline $\begin{array}{l}\text { Condition IV: } \\
\text { Limiting } \\
\text { Faults }\end{array}$ & $\begin{array}{l}\text { Faults that are not expected to happen } \\
\text { during the life of the plant but are } \\
\text { defined as limiting faults against which } \\
\text { the system must be designed }\end{array}$ & $\begin{array}{l}\text { Must not cause a release of radioactive material } \\
\text { that results in an undue risk to public health. } \\
\text { Resumption of operation may be precluded }\end{array}$ \\
\hline
\end{tabular}

\footnotetext{
${ }^{5}$ This transition closely resembles the liquid-vapor transition of subcritical water and, for simplicity, will be referred to as the 'pseudo-critical transition'.

${ }^{6} \mathrm{DHF}=$ Deterioration Heat Flux
} 
As far as the Condition I (normal operation) events are concerned, the ANSI 18.2 requirements lead to the definition of Core Limits. The Core Limits represent the loci of the thermal power, system pressure, and inlet temperatures at various pressures that satisfy the following criteria:

1. The MDNBR (Minimum Departure from Nucleate Boiling Ratio) is not less than the Safety Analyses Limit DNBR (SAL-DNBR) (e.g. a MDNBR of 1.3 is typically considered with several different design DNB correlations).

2. The hot channel exit quality is not greater than the upper limit of the quality range for the applicable DNB correlation.

3. The vessel outlet temperature is lower than the saturation temperature.

The Core Limits define the area of acceptable core operation and bound the operating limits of the plant parameters. As discussed in our last quarterly (MacDonald et al. 2002), the "Minimum departure from nucleate boiling ratio thus becomes the limiting parameter in core design, but simply because it is the best index of fuel cladding damage/failure". Naturally, the SCWR presents a significant difference from PWRs (i.e. no DNB can occur) and thus the core limits defined in the previous list lose significance and a new definition of the core design criteria are needed.

To define proper design criteria for the SCWR, the NRC Standard Review Plan (USNRC 2002), Section 4.2 "Fuel System Design" has been considered. According to the NRC Standard Review Plan:

The objectives of the fuel system safety review are to provide assurance that (a) the fuel system is not damaged as a result of normal operation and anticipated operational occurrences, (b) fuel system damage is never so severe as to prevent control rod insertion when it is required, (c) the number of fuel rod failures is not underestimated for postulated accidents, and (d) coolability is always maintained. "Not damaged," as used in the above statement, means that fuel rods do not fail, that fuel system dimensions remain within operational tolerances, and that functional capabilities are not reduced below those assumed in the safety analysis. This objective implements General Design Criterion 10, and the design limits that accomplish this are called Specified Acceptable Fuel Design Limits (SAFDLs)[...]. [...] Fuel rod failure is defined as the loss of fuel rod hermeticity $[\ldots]^{7}$

The fuel system design bases for Fuel Damage, Fuel Rod Failure, and Fuel Coolability (that according to the previous paragraph are the main requirement for different plant conditions) are given in Tables 3, 4, and 5 and have been directly taken from the NRC Standard Review Plan.

As discussed above, the NRC Standard Review Plan requires that no fuel damage occurs during normal operation and anticipated operational occurrences, and indicates that in addition to precluding fuel rod failure, fuel damage criteria should assure that the fuel system dimensions remain within operational tolerances and that functional capabilities are not reduced below those assumed in the safety analysis. Fuel system damage includes, therefore, fuel rod failure, but also imposes additional requirements summarized in the NRC Standard Review Plan, Section 4.2-II-A-1 and summarized in Table 3.

As far as fuel rod failures are concerned, according to the NRC Standard Review Plan (section 4.2-IIA-2):

${ }^{7}$ Bold added to highlight relevant parts. 
Fuel rod failures can be caused by overheating, pellet/cladding interaction (pci), hydriding, cladding collapse, bursting, mechanical fracturing, and fretting. Where applicable, the fuel rod failure criteria should consider high burnup effects based on irradiated material properties data.

Fuel rod failure criteria are required to address the potential failure mechanisms listed in Table 4 to be considered complete according to the NRC Standard Review Plan. In particular, regarding the overheating of cladding, the NRC Standard Review Plan states:

[...] Although a thermal margin criterion is sufficient to demonstrate the avoidance of overheating from a deficient cooling mechanism, it is not a necessary condition (i.e., DNB is not a failure mechanism) and other mechanistic methods may be acceptable. There is at present little experience with other approaches, but new positions recommending different criteria should address cladding temperature, pressure, time duration, oxidation, and embrittlement. $[\ldots]$

Table 3. Design basis acceptance criteria for fuel system damage.

\begin{tabular}{|c|c|}
\hline \multicolumn{2}{|r|}{ Fuel Rod Damage ${ }^{8}$ - Design Basis } \\
\hline Paragraph & Acceptance Criteria Description (from SRP section 4.2-II-A-1) \\
\hline (a) & $\begin{array}{l}\text { Stress, strain, or loading limits for spacer grids, guide tubes, thimbles, fuel rods, control } \\
\text { rods, channel boxes, and other fuel system structural members should be provided. Stress } \\
\text { limits that are obtained by methods similar to those given in Section III of the ASME Code } \\
\text { are acceptable. Other proposed limits must be justified. }\end{array}$ \\
\hline (b) & $\begin{array}{l}\text { The cumulative number of strain fatigue cycles on the structural members mentioned in (a) } \\
\text { above should be significantly less than the design fatigue lifetime, which is based on } \\
\text { appropriate data and includes a safety factor of } 2 \text { on stress amplitude or a safety factor of } 20 \\
\text { on the number of cycles. Other proposed limits must be justified. }\end{array}$ \\
\hline (c) & $\begin{array}{l}\text { Fretting wear at contact points on the structural members mentioned in paragraph (a) above } \\
\text { should be limited. The allowable fretting wear should be stated in the Safety Analysis } \\
\text { Report and the stress and fatigue limits in paragraphs (a) and (b) above should presume the } \\
\text { existence of this wear. }\end{array}$ \\
\hline (d) & $\begin{array}{l}\text { Oxidation, hydriding, and the buildup of corrosion products (crud) should be limited. } \\
\text { Allowable oxidation, hydriding, and crud levels should be discussed in the Safety Analysis } \\
\text { Report and shown to be acceptable. These levels should be presumed to exist in paragraphs } \\
\text { (a) and (b) above. }\end{array}$ \\
\hline (e) & $\begin{array}{l}\text { Dimensional changes such as rod bowing or irradiation growth of fuel rods, control rods, } \\
\text { and guide tubes need not be limited to set values (i.e., damage limits), but they must be } \\
\text { included in the design analysis to establish operational tolerances. }\end{array}$ \\
\hline (f) & $\begin{array}{l}\text { Fuel and burnable poison rod internal gas pressures should remain below the nominal } \\
\text { system pressure during normal operation unless otherwise justified. }\end{array}$ \\
\hline (g) & $\begin{array}{l}\text { Worst-case hydraulic loads for normal operation should not exceed the holddown } \\
\text { capability of the fuel assembly (either gravity or holddown springs). }\end{array}$ \\
\hline (h) & $\begin{array}{l}\text { Control rod reactivity must be maintained. This may require the control Rods to remain } \\
\text { watertight if water-soluble or leachable materials }\left(\text { e.g., } \mathrm{B}_{4} \mathrm{C} \text { ) are used. }\right.\end{array}$ \\
\hline
\end{tabular}

\footnotetext{
${ }^{8}$ The No-Fuel Damage criterion requires also that the no fuel rod failures requirements in Table 4 are satisfied.
} 
Table 4. Design basis acceptance criteria for fuel rod failure.

\begin{tabular}{|c|c|}
\hline \multicolumn{2}{|r|}{ Fuel Rod Failure - Design Basis ${ }^{9}$} \\
\hline Paragraph & Acceptance Criteria Description (from SRP section 4.2-II-A-2) \\
\hline (a) & $\begin{array}{l}\text { Internal Hydriding: Hydriding as a cause of failure (i.e., primary hydriding) is prevented by } \\
\text { keeping the level of moisture and other hydrogenous impurities within the fuel very low } \\
\text { during fabrication. Acceptable moisture levels for Zircaloy-clad uranium oxide fuel should } \\
\text { be no greater than } 20 \mu \mathrm{g} / \mathrm{g}(20 \mathrm{ppm}) \text {. Current ASTM specifications for } \mathrm{UO}_{2} \text { fuel pellets state } \\
\text { an equivalent limit of } 2 \mu \mathrm{g} / \mathrm{g}(2 \mathrm{ppm}) \text { of hydrogen from all sources. For other materials clad } \\
\text { in Zircaloy tubing, an equivalent quantity of moisture or hydrogen can be tolerated. A } \\
\text { moisture level of } 2 \mathrm{mg} \mathrm{H}_{2} \mathrm{O} \text { per cm of hot void volume within the Zircaloy cladding has been } \\
\text { shown to be insufficient for primary hydride formation. }\end{array}$ \\
\hline (b) & $\begin{array}{l}\text { Cladding Collapse: If axial gaps in the fuel pellet column occur due to densification, the } \\
\text { cladding has the potential of collapsing into a gap (i.e., flattening). Because of the large local } \\
\text { strains that accompany this process, collapsed (flattened) cladding is assumed to fail. }\end{array}$ \\
\hline (c) & $\begin{array}{l}\text { Fretting: Fretting is a potential cause of fuel failure, but it is a gradual process that would } \\
\text { not be effective during the brief duration of an abnormal anticipated operational occurrence } \\
\text { or a postulated accident. Therefore, the fretting wear requirement in paragraph (c) of } \\
\text { subsection II.A.1, Fuel Damage, is sufficient to preclude fuel failures caused by fretting } \\
\text { during these transients. }\end{array}$ \\
\hline (d) & $\begin{array}{l}\text { Overheating of Cladding: It has been traditional practice to assume that failures will not } \\
\text { occur if the thermal margin criteria (DNBR for PWRs and CPR for BWRs) are satisfied. For } \\
\text { normal operation and anticipated operational occurrences, violation of the thermal margin } \\
\text { criteria is not permitted. For postulated accidents, the total number of fuel rods that exceed } \\
\text { the criteria has been assumed to fail for radiological dose calculation purposes. }\end{array}$ \\
\hline (e) & $\begin{array}{l}\text { Overheating of Fuel Pellets: It has also been traditional practice to assume that failure will } \\
\text { occur if centerline melting takes place. This analysis should be performed for the maximum } \\
\text { linear heat generation rate anywhere in the core, including all hot spots and hot channel } \\
\text { factors, and should account for the effects of burnup and composition on the melting point. } \\
\text { For normal operation and anticipated operational occurrences, centerline melting is not } \\
\text { permitted. The assumption that centerline melting results in fuel failure is conservative. }\end{array}$ \\
\hline$(\mathrm{f})$ & $\begin{array}{l}\text { Excessive Fuel Enthalpy: For a severe reactivity initiated accident (RIA) in a BWR at zero } \\
\text { or low power, fuel failure is assumed to occur if the radially averaged fuel rod enthalpy is } \\
\text { greater than } 711 \mathrm{~J} / \mathrm{g}(170 \mathrm{cal} / \mathrm{g} \text { ) at any axial location. For full-power RIAs in a BWR and all } \\
\text { RIAs in a PWR, the thermal margin criteria (DNBR and CPR) are used as fuel failure criteria } \\
\text { to meet the guidelines of Regulatory Guide } 1.77 \text { (Ref. } 6) \text { as it relates to fuel rod failure. The } \\
711 \mathrm{~J} / \mathrm{g}(170 \mathrm{cal} / \mathrm{g} \text { ) enthalpy criterion is primarily intended to address cladding overheating } \\
\text { effects, but it also indirectly addresses pellet/cladding interactions (PCI). Other criteria may } \\
\text { be more appropriate for an RIA, but continued approval of this enthalpy criterion and the } \\
\text { thermal margin criteria may be given until generic studies yield improvements. }\end{array}$ \\
\hline
\end{tabular}

\footnotetext{
${ }^{9}$ Paragraphs (a) to (c) address failure mechanism that are typically more limiting during normal operation; paragraphs (d) to (h) address failure mechanism that are typically more limiting during anticipated operational occurrences and postulated accidents and are typically addressed in the Safety Analysis part (chapter 15) of the Safety Analysis Report.
} 


\begin{tabular}{|c|c|}
\hline \multicolumn{2}{|r|}{ Fuel Rod Failure - Design Basis ${ }^{9}$} \\
\hline Paragraph & Acceptance Criteria Description (from SRP section 4.2-II-A-2) \\
\hline$(\mathrm{g})$ & $\begin{array}{l}\text { Pellet/Cladding Interaction (PCI): There is no current criterion for fuel failure resulting } \\
\text { from PCI, and the design basis can only be stated generally. Two related criteria should be } \\
\text { applied, but they are not sufficient to preclude PCI failures. } \\
\text { 1. The uniform strain of the cladding should not exceed 1\%. In this context, uniform } \\
\text { strain (elastic and inelastic) is defined as transient-induced deformation with gage } \\
\text { lengths corresponding to cladding dimensions; steady-state creepdown and } \\
\text { irradiation growth are excluded. Although observing this strain limit may preclude } \\
\text { some PCI failures, it will not preclude the corrosion-assisted failures that occur at } \\
\text { low strains, nor will it preclude highly localized overstrain failures. } \\
\text { 2. Fuel melting should be avoided. The large volume increase associated with melting } \\
\text { may cause a pellet with a molten center to exert a stress on the cladding. Such a PCI } \\
\text { is avoided by avoiding fuel melting. Note that this same criterion was invoked in } \\
\text { paragraph (e) to ensure that overheating of the cladding would not occur. }\end{array}$ \\
\hline (h) & $\begin{array}{l}\text { Bursting: To meet the requirements of } 10 \text { CFR } 50.46 \text { as it relates to ECCS performance } \\
\text { evaluation, a calculation of the swelling and rupture of the cladding resulting from the } \\
\text { temperature distribution in the cladding and from pressure differences between the inside and } \\
\text { outside of the cladding should be included in the ECCS evaluation model. Regulatory Guide } \\
1.157 \text { provides guidelines for performing a realistic (i.e., best-estimate) model to calculate } \\
\text { the degree of cladding swelling and rupture. Alternatively, Appendix K of } 10 \text { CFR } 50 \\
\text { presents acceptable features of an evaluation model for predicting the degree of swelling and } \\
\text { rupture in the Zircaloy cladding. }\end{array}$ \\
\hline (i) & $\begin{array}{l}\text { Mechanical Fracturing: A mechanical fracture refers to a defect in a fuel rod caused by an } \\
\text { externally applied force such as a hydraulic load or a load derived from core-plate motion. } \\
\text { Cladding integrity may be assumed if the applied stress is less than } 90 \% \text { of the irradiated } \\
\text { yield stress at the appropriate temperature. Other proposed limits must be justified. Results } \\
\text { from the seismic and LOCA analysis may show that failures by this mechanism will not } \\
\text { occur for less severe events. }\end{array}$ \\
\hline
\end{tabular}

In conclusion, the acceptance criteria for the SCWR can be expressed as:

- $\quad$ Fuel Damage (see Tables 3 and 4) will not occur during Condition I and II events. A very small amount of fuel damage may occur, and this will be within the capability of the plant cleanup system and will be consistent with the plant design basis.

- The reactor can be brought to a safe state following a Condition III event with only a small fraction of fuel rods damaged. The fraction of fuel rods damaged must be limited to meet the dose guidelines of 10CFR100 although enough fuel damage might occur to preclude immediate resumption of operation.

- $\quad$ The reactor can be brought to a safe state and the core kept subcritical with acceptable heat transfer geometry (Table 5, coolability) following transients arising from Condition IV events.

These acceptance criteria, coupled with the content of Tables 3, 4, and 5 define a complete fuel system design basis for the SCWR (or for any other LWR). 
Table 5. Design basis acceptance criteria for fuel coolability.

\begin{tabular}{|c|c|}
\hline \multicolumn{2}{|r|}{ Fuel Rod Coolability - Design Basis } \\
\hline Paragraph & Acceptance Criteria Description (from SRP section 4.2-II-A-2) \\
\hline (a) & $\begin{array}{l}\text { Cladding Embrittlement: To meet the requirements of } 10 \text { CFR Part } 50, \S 50.46 \text {, as it relates } \\
\text { to cladding embrittlement for a } \mathbf{L O C A} \text {, acceptance criteria of } 1204^{\circ} \mathbf{C}\left(2200^{\circ} \mathbf{F}\right) \text { on peak } \\
\text { cladding temperature and } 17 \% \text { on maximum cladding oxidation must be met. Similar } \\
\text { temperature and oxidation criteria may be justified for other accidents. }\end{array}$ \\
\hline (b) & $\begin{array}{l}\text { Violent Expulsion of Fuel In severe reactivity initiated accidents, such as rod ejection in a } \\
\text { PWR or rod drop in a BWR, the large and rapid deposition of energy in the fuel can result in } \\
\text { melting, fragmentation, and dispersal of fuel. The mechanical action associated with fuel } \\
\text { dispersal can be sufficient to destroy the cladding and the rod-bundle geometry of the fuel } \\
\text { and to produce pressure pulses in the primary system. To meet the guidelines of Regulatory } \\
\text { Guide } 1.77 \text { as it relates to preventing widespread fragmentation and dispersal of the fuel and } \\
\text { avoiding the generation of pressure pulses in the primary system of a PWR, a radially } \\
\text { averaged enthalpy limit of } 1.17 \mathrm{KJ} / \mathrm{g}(280 \mathrm{cal} / \mathrm{g}) \text { should be observed. This } 1.17 \mathrm{KJ} / \mathrm{g}(280 \\
\text { cal/g) limit should also be used for BWRs. }\end{array}$ \\
\hline (c) & $\begin{array}{l}\text { Generalized Cladding Melting: Generalized (i.e., non-local) melting of the cladding could } \\
\text { result in the loss of rod-bundle fuel geometry. Criteria for cladding embrittlement in } \\
\text { paragraph (a) above are more stringent than melting criteria would be; therefore, additional } \\
\text { specific criteria are not used. }\end{array}$ \\
\hline (d) & $\begin{array}{l}\text { Fuel Rod Ballooning: To meet the requirements of } 10 \text { CFR } 50.46 \text { as it relates to evaluating } \\
\text { ECCS performance during accidents, burst strain and flow blockage caused by ballooning } \\
\text { (swelling) of the cladding must be accounted for in the analysis of the core flow distribution. } \\
\text { Regulatory Guide } 1.157 \text { describes models, correlations, data, and methods that are acceptable } \\
\text { for meeting the requirements for a realistic calculation of ECCS performance during a } \\
\text { LOCA. Alternatively, Appendix K to } 10 \mathrm{CFR} 50 \text { presents acceptable features of a } \\
\text { conservative evaluation model to consider burst strain and flow blockage. }\end{array}$ \\
\hline (e) & $\begin{array}{l}\text { Structural Deformation: Earthquakes and postulated pipe breaks in the reactor coolant } \\
\text { would result in external forces on the fuel assembly. Analytical procedures are discussed in } \\
\text { Appendix A to the NRC Standard Review Plan and are applied to verify compliance to two } \\
\text { principal criteria for a LOFA: (a) fuel rod fragmentation must not occur as a direct } \\
\text { consequence of blowdown loads, and (b) the 10CFR50.46 temperature and oxidation limits } \\
\text { must not be exceeded. Also, control rod insertability must be satisfied. For PWRs, if the } \\
\text { combined loads on the assembly remain below a P(crit) value defined as the allowable } \\
\text { crushing load in Appendix A.c to Section } 4.2 \text { of the Standard Review Plan, then significant } \\
\text { deformation would not occur and no additional analysis would be required to meet this } \\
\text { criterion. If P(crit) is exceeded, then additional analysis will be required to demonstrate that } \\
\text { deformation is not severe enough to prevent control rod insertion and fuel coolability. }\end{array}$ \\
\hline
\end{tabular}

Not all the different issues in Tables 3, 4, and 5 have to be addressed for our preliminary investigation, and a limited set of design requirements (addressing in particular paragraph (d) in Table 3 and paragraphs (d) and (e) in Table 4) can be defined. The cladding temperature will have to be limited to prevent cladding overheating (par (d), Table 4) and excessive corrosion (par (d), Table 3). Considering the cladding temperature as an alternative approach to DNB to evaluate cladding overheating allows defining the core limits for the SCWR presented in our last quarterly. The proposed SCWR core design criteria are: 
\{Criterion 1\}. The MNCTD (Minimum Nominal Cladding Temperature Difference) ${ }^{10}$ is not less than the Design Limit MNCTD (DL-MNCTD) (a DL-MNCTD will have to be defined statically based on the heat transfer correlation uncertainties).

\{Criterion 2\}. The hot channel exit enthalpy is not greater than the upper limit of the enthalpy range for the applicable Heat Transfer correlation.

\{Criterion 3\}. The vessel outlet temperature is lower than the vessel design temperature.

Criteria 1-3 will be used to define the Core Limits for the SCWR, as the loci of pressure, core inlet temperature, and power that satisfy these three criteria. Core Limits will be generated by calculating for each power level, from $20 \%$ to $118 \%$ (118\% is the typical overpower limit for PWRs), and for each system pressure, from the low pressure and high pressure trip setpoints, the maximum core inlet temperature that satisfies the criteria. This definition constitutes the core of the Reactor Protection System (that will be studied/designed in future activities).

Linear power will be limited on the basis of fuel melting considerations (par (e), Table 4). According to the NRC Standard Review Plan:

It has also been traditional practice to assume that failure will occur if centerline melting takes place. This analysis should be performed for the maximum linear heat generation rate anywhere in the core, including all hot spots and hot channel factors, and should account for the effects of burnup and composition on the melting point. For normal operation and anticipated operational occurrences, centerline melting is not permitted. [...] The assumption that centerline melting results in fuel failure is conservative.

Therefore, a fourth design criterion can be added as:

\{Criterion 4\}. Maximum Fuel Centerline Temperature in normal operation and anticipated transients: the fuel centerline temperature shall be below the melting point at $118 \%$ of nominal power (overpower limit) for all Condition I and II events. The melting temperature should consider high burnup effects based on irradiated material property data. This criterion imposes a limit on the maximum allowable linear power, which depends on the coolant temperature, power profiles and rod diameter.

Given the analogies between aspects of the heat transfer in the SCWR and liquid metal reactors, interesting insights may be obtained from considering the safety analyses of Liquid Metal Fast Breeder Reactors (LMFBRs). For both applications a severe heat transfer deterioration phenomenon like DNB (or CHF for BWRs) does not exist, and a cladding temperature limit is used instead. The LMFBR design requirements are established on the basis of the ASME Code Section III, Article NB-3112-3 (ASME 1974a and 1974b) and RDT standards (USERDA 1974a and 1976). As discussed in Tang et al. (1978), RDT Standard C-16-1T (USERDA 1974b) defines allowable severity levels with respect to structural consequences for fuel components according to their likelihood of occurrence. Table 6 (from Table 3-I in Tang et al. 1978) summarizes the design requirements and definition for LMFBR reactors. In addition to these requirements, the General Design Criteria (USNRC) must also be satisfied. Table 7 (from Graham et al. 1974) presents typical acceptance criteria for the different event categories for LMFBR fuel. The analogies with Table 2 and with the NRC Standard Review Plan acceptance criteria discussed in Tables 3, 4, and 5 are evident: what is interesting is that the acceptance criteria for LMFBR are expressed in a form more suitable to application to the SCWR, compared to PWRs or BWRs.

\footnotetext{
${ }^{10}$ MNCTD is defined as the minimum value of the difference of the maximum allowable temperature and the cladding temperature as calculated in the analysis. The Maximum Allowable Temperature will be discussed in the following section.
} 
The next section will discuss the definition of the two parameters that are needed to define the criteria here introduced: the Maximum Allowable Cladding Temperature (used in Criterion 1) and the Fuel Melting Temperature (used in Criterion 4). Then, the focus will shift from the definition of core acceptance criteria to the verification of the required criteria. In particular heat transfer correlations and models for supercritical water will be discussed and analyzed to verify the availability of the necessary correlations and data for at least preliminary evaluations of the SCWR core based on the just defined criteria.

Table 6. Design requirements and definitions for LMFBR components (q.v. Table 3-I in Tang et al. 1978).

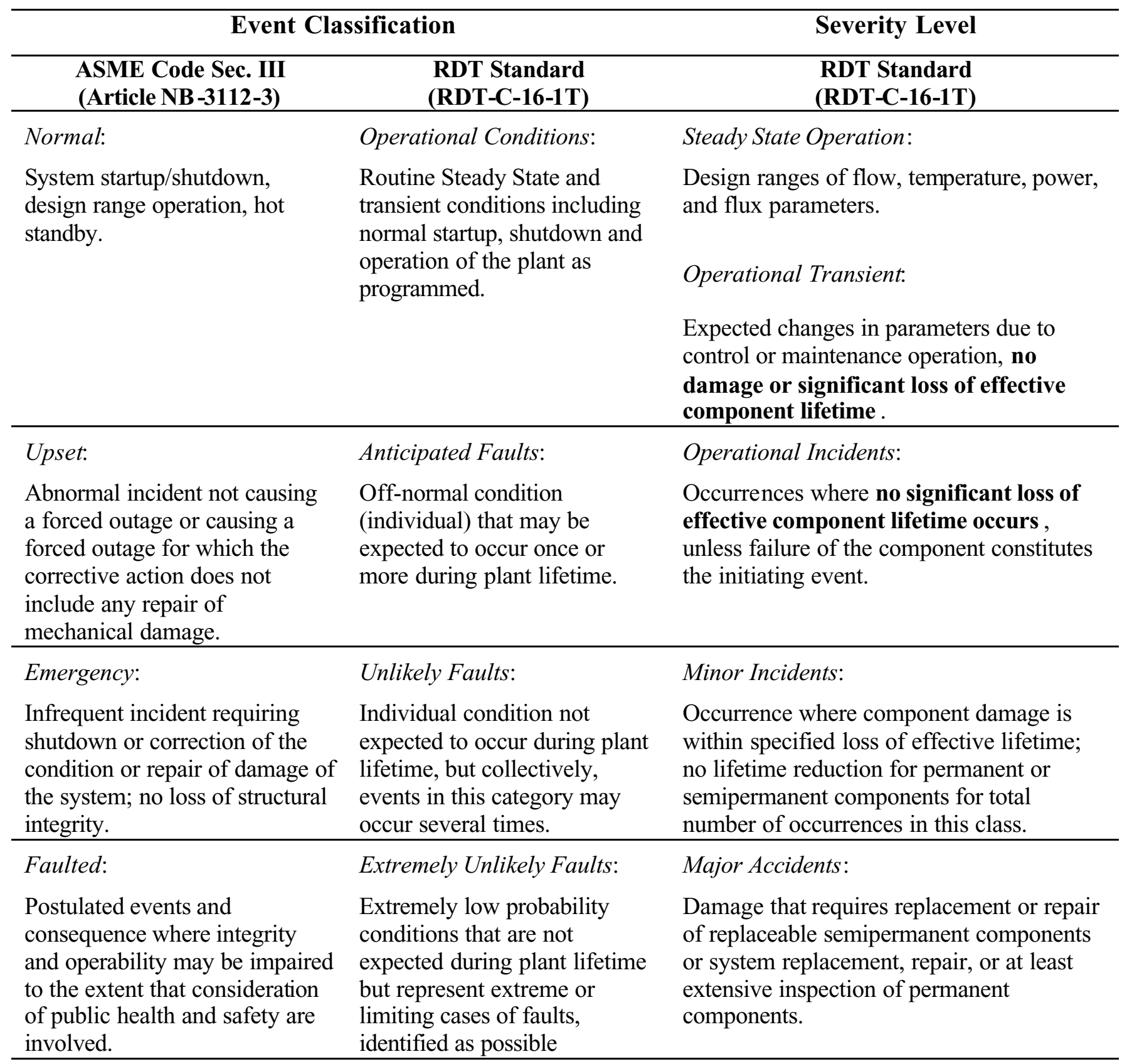


Table 7. Classification of accidents and acceptance criteria (from Graham et al. 1974).

\begin{tabular}{|c|c|c|c|c|}
\hline Level & $\begin{array}{c}\text { Event or } \\
\text { Accident Class }\end{array}$ & Definition & $\begin{array}{c}\text { Probability } \\
\text { (per Reactor Year) }\end{array}$ & $\begin{array}{c}\text { Upper Limit } \\
\text { Acceptance Criteria }\end{array}$ \\
\hline 1 & $\begin{array}{l}\text { Normal } \\
\text { Operation }\end{array}$ & $\begin{array}{l}\text { Event that will normally } \\
\text { occur: } \\
\text { - } \quad \text { Full power operation } \\
\text { - } \quad \text { Startup/shutdown } \\
\text { - } \quad \text { Random fuel pin failure }\end{array}$ & 1 & $\begin{array}{l}\text { Accumulated cladding } \\
\text { strain }<0.1 \% \\
\text { (no significant loss of } \\
\text { effective lifetime) }\end{array}$ \\
\hline \multirow[t]{2}{*}{2} & $\begin{array}{l}\text { Anticipated } \\
\text { Transients } \\
\text { (Upset) }\end{array}$ & $\begin{array}{l}\text { Events that, based on } \\
\text { experience, are expected to } \\
\text { occur at least once during } \\
\text { the plant lifetime. }\end{array}$ & 1 to $3 \times 10^{-2}$ & $\begin{array}{l}\text { Accumulated cladding } \\
\text { strain }<0.3 \%\end{array}$ \\
\hline & $\begin{array}{l}\text { Unlikely Events } \\
\text { (Emergency) }\end{array}$ & $\begin{array}{l}\text { Events that are not expected } \\
\text { to occur individually, but } \\
\text { that might, based on the } \\
\text { number of such possibilities, } \\
\text { occur once during the } \\
\text { lifetime of the plant. }\end{array}$ & $3 \times 10^{-2}$ to $\sim 10^{-4}$ & $\begin{array}{l}\text { Accumulated cladding } \\
\text { strain }<0.7 \% \\
\text { (Integrity limit, above } \\
\text { this limit fuel cladding } \\
\text { can fail) }\end{array}$ \\
\hline \multirow[t]{2}{*}{3} & $\begin{array}{l}\text { Extremely } \\
\text { Unlikely Events } \\
\text { (Faulted }\end{array}$ & $\begin{array}{l}\text { Events never expected to } \\
\text { occur. }\end{array}$ & $\sim 10^{-4}$ to $\sim 10^{-7}$ & $\begin{array}{l}\text { No loss of in-place } \\
\text { coolable geometry. } \\
\text { Interpreted for LMFBR } \\
\text { as: }\end{array}$ \\
\hline & $\begin{array}{l}\text { Hypothetical } \\
\text { Events }\end{array}$ & $\begin{array}{l}\text { Design margins to provide } \\
\text { for unforeseen events. }\end{array}$ & & $\begin{array}{l}\text { - } \quad \text { No clad melting and } \\
\text { relocation } \\
\text { - } \quad \text { No sodium boiling }\end{array}$ \\
\hline
\end{tabular}

\subsubsection{Temperature Limits For The Cladding And Fuel}

As discussed in the previous section, to properly complete the definition of the core design criteria, a melting inception temperature for the fuel must be defined. The melting temperature of unirradiated uranium dioxide is approximately $5080^{\circ} \mathrm{F}$ (Beaumont et al. 1978), but the melting temperature decreases by about $58^{\circ} \mathrm{F}$ per 10,000 -megawatt days per metric ton of uranium burnup. A typical limit for the peak fuel centerline temperature in $65,000 \mathrm{MWd} /$ ton fuel for prevention of centerline melt is $4700^{\circ} \mathrm{F}$. Therefore, to satisfy Criterion 4 from the previous section, fuel melting must be prevented by demonstrating that the peak fuel temperature, calculated at the hot spot and for overpower conditions ( $118 \%$ nominal power), is lower than $4700^{\circ} \mathrm{F}$ during all Condition I and II occurrences.

Also, cladding temperature limits have to be defined. According to our preliminary material considerations and based on the criteria defined in Table 7, the following limits have been defined: 
- Considering Tables 6 and 7, an additional limit (beyond the no fuel damage and no fuel rod failure requirements) can be added: no loss of effective lifetime is expected for Condition I events. This is equivalent to requiring that the Cladding Temperature will be compatible with the desired core lifetime. Thus the maximum allowable cladding temperature for Condition I events (MAT-I) must satisfy three distinct requirements: no fuel damage, no fuel rod failure and no loss of effective lifetime. It is anticipated that corrosion concerns will define the MAT-I. Although the cladding material selection process is still under development, a preliminary estimate of the value for MAT-I is $620^{\circ} \mathrm{C}$.

- The requirement for Condition II Events is the same as the requirement for Condition I events (see Table 6, anticipated transients, except that the requirement on the effect on lifetime can be mitigated, since it is anticipated that the reactor will operate in these conditions only for limited period of times. The requirement will still be "no significant loss of lifetime" but naturally corrosion concerns will not be an issue (limited extension in time). Based on preliminary calculations at the INEEL, MAT-II has been defined as $800^{\circ} \mathrm{C}$.

\subsubsection{Calculation of the Cladding Temperature: a Critical Review of Supercritical Water Heat Transfer Correlations}

This section and the following one will focus on how the limits discussed above will be applied to actual SCWR calculations. The first issue that has to be solved is "how to calculate the cladding temperature" and therefore "which heat transfer correlation should be used for SCWR calculations". The selection of an appropriate correlation and a critic al comparison of difference correlations is the objective of this section.

Before entering into a quantitative analysis of the different correlations, some preliminary qualitative considerations should be discussed. No phenomena comparable to departure from nucleate boiling (for PWR and BWR) or dryout (for BWR) exist for SCWRs. However, SCW presents a phenomenon known as Deterioration of Heat Flux or DHF: for high heat fluxes and low fluid velocities a significant deterioration in the heat transfer coefficient has been observed at temperatures near the pseudo-critical temperature (where the heat transfer coefficients are much higher than at higher or lower temperatures). An interesting discussion on DHF and the various correlations for predicting it is presented in Cheng and Schulenberg (2001) and in Cheng et al. (2002). Deterioration of Heat Flux is a phenomena very different than the Heat Flux Crisis which may occur in PWRs and BWRs, not only from the point of view of the physics involved, but, most important, from the point of view of its onset and effects.

DHF is first and foremost a much milder phenomena: the deterioration in heat flux is relatively limited and thus leads to a limited increase in the cladding temperature. Therefore, it is not a good design criteria, because it is not, by itself, an index of cladding damage. Given the very wide range of temperatures in a SCWR reactor (and the fact that DHF may occur only in a limited temperature region around the pseudo-critical temperature) and the very low heat transfer rates at the higher temperatures, it is not possible to say that if DHF is excluded, than no cladding overtemperature will occur. In other words, the mildness of the phenomena makes it unsuitable as the main and only design criterion for cladding temperature.

Moreover, not only is the phenomena mild, but it also has a very smooth onset, so that it is very difficult to define when DHF begins. This is also the reason for the large differences between the different correlations used for predicting DHF, as correctly pointed out in Cheng and Schulenberg (2001). 
Due to these reasons (mild effects and smooth onset), this phenomenon is better considered in the heat transfer correlations, which should either include it in their formulation or define a map of operating conditions under which a post-DHF correlation should be used, rather then through specific DHF onset correlations. This is the reason why no specific DHF based design criterion has been defined. It is here suggested to retain DHF only as an index of potential problems: if the heat-transfer correlations that take into account this phenomenon (e.g. the Bishop and Oka-Koshizuka correlations introduced in the next section) the Minimum DHF Ratio (MDHFR) should only be calculated as a supporting parameter. Even if the MDHFR is not needed as a design criteria, the penalization on heat transfer coefficient in DHF conditions is such (q.v. the results of the two correlations studied in the next section) that it will be wise to operate as far away as possible from DHF conditions, since this will guarantee better performance and core thermathydraulic design margins.

A typical correlation for DHF is the Yamagata (1972) correlation. Cheng and Schulenberg (2001) suggest that it gives reasonably conservative values of the DHF when compared to other available correlations.

$$
D H F=200 \cdot G^{1.2}
$$

where DHF is the deterioration heat flux in $\left[\mathrm{W} / \mathrm{m}^{2}\right]$ and $\mathrm{G}$ is the mass velocity in $\left[\mathrm{kg} /\left(\mathrm{m}^{2} \mathrm{~s}\right)\right]$. Note that if the channel geometry is fixed, it is evident that the mass velocity in the Yamagata correlation is directly proportional to the linear power (or power density, which is equivalent) while the DHF is proportional to the mass velocity to a power greater than 1 . It is therefore evident that for supercritical water, given a fixed geometry, increasing the linear power will actually increase the MDHFR, thus increasing the core margins.

\subsubsection{Heat Transfer Correlations}

Several Different correlations have been developed during the sixties and seventies for heat transfer in supercritical water. Cheng and Schulenberg (2001) include a very thorough summary and comparison of the available correlations. However, two considerations must be noted concerning all these correlations:

1. All the correlations have been developed for heat transfer in geometries with flow inside tubes. Experiments with tube bundles similar to the core of a SCWR have not been conducted. Naturally, no correlation takes into account the effect of mixing vane grids, wire spacers, or other peculiarities of the core geometry.

2. The reliability of the correlations has to be verified.

Therefore, one of the more urgent tasks for development of SCWRs is to develop and validate appropriate heat transfer correlations. It is important to note that if the criteria discussed in Section 3.2 are adopted, the interest will shift from DNB and CHF correlations of the type used in PWRs and BWRs, to cladding temperature. Since the cladding temperature is determined by the heat transfer correlation, it is easy to understand that in the SCWR design the heat transfer correlation will replace the CHF correlations for determining the thermathydraulic margin and the safety of the system. Extensive effort will be needed to develop valid correlations, replacing the expensive but fundamental DNB/CHF tests with similarly expensive heat transfer tests developed for the geometry of interest.

In analogy with a conventional LWR DNB analysis, a criterion similar to the $95 / 95$ rule will have to be defined. The limits for the DNB correlations are defined as the value of the DNB that guarantees, with a $95 \%$ probability at a $95 \%$ confidence, that DNB conditions will not occur. Naturally the definition of 
the correlation limit requires a detailed statistical analysis of the correlation data, and the same procedure will be required for the heat transfer correlations that will be used in the design of the SCWR. (A discussion on the treatment of uncertainties and hot channel factors will be the focus of Section 3.2.3.)

In agreement with Cheng and Schulenberg (2001), the correlation published by Bishop et al. (1964) will be used for the analysis performed in this NERI project:

$$
\begin{aligned}
& N U_{B}=0.0069 \cdot \operatorname{Re}_{B}^{0.90} \cdot \overline{\operatorname{Pr}}_{B}^{0.66} \cdot\left(\frac{\rho_{w}}{\rho_{b}}\right)^{0.43} \cdot\left(1+\frac{2.4 \cdot D h}{L}\right) \\
& \overline{\operatorname{Pr}}_{B}=\left(\overline{C p} \cdot \frac{\mu_{B}}{\lambda_{B}}\right) \\
& \overline{C p}=\frac{h_{w}-h_{b}}{T_{w}-T_{b}}
\end{aligned}
$$

Where the subscript $b$ indicates bulk fluid properties and $w$ indicates wall temperature properties. Also, the recently developed Oka-Koshizuka (not included in the study described by Cheng and Schulenberg) correlation will be considered:

$$
\begin{aligned}
& N u=0.015 \cdot \operatorname{Re}^{0.85} \cdot \operatorname{Pr}^{C} \\
& C=0.69-\frac{81000}{D H F}+f_{c} \cdot q^{\prime \prime} \\
& f_{c}= \begin{cases}2.9 \cdot 10^{-8}+\frac{0.11}{D H F} & 0 \leq h \leq 1500 \mathrm{KJ} / \mathrm{kg} \\
-8.7 \cdot 10^{-8}-\frac{0.65}{D H F} & 1500 \mathrm{KJ} / \mathrm{kg} \leq h \leq 3300 \mathrm{KJ} / \mathrm{kg} \\
-9.7 \cdot 10^{-7}+\frac{1.30}{D H F} & 3300 \mathrm{KJ} / \mathrm{kg} \leq \mathrm{h} \leq 4000 \mathrm{KJ} / \mathrm{kg}\end{cases} \\
& D H F=200 \cdot G^{1.2}\left[\mathrm{~W} / \mathrm{m}^{2}\right] \quad \text { (YamagataCorrelation) } \\
& G=\text { mass velocity }\left[\mathrm{kg} / \mathrm{m}^{2} \mathrm{~s}\right]
\end{aligned}
$$

Figures 32 and 33 show a comparison of the two correlations for the following conditions:

$$
\begin{aligned}
& q^{\prime \prime}=1 M W / \mathrm{m}^{2} \\
& P=25 M P a \\
& G=1000 \mathrm{~kg} / \mathrm{m}^{2} \mathrm{~s}
\end{aligned}
$$

Core Height $=4.2 \mathrm{~m}$

$$
D h=4,6 \mathrm{~mm}
$$

Figure 34 and 35 show a comparison of the two correlations using the same conditions, but with a heat flux of $0.5 \mathrm{MW} / \mathrm{m}^{2}$. The difference between the two cases is that the first case has a MDHFR of 0.8 (i.e. DHF is expected), while the second case has a MDHFR of 1.6 (DHF is not expected). The purpose of this analysis was to verify the behavior of the two selected correlations in DHF and non-DHF conditions so as to verify if and how DHF was taken in consideration by the two correlations. 
The behavior of the two correlations is in acceptable agreement, especially considering the comparison of several other correlations given by Cheng and Schulenberg (2001), but differences up to $40 \%$ in the predicted heat transfer coefficient occur at some temperatures. Comparing Figures 32 and 34, it is evident that the agreement between the correlations does not change significantly between the two cases (with and without DHF) and it therefore appears that both correlations account for the DHF phenomena in a more or less analogous (at least quantitative) way.

The heat transfer coefficients calculated in the critical temperature region by both correlations are different for the cases with and without DHF. This seems to suggest that both correlations are in some way taking the DHF into account. For the Bishop et al. correlation, a heat transfer coefficient (Ht) less than half the value of the non-DHF value is calculated (non-DHF conditions $\mathrm{Ht}=33.6\left[\mathrm{KW} / \mathrm{m}^{2} \mathrm{C}\right]$; DHF conditions $\mathrm{Ht}=15.8\left[\mathrm{KW} / \mathrm{m}^{2} \mathrm{C}\right]$; DHF to nonDHF Ht ratio: 0.47). For the OkaKoshizuka correlation, the heat transfer coefficient calculated in DHF conditions is around 2.5 times lower than the coefficient calculated in the non-DHF case (non-DHF conditions $\mathrm{Ht}=33.3\left[\mathrm{KW} / \mathrm{m}^{2} \mathrm{C}\right]$; DHF conditions $\mathrm{Ht}=13.23\left[\mathrm{KW} / \mathrm{m}^{2} \mathrm{C}\right]$; DHF to nonDHF Ht ratio: 0.40). No effect due to the different DHF conditions is evident outside the critical

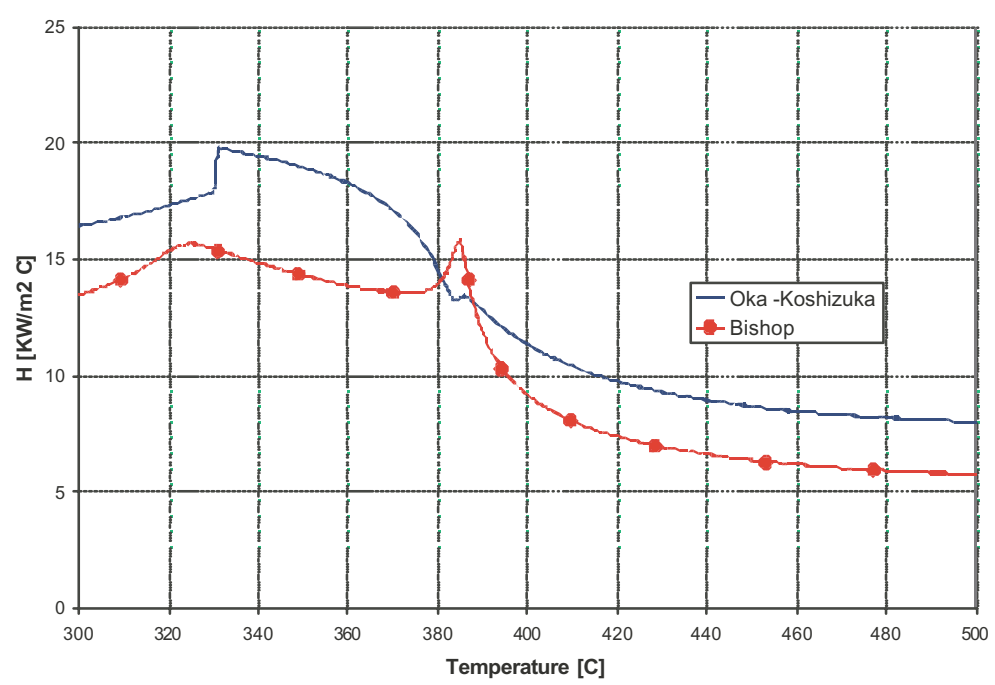

Figure 32. Heat transfer coefficients calculated with the Oka-Koshizuka and with the Bishop et al. correlations versus temperature at a heat flux of $1000 \mathrm{KW} / \mathrm{m}^{2}$ (DHF expected).

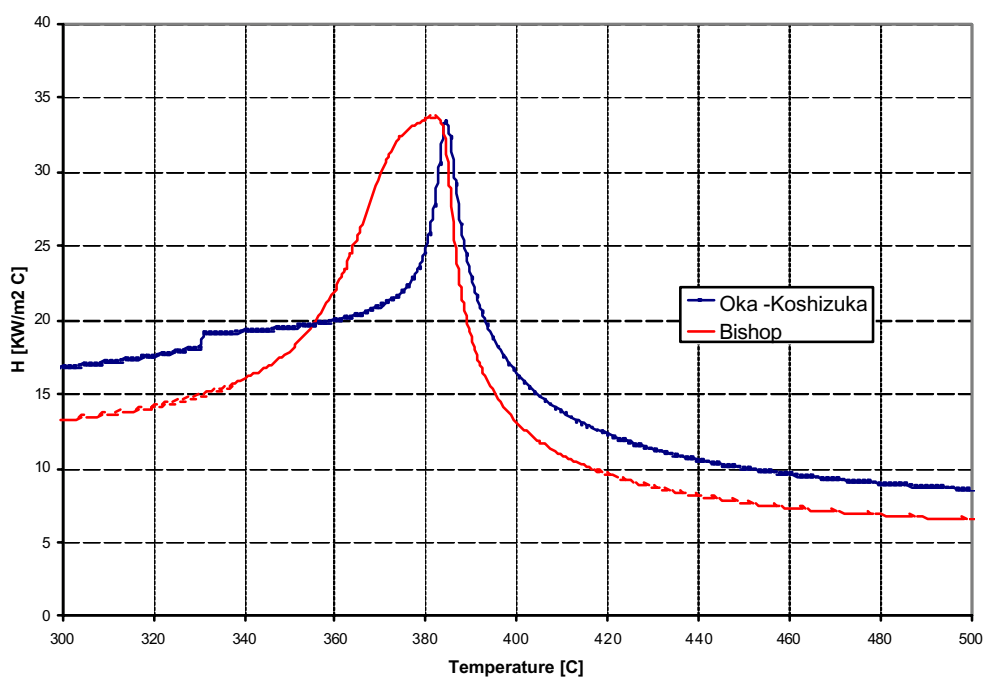

Figure 33. Percentage deviation of the heat transfer coefficients predicted by the Oka-Koshizuka correlation compared to the Bishop et al. correlation versus temperature, at a heat flux of $1000 \mathrm{KW} / \mathrm{m}^{2}$ (DHF expected). temperature region, thus indicating that both correlations are appropr iately considering the effect of DHF (that is a phenomenon only present for temperatures near to the critical temperature).

From a qualitative point of view, it is interesting to note how the Oka-Koshizuka correlation calculates completely different heat transfer coefficients in the region around the critical temperature in the two cases: a peak in heat transfer coefficient in this region is present only in the non-DHF case (Figure 34). No such peak is shown (Figure 32) in the DHF case and instead a deteriorated (i.e. lower than in the neighboring regions) heat flux is calculated in this region. 
The Bishop et al. correlation does not predict a drop in the heat transfer coefficient near the pseudocritical temperature, but the quantitative difference between the case with and without DHF is analogous to that calculated with the Oka-Koshizuka correlation.

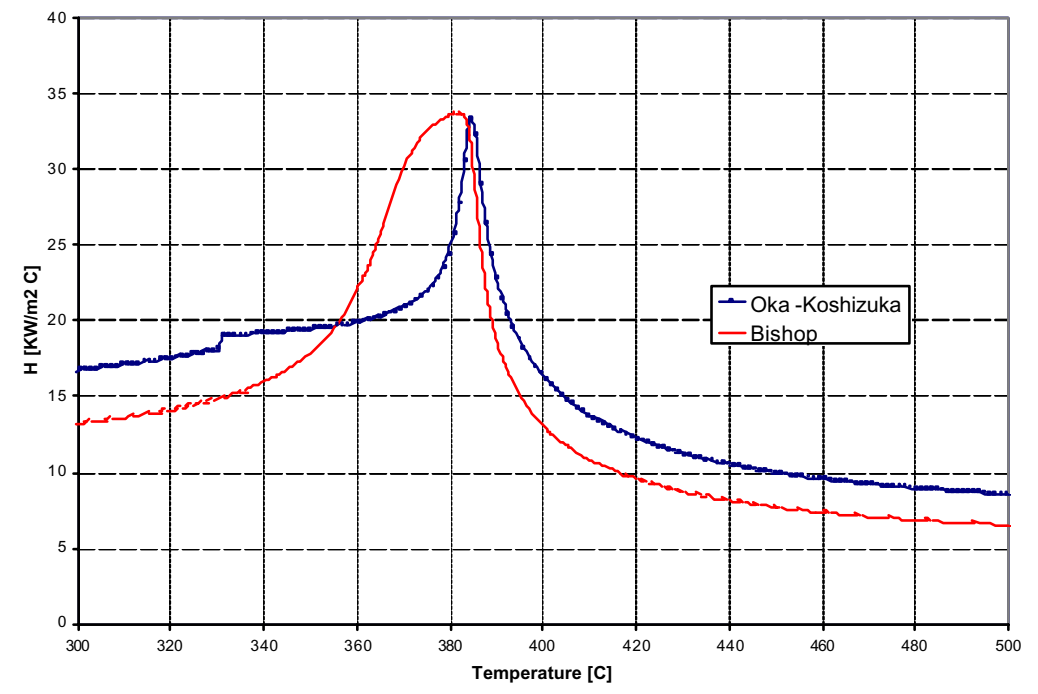

Figure 34. Heat Transfer coefficients calculated with the Oka-Koshizuka and Bishop correlations for different temperatures at a heat flux of $500 \mathrm{KW} / \mathrm{m}^{2}$, MDHFR=1.6

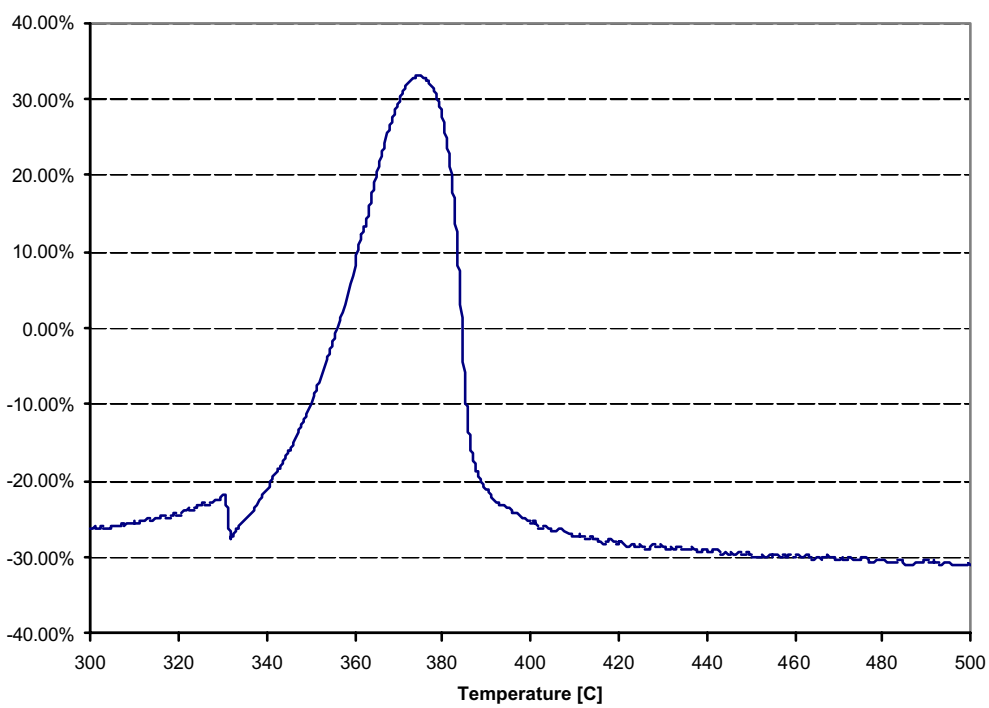

Figure 35. Percentage deviation of the heat transfer predicted by the Oka-Koshizuka correlation compared to the Bishop correlation. Heat flux of $500 \mathrm{KW} / \mathrm{m}^{2}$, MDHFR=1.592.

While this comparison of the different correlations in DHF and non-DHF conditions was missing in Cheng and Schulenberg (2001), it can be used to show that DHF appears to be considered in at least the Bishop et al. and Oka-Koshizuka correlations, and it would seem possible to eliminate Design Criterion 5 (as discussed in Section 3.1.3) if these correlations are used. Both correlations take into account DHF in an acceptable way, conforming to the expected physical behavior. Also, Cheng and Schulenberg (2001) compared different correlations in a case where DHF was present, thus showing significant differences (for example) between the Dittus-Boelter correlation (that clearly cannot take DHF into consideration) and the Bishop et al. Correlation. Figures 36 to 39 compare the heat transfer coefficients calculated by 
the Dittus-Boelter correlation with heat transfer coefficients calculated by the Bishop et al. and the Oka-Koshizuka correlations (with and without DHF), showing that the agreement between the Bishop et al. and Oka-Koshizuka correlations and the Dittus-Boelter correlation increases in the non-DHF cases, thus demonstrating that the Bishop et al. and Oka-Koshizuka correlations correctly predict better heat transfer coefficients in non-DHF conditions.

Figures 36 and 37 demonstrate how the Bishop et al. correlation seems to take post-DHF heat transfer into consideration, showing significant differences between the two cases. Also, a supplemental case with a MDHFR of 3.184 was calculated to show the effect of increasing the margin from DHF conditions. The farther the system is operated from DHF, the better the agreement between the Bishop et al. and the "ideal" Dittus-Boelter coefficient. With a very large MDHFR the Bishop et al. correlation calculates better heat transfer coefficients than the DittusBoelter correlation. (Please note that different values of the MDHFR have been obtained by simply changing the heat flux in each case, with all the other parameters constant.) As expected, the effect of the DHF conditions is mostly limited to the heat transfer values around the pseudo-critical temperature. For high and low temperatures, the Bishop correlation gives very similar results in the three cases.

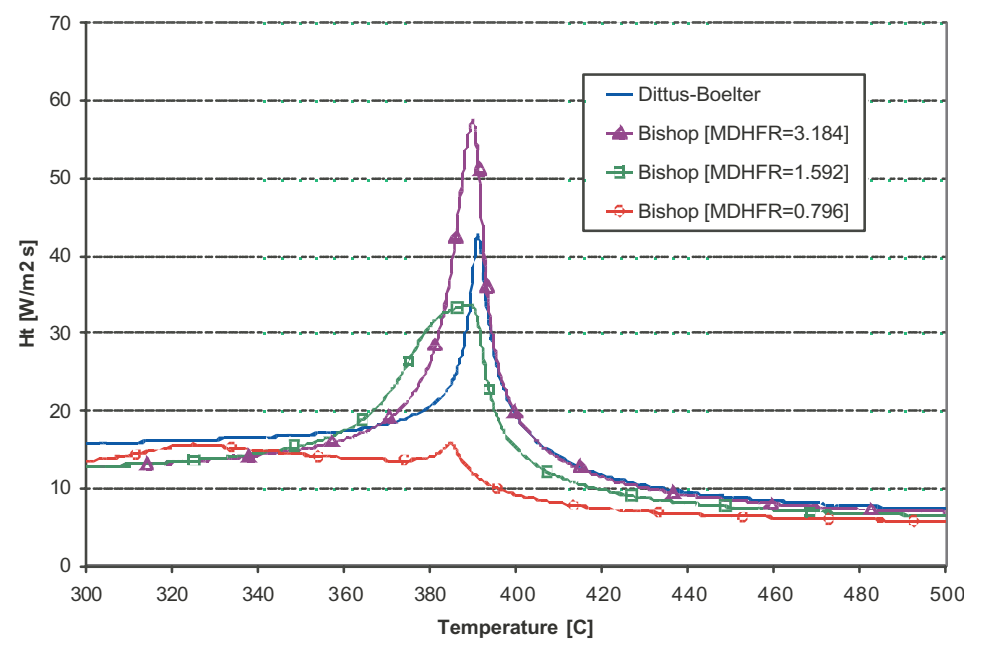

Figure 36. Comparison of the heat transfer coefficients calculated with the Dittus -Boelter correlation and the Bishop et al. (Westinghouse) correlation for cases with different MDHFR.

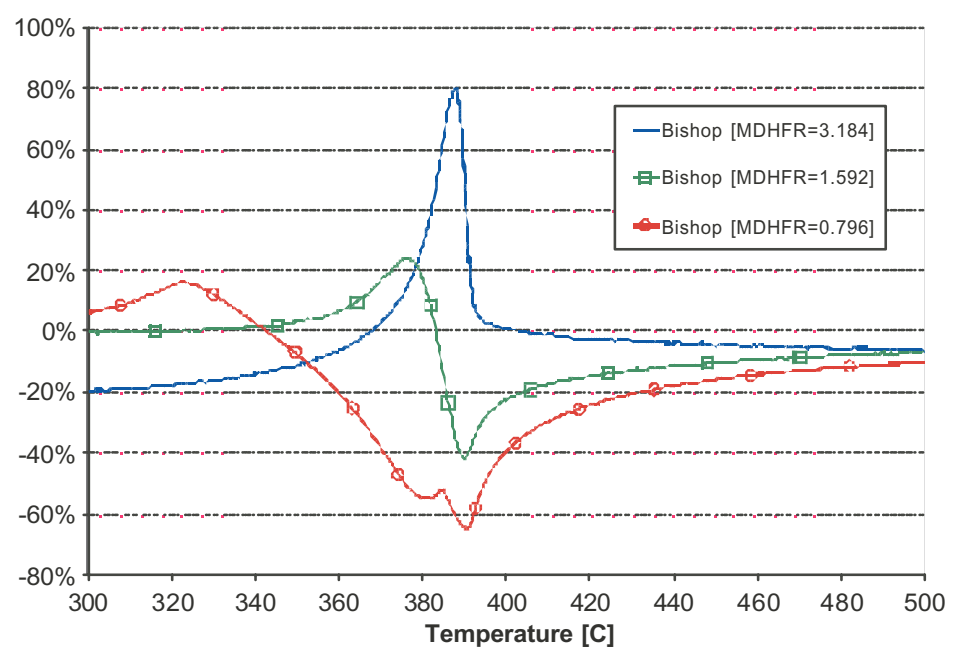

Figure 37. Percentile difference between the Bishop and the Dittus-Boelter correlations for different MDHFR cases.

Figures 38 and 39 shows the same comparisons for the Oka-Koshizuka correlation. The behavior of the Oka-Koshizuka correlation is very interesting from a qualitative point of view, showing clearly the case with DHF conditions (no heat transfer peak, but rather a heat transfer deterioration) and the improvement in heat transfer for large values of the MDHFR. It is interesting to note how both the Bishop et al. (Figure 36) and Oka-Koshizuka (Figure 38) correlations calculate a heat transfer coefficient higher that the one predicted by the Dittus-Boelter correlation for large MDFHRs (in Figures 36 and 38, the $\mathrm{MDHFR}=3.184$ case). Also, the agreement between the two correlations (Oka-Koshizuka and Bishop) is maintained, and even improved, at large MDHFR values. 


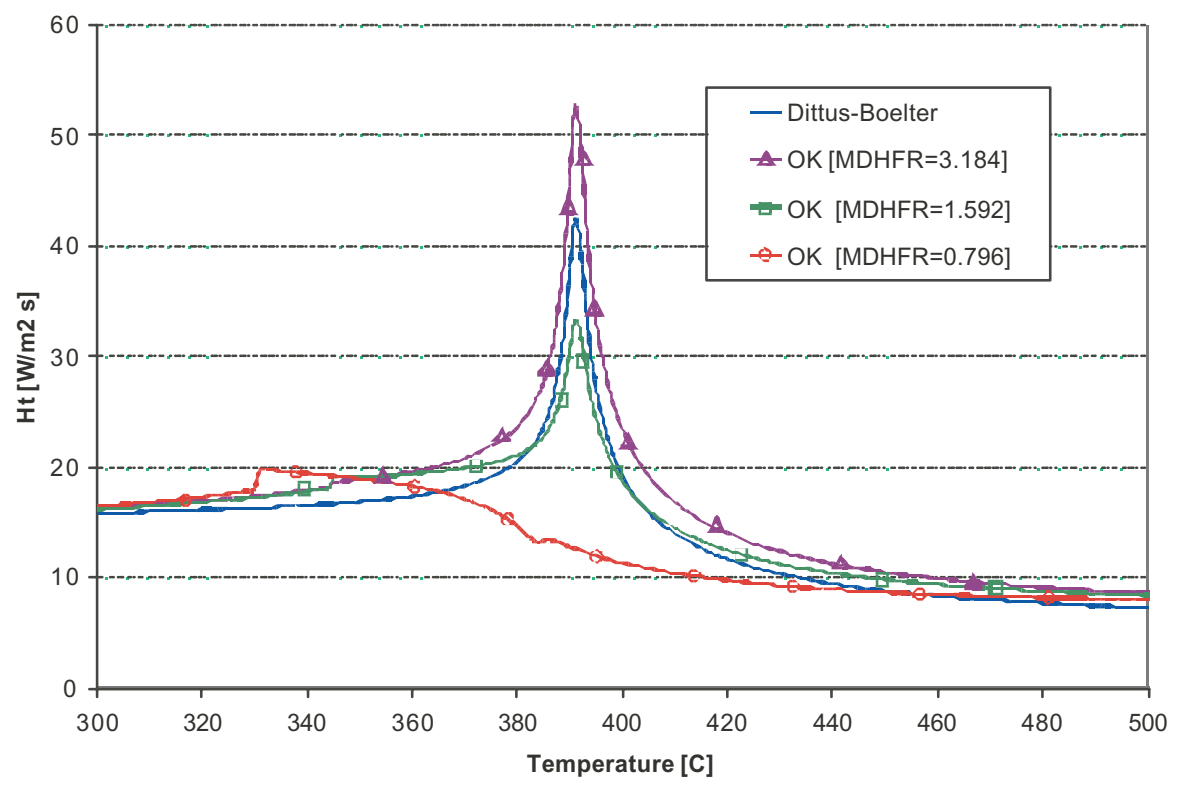

Figure 38. Comparison of heat transfer coefficients calculated with the Dittus-Boelter correlation and with the Oka-Koshizuka correlation for cases with different MDHFR.

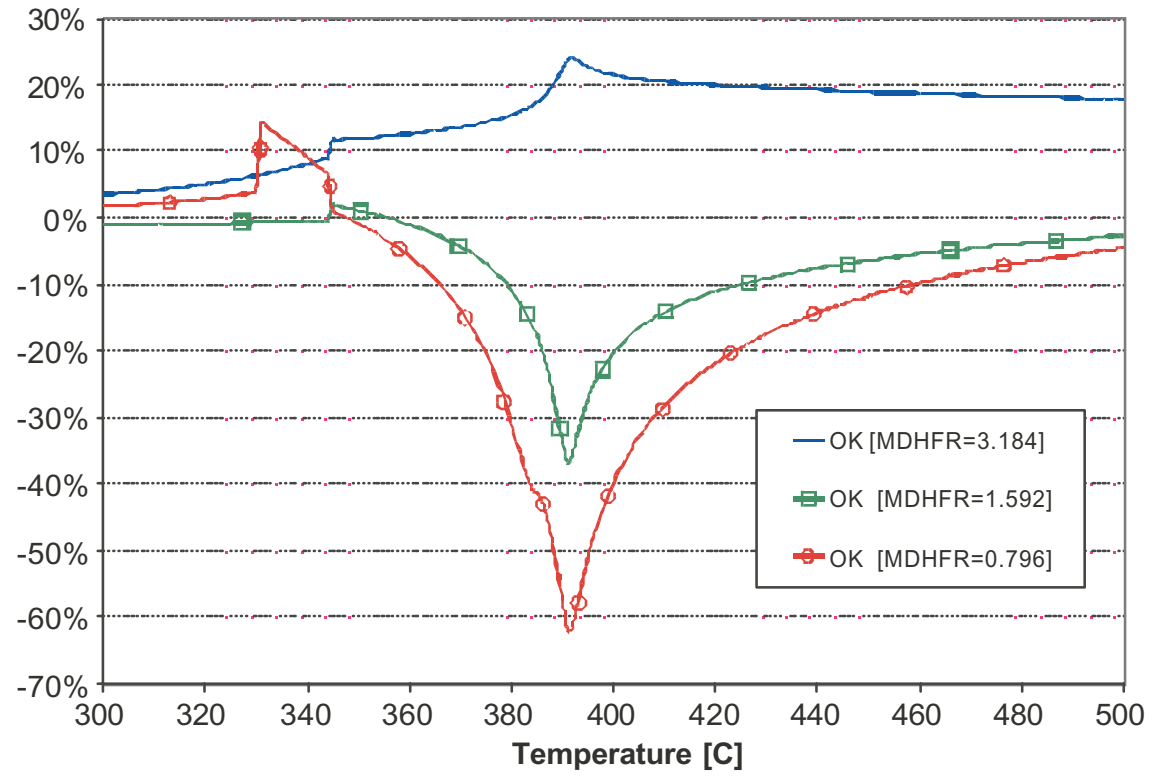

Figure 39. Percentile difference between the Oka-Koshizuka and the Dittus -Boelter correlations for different MDHFR cases.

\subsubsection{Supercritical Water Properties}

Properties for supercritical water have been calculated using the NIST/ASME properties (Harvey et al. 1996). Figures 40 to 43 show the behavior of the main properties used throughout this analysis. 


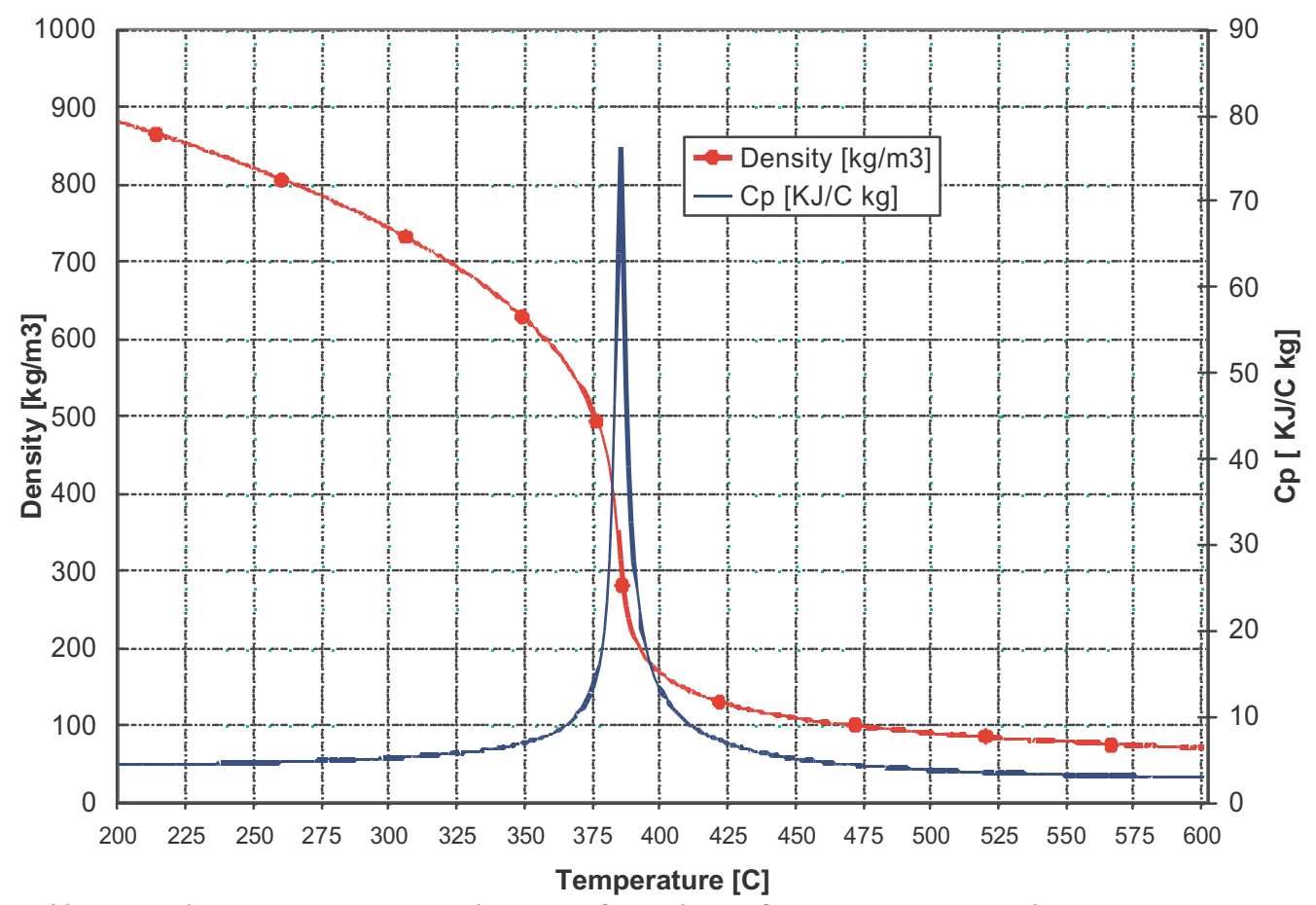

Figure 40. Density and heat capacity as a function of temperature at 25MPa. The very peculiar peak in heat capacity between 375 and $400^{\circ} \mathrm{C}$ is due to the transition over the pseudocritical temperature $\left(\sim 385^{\circ} \mathrm{C}\right)$.

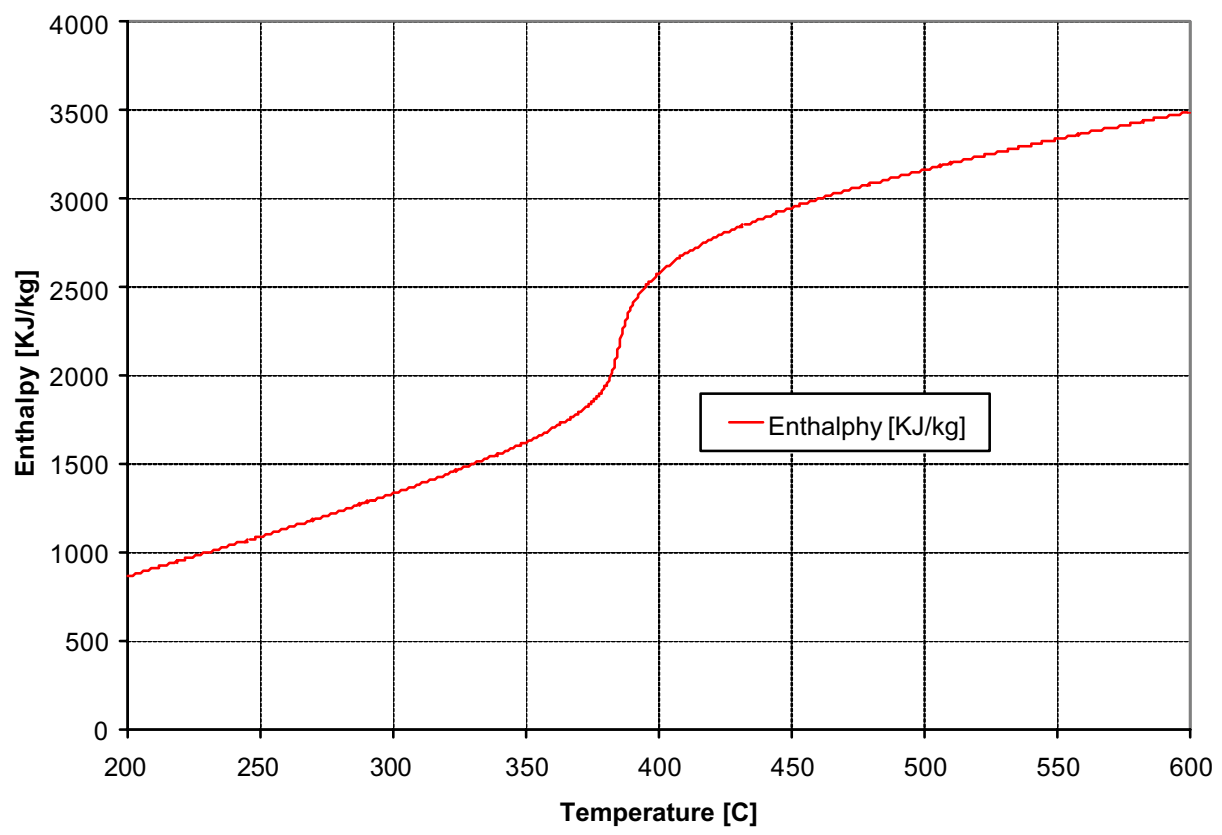

Figure 41. Enthalpy as a function of temperature at $25 \mathrm{MPa}$. The large Enthalpy increase in the pseudocritical transition reminds the boiling transition in subcritical water, although on a much milder scale. 


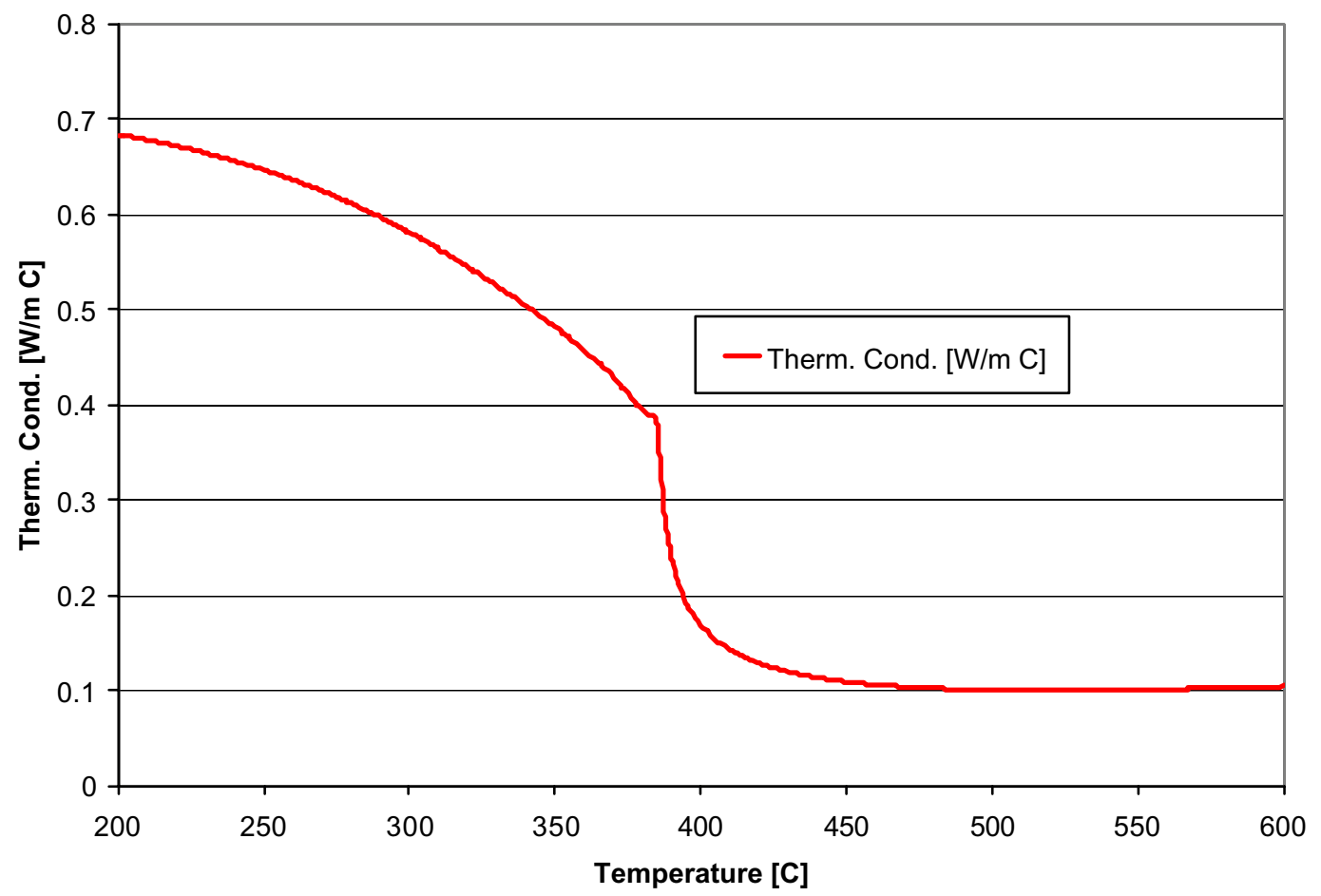

Figure 42. Conductivity as a function of temperature at $25 \mathrm{MPa}$.

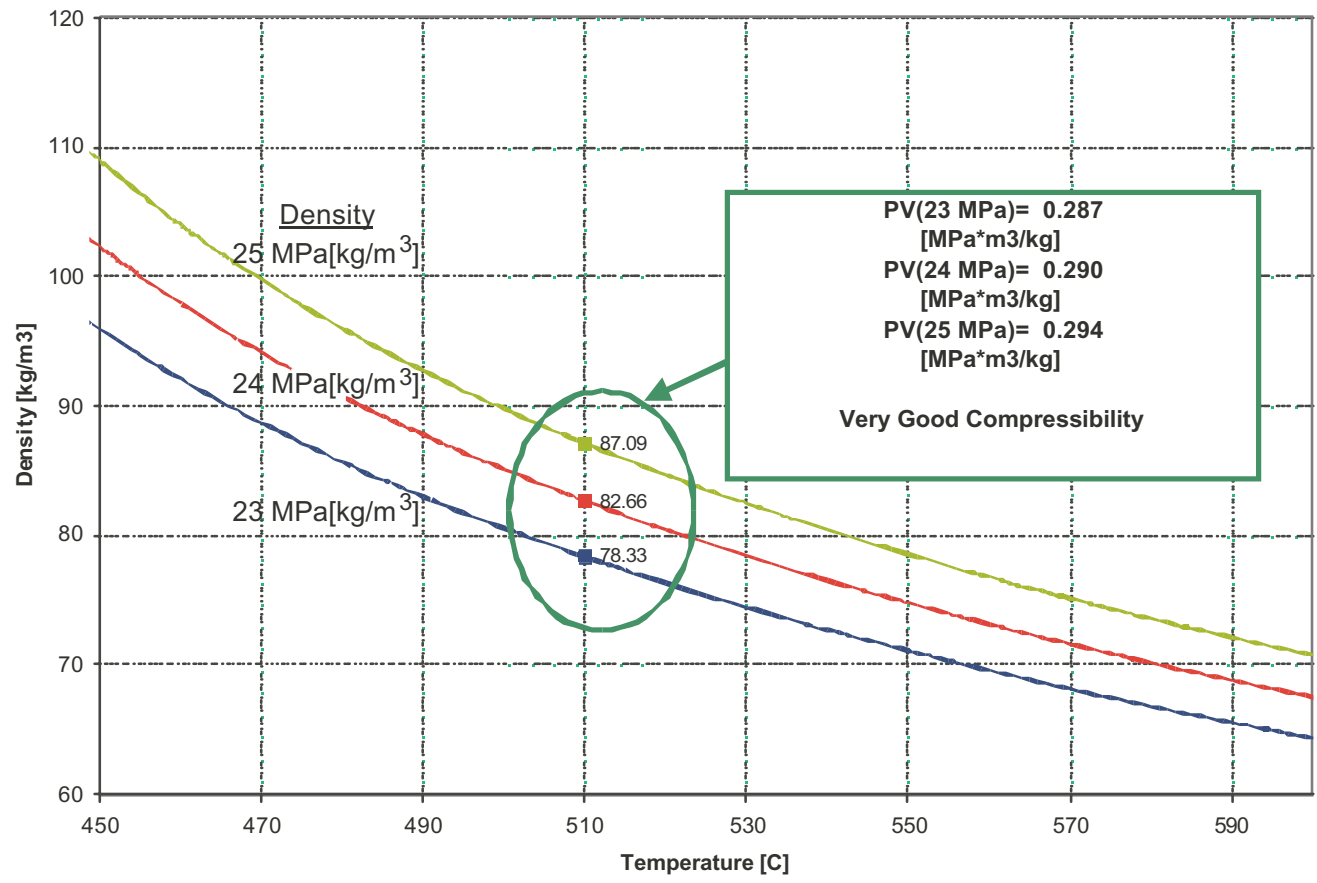

Figure 43. Density as a function of pressure and temperature in the supercritical region. Supercritical water beyond the pseudocritical point behaves in very good agreement with the perfect gas law. 


\subsubsection{Hot Channel Factors and Implementation of the Design Criteria}

The design criteria introduced in Section 3.2.1 need to be verified for any fuel rod in the core. Therefore the first step in the application of this design criteria is the identification of the power distributions in the core:

- Radial Peaking Factor $\left(\mathrm{F}_{\Delta \mathrm{H}, \mathrm{A}}\right)$ : The SCWR is anticipated to present a very flat radial power profile, due to the strong density feedback effect linked to the large changes in density of the coolant along the channel. While a typical radial power peaking design value for PWRs is 1.5-1.65, preliminary studies on the SCWR suggest that the radial power peaking will be around 1.25-1.26 (Cheng and Schulenberg 2001,Dobashi et al. 1998 and 2000) for the SCWRs.

- Local Peaking Factor $\left(\mathrm{F}_{\Delta \mathrm{H}, \mathrm{L}}\right)$ : The local peaking factors for the high temperature SCLWR-H have been estimated as 1.14 (Mukohara et al. 2000) to 1.16 (Dobashi et al. 1998 and 2000) depending on whether the density feedback is considered or not. These peaking factors have been calculated for a hexagonal lattice with a 258 fuel pin and 30 water rod assembly. Different possible geometries for both square and hexagonal lattices have been summarized in (Cheng and Schulenberg 2002). Grid spacers are considered.

- Axial Peaking Factor $\left(\mathrm{F}^{\mathrm{N}} \mathrm{z}\right)$ : A rather typical axial peaking factor of $\sim 1.58$ has been proposed for the SCWR (Dobashi et al. 1998 and 2000). Axial power distributions for a supercritical water reactor have been studied by Koshizuka and are estimated to have a profile similar to a design cosine (Cheng and Schulenberg 2002).

The Radial Peaking Factor defines the hot channel, the Local Peaking Factor identifies the hot rod in the hot assembly, while the Axial Power Profile identifies the location of the hot spot in the fuel rod. The product of $\left(\mathrm{F}_{\Delta \mathrm{H}, \mathrm{A}}\right) \cdot\left(\mathrm{F}_{\Delta \mathrm{H}, \mathrm{L}}\right) \cdot\left(\mathrm{F}^{\mathrm{N}} \mathrm{z}\right)$ gives the maximum local heat flux on the surface of a rod divided by the average fuel rod heat flux.

The thus defined peaking factors allow for a proper definition of the hot spot and hot channel, but are not by themselves sufficient for an evaluation of the design limits defined in Section 2. In fact, the impact of theoretical and experimental analysis uncertainties, instrumentation and control inaccuracies, manufacturing tolerances, material properties and correlations uncertainties, and changes of reactor conditions during the lifetime must be taken into consideration in predicting the thermathydraulic performance to ensure that proper margins are provided to meet both lifetime and safety design limits with a sufficient degree of confidence. A discussion on the treatment and nature of these uncertainties will be given in the following sections.

For example, the typical requirement for a PWR (having taken DNB as the principal index of clad damage/failure) is that there is an at least $95 \%$ probability with a $95 \%$ confidence that no DNB phenomenon will occur in the core. In its simplest application, the $95 / 95$ rule has been applied by defining a Correlation Limit DNBR such that there is a 95\% probability that DNB will not occur when the calculated DNBR is greater or equal than the correlation limit. Calculations of the DNBR for the plant are then developed treating all parameters in a conservative way (nominal value plus uncertainty). This approach is very conservative and more realistic, statistically based methodologies for the application of the 95/95 rules have been studied and proposed by Westinghouse and approved by NRC (Chelemer et al. 1975, Friedland and Ray 1989).

An alternative approach has also been endorsed by the NRC in its Standard Review Plan: 'For DNBR, CHFR or CPR correlations, the limiting (minimum) value of DNBR, CHFR, of CPR is to be 
established such that at least 99.9\% of the fuel rods in the core would not be expected to experience departure from nucleate boiling or boiling transition during normal operation or anticipated operational occurrences."

Since the main design criteria for the SCWR is not DNB but the cladding temperature, the situation is more similar to the LMFBRs and therefore an approach similar to that studied by Westinghouse for the Clinch River Breeder Reactor (CRBRP) will be considered here (see Carelli and Bach 1979, Carelli and Spencer 1976, Friedland 1980, and Tang et al. 1978). On the other hand, some differences make the SCWR unsuitable for a strict application of the CRBRP methodology, and an intermediate approach between the CRBRP methodology and the PWR studies will have to be considered. Section 2.3.1 will introduce the CRBRP methodology, while section 2.3.2 will discuss the reasons why this methodology is not entirely suitable for the SCWR and will propose a new approach. It may be worth pointing out that an approach very similar to that developed by Westinghouse for the CRBRP has been adopted in the Japanese studies on supercritical water reactors.

\subsubsection{Semi-Statistical Approach for the CRBRP}

There are three possible approaches for combining uncertainty factors in the study of a nuclear reactor and in the verification of the required confidence in the acceptance criteria (for example for LMFBR that there is a $99.9 \%$ probability that no rods experience cladding temperatures above the acceptable value, appropriately defined).

The cumulative method, using direct combination, represents the worst conditions. It assumes all uncertainties have the most unfavorable value and occur at the same location and time. This assumption is very conservative, and virtually ensures that at no point in the core will the limits ever be exceeded. Such an approach causes a substantial decrease in the expected performance of the reactor, but given its simplicity it has been widely employed at the beginning of the nuclear era. Given the high degree of conservativness and the penalty on the power associated to this approach, different statistical approaches were developed to treat the uncertainties in a more realistic way and to lower the burden on the plant performance.

A completely statistical method, in which all uncertainties are treated statistically, represents the most optimistic expectation. By using this method, the hot channel / hot spot factor is not an absolute factor, but is a function of the confidence level.

An intermediate approach, developed by Westinghouse, is the so-called semi-statistical method. This method was adopted as a reasonable compromise between cumulative and fully statistical methods and is commonly used in liquid metal reactor designs. The method postulates that actually not all parameters are statistical in nature. Therefore, the sum of uncertainties is divided into two principal groups: statistical and non-statistical sub-factors. By calculating the total hot-spot factor for a certain temperature rise, systematic uncertainties are treated cumulatively and statistical uncertainties are treated statistically.

The separation of the uncertainties into two principal groups is typical of the Westinghouse analytical procedure both for PWRs and for the LMFBR. A non-statistical (or direct) uncertainty is defined as a variation in a design variable, which is known or conservatively assumed to occur, but is not included in the nominal analysis. Computationally, the non-statistical factors represent multipliers applied to the nominal magnitudes of the variables to provide the worst value that might occur. The direct factors are related to effects that are assumed to occur with certainty, for example measurement deadbands for 
different variables, inlet flow maldistribution, direct bias, cladding temperature increases beneath the wire wrap (for LMFBR using wire wraps), etc. A variable that has a random frequency distribution of occurrence is treated statistically. For example, experimental data (such as materials properties) are treated statistically since there is a random error in their evaluation. Other typical random effects are manufacturing variability of fissile fuel contents, dimensional tolerances, instrumentation uncertainties, and uncertainties in experimental data.

The nominal (without uncertainties) cladding inlet temperature can be expressed as:

$$
T_{\text {gap }, \text { nom }}=T_{i n, \text { nom }}+\Delta T_{\text {cool,nom }}+\Delta T_{\text {film,nom }}+\Delta T_{\text {cald }, \text { nom }}
$$

where the heat transport path between coolant and cladding have been divided into three paths (coolant or enthalpy rise, film, and cladding). In an analogous way if the fuel temperature is to be calculated:

$$
T_{\text {fuel centerlinenom }}=T_{\text {in,nom }}+\Delta T_{\text {cool, nom }}+\Delta T_{\text {film,nom }}+\Delta T_{\text {cald, nom }}+\Delta T_{\text {gap ,nom }}+\Delta T_{\text {fuel, nom }}
$$

and in general the temperature of each of the five zones can be expressed as:

$$
T_{m, n o m}=T_{i n, n o m}+\sum_{j=1}^{m} \Delta T_{j, n o m}
$$

where $m$ is the index representing the fuel system component (for example $m=3$ for the cladding). To calculate the value for each fuel component region including the value of hot channel and hot spot factors, the following expression is defined:

$$
T_{m}=T_{i n, n o m} \cdot F_{0}+\sum_{j=1}^{m} F_{j} \Delta T_{j, n o m}
$$

where $F_{j}$ represent the total hot spot factor for component $j$ and is defined as:

$$
F_{j}=\frac{T_{j}-T_{j-1}}{\Delta T_{j, n o m}}
$$

and $\mathrm{F}_{0}$ has been introduced to account for uncertainties also in the inlet temperature. Considering also the uncertainties in inlet temperature and treating this as an additional fuel component, the temperature of component $\mathrm{m}$ can be defined as:

$$
T_{m}=T_{i n, n o m}+\sum_{j=0}^{m} \Delta T_{j, n o m}+\sum_{j=0}^{m}\left(F_{j}-1\right) \Delta T_{j, n o m}
$$

If all uncertainties are treated as non-statistical or direct uncertainties (thus the semi-statistical approach becomes a cumulative method), all the uncertainties are assumed to have the most unfavorable value and $F_{j}$ is simply calculated on the basis of this model. In a semi-statistical approach only part of the uncertainties are treated in a direct way, and the component $\mathrm{m}$ temperature can be expressed as:

$$
T_{m}=T_{i n, n o m}+\sum_{j=0}^{m} \Delta T_{j, \text { nom }}+\sum_{j=0}^{m}\left(F_{j, d i r}+F_{j, s t}-1\right) \Delta T_{j, n o m}
$$


where statistical and direct parts of $F_{j}$ have been highlighted. How the different uncertainties are applied in the calculation of fuel rod temperature for the hot channel is shown in Figure 44.

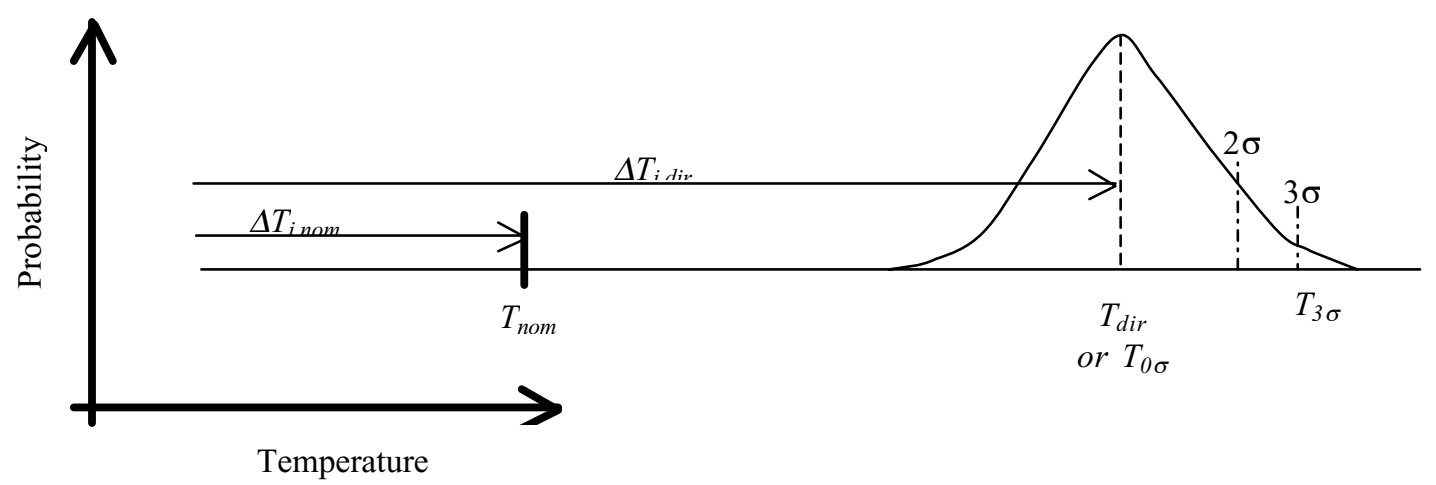

Figure 44. Conceptual application of a semi-statistical method

And $\Delta T_{j, d i r}=\Delta T_{j, \text { nom }}+\left(F_{j, d i r}-1\right) \Delta T_{j, \text { nom }}$

The nominal temperature difference, $\Delta T_{n o m}$, is multiplied by the product of the direct hot channel factors to give the temperature rise including non-statistical factors, $\Delta T_{d i r}$. Using this value, the nominal temperature is increased to $T_{d i r}$ or $T_{0 \sigma}$. $T_{d i r}$ represents the mean value about which the statistical uncertainties are applied. The nominal channel can be any channel in the assembly, with the nominal channel coolant $\Delta T$ calculated using subchannel analysis codes. In practice, the channel with the highest power density in the LMFBR is singled out for application of the hot channel factors. According to the methodology illustrated in Figure 44, a temperature for the $\mathrm{m}$ component is calculated as $\mathrm{T}_{\text {dir }}$ by considering in the calculation procedure (with subchannel analysis codes or other core $\mathrm{T} \& \mathrm{H}$ codes) the effect of the direct uncertaintie s (all accounted in a conservative way as previously discussed), and then the effect of statistical uncertainties need to be superimposed to this calculated temperature.

To better explain the application of the statistical part of equation (25), some discussion of the treatment of statistical factors is warranted (q.v. Carelli and Spencer 1976, pages 3 to 12). If a temperature $\mathrm{T}$ can be expressed as a linear function of independent random variables $\left(\mathrm{x}_{\mathrm{i}}\right)$ :

$$
\mathrm{T}=\mathrm{a}_{0}+\mathrm{a}_{1} \mathrm{x}_{1}+\mathrm{a}_{2} \mathrm{x}_{2}+\mathrm{a}_{3} \mathrm{x}_{3}+\ldots+\mathrm{a}_{\mathrm{n}} \mathrm{x}_{\mathrm{n}}
$$

Then the variance of $T$ is equal to the sum of variances of the $a_{i} x_{i}$ 's

$$
\sigma_{T}^{2}=\sum_{i=1}^{n} a_{i}^{2} \sigma_{1}^{2}
$$

It is important to note that even if the independent variables do not have a normal distribution, $\mathrm{T}$ will tend to approach a normal distribution as the number of variables grows. The two fundamental assumptions at the basis of Figure 44 have already been introduced: (1) all the statistical uncertainty factors are assumed to be independent from each other, and (2) a normal distribution is assumed for all the uncertainty factors and for the overall variance of the temperature of component $\mathrm{m}$. If $\mathrm{T}$ is an arbitrary function of the independent variables it can be naturally approximated by a Taylor series around its mean value $\left(\mathrm{T}_{\text {dir }}\right.$ from Figure 44, where all the variables are at their mean values, with no uncertainties) with negligible errors 
provided that deviations from the mean value are small for each variable (as is the case with most hot channel factors):

$$
T \cong T_{d i r}+\left.\sum_{i=1}^{n} \frac{\partial T_{d i r}}{\partial x_{i}}\right|_{\bar{x}} \Delta x_{i}
$$

and

$$
\sigma_{T}^{2}=\sum_{i=1}^{n}\left(\left.\frac{\partial T_{d i r}}{\partial x_{i}}\right|_{\bar{x}}\right)^{2} \sigma_{i}^{2}
$$

and if $\mathrm{T}$ has a normal distribution, than the probability that $\mathrm{T}_{\mathrm{dir}}+2 \sigma$ will not be exceeded is $97.73 \%$, and the probability that $\mathrm{T}_{\mathrm{dir}}+3 \sigma$ will not be exceeded is $99.87 \%$.

Therefore, the maximum temperature of a fuel component $\mathrm{m}$, for example the cladding $(\mathrm{m}=3)$ with $99.9 \%$ confidence level is:

$$
T_{\text {gap }, \max }=T_{i n}+\Delta T_{\text {in,dir }}+\Delta T_{\text {cool,dir }}+\Delta T_{\text {film,dir }}+\Delta T_{\text {cald }, d i r}+3 \sigma
$$

As mentioned above, the one fundamental assumption for this statistical uncertainties approach is that all the uncertainty factors have a normal distribution. Regarding this assumption, the most commonly nonnormal distributions are rectangular distributions, typical for a variable such as a dimension with specified bounds. For such a distribution, the bounds correspond to $\pm \sqrt{3} \sigma$. Therefore, if some of the variables have a rectangular distribution, than the $2 \sigma$ or $3 \sigma$ coverage discussed above will be greater (more conservative) than if the distributions were all normal with the same standard deviation.

Tables 8 and 9 summarize the uncertainty factors for the CRBRP (from Carelli and Spencer 1976)

Table 8. Direct uncertainty subfactors for cladding temperature evaluation.

\begin{tabular}{|l|c|c|c|}
\hline \multicolumn{1}{|c|}{ Uncertainty Fact $(\boldsymbol{i}) \quad$ C Component $(\boldsymbol{j})$} & Coolant & Film & Cladding \\
\hline Reactor Power Lever & 1.03 & 1.03 & 1.03 \\
\hline Physics Modeling: 2D/3D & 1.01 & 1.1 & 1.1 \\
\hline Physics Modeling: Axial Shape (Bias) & 1.0 & 1.03 & 1.03 \\
\hline Inlet Flow Maldistribution & 1.02 & 1.0 & 1.0 \\
\hline Flow Distribution Calculation Uncertainty & 1.03 & 1.0 & 1.0 \\
\hline Pellet-Cladding Eccentricity & 1.0 & 1.11 & 1.08 \\
\hline Cladding Thermal Conductivity & 1.0 & 1.0 & 1.035 \\
\hline Combined Direct Factor & 1.093 & 1.295 & 1.304 \\
\hline
\end{tabular}


Table 9. Statistical uncertainty subfactors for cladding temperature evaluation $(3 \sigma)$.

\begin{tabular}{|l|l|l|l|}
\hline \multicolumn{1}{|c|}{ Uncertainty Fact $(\boldsymbol{i}) \quad$ Coolant } & \multicolumn{1}{c|}{ Film } & \multicolumn{1}{c|}{ Cladding } \\
\hline Physics Experimental & 1.055 & 1.055 & 1.055 \\
\hline Physics Modeling: Pin Interpolation & 1.01 & 1.01 & 1.01 \\
\hline Physics Modeling: Axial Shape & 1.0 & 1.01 & 1.01 \\
\hline Fissile Content & 1.052 & 1.052 & 1.052 \\
\hline Inlet Flow Maldistribution & 1.039 & 1.0 & 1.0 \\
\hline Flow Distribution Calculation Uncertainty & 1.055 & 1.0 & 1.0 \\
\hline Wire Wrap Orientation & 1.01 & 1.0 & 1.0 \\
\hline Subchannel Flow Area & 1.019 & 1.0 & 1.0 \\
\hline Film Heat Transfer Coefficient & 1.0 & 1.12 & 1.0 \\
\hline Pellet-Cladding Eccentricity & 1.0 & 1.13 & 1.11 \\
\hline Cladding Thickness & 1.0 & 1.0 & 1.08 \\
\hline Cladding Thermal Conductivity & 1.0 & 1.0 & 1.075 \\
\hline Coolant Properties & 1.017 & 1.0 & 1.0 \\
\hline
\end{tabular}

Once the methodology is defined, the issue becomes the determination of the hot channel factors for the supercritical reactor: this will require both the definition of the different uncertainties and the quantification of their effect on the cladding, film, and coolant $\Delta \mathrm{T}$. As will be discussed in Section 3.3, due to the large enthalpy rise and to the fact that at the core exit limited changes in the overall channel enthalpy rise will lead to large changes in temperatures, limiting the coolant (often called the $\Delta \mathrm{H}$ factor) direct and statistical factors becomes fundamental. For subchannel analyses on a supercritical water reactor (the SCFR-H) Mukohara et al. (2000) has used a similar approach to calculate the hot channel factors for the SCWR and explore different solutions to limit the hot channel enthalpy rise factors ${ }^{11}$.

The application of this approach is very simple and might be clarified by an example. If the following $0 \sigma$ conditions (nominal values plus direct uncertainties) are considered:

Inlet Temperature $=300 \mathrm{C}$

Coolant $\Delta \mathrm{T}=200 \mathrm{C}$

Film $\Delta \mathrm{T}=30 \mathrm{C}$

Cladding $\Delta \mathrm{T}=20 \mathrm{C}$

And if only the statistical uncertainty in physics experimental results and modeling (the first three items of Table 9) are considered (i.e. assuming these are the only uncertainties) the $3 \sigma$ confidence for the cladding temperature would be calculated by defining the $3 \sigma$ temperature uncertainties from Table 9 and the nominal conditions given above as:

\footnotetext{
${ }^{11}$ Reference to different coefficients for the CRBRP is due to a reference in the Mukohara et al. (2000) paper to CRBRP coefficients from N. E. Todreas and M. S. Kazimi, "Nuclear Systems II," Hemisphere Publishing Corporation, while the values in Table 7 and 8 are from the final thermal hydraulic performance report for CRBRP (Carelli et al. 1985).
} 


\begin{tabular}{|l|c|c|c|c|}
\hline & $\begin{array}{c}\text { Coolant } \Delta \mathbf{T} \\
{[\mathbf{C}]}\end{array}$ & $\begin{array}{c}\text { Film } \Delta \mathbf{T} \\
{[\mathbf{C}]}\end{array}$ & $\begin{array}{c}\text { Cladding } \Delta \mathbf{T} \\
{[\mathbf{C}]}\end{array}$ & TOTAL \\
\hline Physics Experimental & 11 & 1.65 & 1.1 & 13.75 \\
\hline Physics Modeling: Pin Interpolation & 2 & 0.3 & 0.2 & 2.5 \\
\hline Physics Modeling: Axial Shape & - & 0.3 & 0.2 & 0.5 \\
\hline
\end{tabular}

The Overall $3 \sigma$ would be equal to $\sqrt{\sum_{i=1}^{n} \sigma_{i}^{2}}$ and thus $3 \sigma=13.98 \mathrm{C}$, and therefore the cladding temperature with a $3 \sigma$ confidence would be $563.98 \mathrm{C}$, meaning that there is a $99.87 \%$ probability that the cladding temperature will be below $563.98 \mathrm{C}$.

\subsubsection{Semi-Statistical Approach for the SCWR}

The approach discussed in the previous section and applied to the CRBRP and to other SCWR studies has the advantage of allowing a clear representation of the system uncertainties and thus allows the identification of the more significant areas in which a technical development leading to a reduction of uncertainties would have a significant effect on the thermal margin for the plant. The standard procedure for the application of such a procedure would be (1) a thermathydraulic study of the core with a subchannel analysis code using nominal values for the plant parameters and operating conditions; (2) definition of the different hot channel factors that will have an influence in the calculation of the thermal margin and quantification (cladding temperature and fuel centerline temperature); and finally (3) evaluation of the effect of the $3 \sigma$ deviation in each fuel component $\Delta \mathrm{T}$ to compile a table as those (Tables 8 and 9) presented in the previous section.

However, while an approach that considers each hot factor separately is appropriate for LMFBRs, it would not be appropriate for a SCWR. First of all, the Coolant $\Delta \mathrm{T}$ would have to be replaced with a Coolant $\Delta \mathrm{H}$, given the fact that, due to the transition between subcritical and supercritical temperature, no direct proportionality between enthalpy and temperature exists. In second place, the fundamental assumption of the CRBRP methodology is that each effect can be considered separately: while this is true with a good approximation for a LMFBR, it is not true for the SCWR. For these reasons, more recent methodologies developed for LWRs take into account the uncertainties in a more integrated way. On the other hand, PWR methodologies are essentially focused on the calculation of the departure from nucleate boiling ratio, while the relevant thermal design parameters for the SCWR are more similar to the parameters (cladding temperature and fuel temperature) used for the CRBRP.

A different approach will therefore be used for SCWRs, combining the semistatistical method described above with the Westinghouse procedures for LWRs. The first approach used by Westinghouse for the design of PWRs was the Standard Thermal Design Procedure (STDP) in which all the uncertainties where treated in a direct, cumulative way. This approach is similar to the cumulative approach described in the previous section, with one important difference: given the complex interaction of the different uncertainty factors and their effect on the departure from nucleate boiling ratio (the only parameter of interest in PWR, rather than the need to calculate temperatures in different regions for LMFBR) the uncertainty factors where not applied to the DNBR, but rather where directly considered in the calculation procedure of the MDNBR (for example, increasing the power by $3 \%$ and studying the core thermalhydraulic response in those conditions). It became evident later that not all the parameters should be treated in a direct way, but rather a statistical approach was more appropriate. The Improved Thermal 
Design Procedure, ITDP, was therefore developed, where direct uncertainty factors and hot channel factors were directly accounted for in the thermathydraulic model of the core, while a more refined treatment was developed to treat the statistical uncertainty in input parameters (Cheler et al. 1975, Friedland and Ray 1989). In the ITDP, probability distributions were defined for those parameters and sensitivity studies developed to verify their effect on the MDNBR. .

An overview of the ITDP for PWRs and the evolution of an appropriate hot channel factor methodology for the SCWR will be developed in the next quarter, and a complete, semistatistical approach will be developed, to define the SCWR principal design requirement that:

"For Condition I and II events for the SCWR, there is an at least 95\% probability with a 95\% confidence that cladding overheating (MAT-I and MAT-II) does not occur"

That is the same criteria used for PWRs, except that in those reactors the limit is based on DNB and is the same for Condition I and II events, while for the SCWR two different cladding temperature limits have been defined for the SCWR. A simpler approach has been selected for the first phase of the thermal hydraulic design, with a direct treatment of the uncertainty factors similar to the Westinghouse STDP.

\subsubsection{Direct (Non-Statistical) Hot Channel Factors for the SCWR}

For the SCWR, an approach for estimating the worst thermal-hydraulic conditions similar to the ITDP described in the previous section will be adopted. A preliminary list of different hot channel factors proposed for the analyses and a discussion of how each factor will be treated (either direct or statistical) follows. However, a direct, cumulative treatment of all the uncertainties will be employed in our preliminary analyses, both to simplify the analyses and to allow for comfortable design margins at this stage of the design. This list of hot channel factors cannot be considered complete at this stage of the design, and the uncertainty values are only rough estimates, based on CRBRP and Westinghouse PWR experience.

\section{- Plant Operating Parameters}

- $\quad$ Reactor Power Level: a typical calorimetric error of $2 \%$ is considered. For preliminary analysis this factor will be treated in a direct way, increasing the power level of the reactor by $2 \%$ for the calculation of cladding temperature. This is, however, a parameter that is typically treated statistically in PWRs, and therefore the same approach will be used once a proper methodology is defined. A rectangular probability distribution should be assumed, and therefore a standard deviation of $1.2 \%(2 / \sqrt{3})$ is calculated.

- $\quad$ System Pressure Distribution: The system pressure control system for the SCWR is not yet determined, and naturally a direct cycle would have a different behavior than an indirect cycle. For an indirect system, the pressure is typically controlled by a pressurizer to $+/-30$ psi $(\sim 200$ Kpa). For the SCWR, the effect of this uncertainty should be small compared to PWRs (where it becomes important in DNB considerations), and therefore the same value is considered pending further investigation. This parameter shall be treated statistically, present a rectangular distribution, and would have a standard deviation of $17.3 \mathrm{psia}(120 \mathrm{Kpa})$.

- Core Inlet Temperature: Calibration errors associated with the measurement of the inlet temperature are typically in the range of $+/-4 \mathrm{~F}\left(2.22^{\circ} \mathrm{C}\right)$. This uncertainty is treated statistically in PWRs, has a rectangular distribution and a standard deviation of $2.3^{\circ} \mathrm{F}\left(1.28^{\circ} \mathrm{C}\right)$. 
- Primary Coolant Flow Rate: Uncertainties in the flow prediction are typically treated in two different ways, distinguishing between direct and statistical components. For preliminary analysis it will be assumed that $95 \%$ of the nominal flow will be available to cool the core. With the more detailed methodology, a first uncertainty will be applied directly, and the minimum measured flow $(97 \%$, defined as the minimum flow that must be confirmed by instrumentation to run the plant) will be considered in the model. Also, a statistical uncertainty in measurement of $2 \%$ will be considered, with a rectangular distribution and a $1.2 \%$ standard deviation.

- Core Bypass Flow: For our preliminary analyses and pending a definition of the bypass flow for the SCWR, the bypass flow will be treated as a direct factor, assuming that $6 \%$ of the total flow will be "lost" as bypass. The bypass flow will have to account for several different effects like guide thimble tube cooling, flow in the baffle-former region, and flow used for head cooling.

- Inlet Flow Maldistribution: A typical 5\% maldistribution is considered for the hot assembly. For PWR this is typically treated as a direct uncertainty and is applied by reducing the inlet flow to the hot assembly by 5\%, and increasing the flow of the most peripheral assemblies (so to minimize cross flow from the assemblies near the hot one) to maintain the same overall flow. This uncertainty is more important for a canned assembly design: in an open core, the effect will tend to vanish along the channel due to crossflow from neighboring assemblies.

\section{- Nuclear Hot Channel Factors}

- Nuclear Enthalpy Rise Hot Channel Factor (Assembly and Local), Nuclear Axial Hot Channel Factor: As discussed in Section 3.2.3, an enthalpy rise hot channel factor $F_{\Delta H}^{N}$ of 1.45 (1.16 times 1.25) and an axial nuclear hot channel factor $F_{Q}^{N}$ of 1.55 peak-to-average-factor with an assumed chopped cosine profile have been preliminarily defined for the hot rod. These values are assumed to be best estimate values, not accounting any uncertainty in core map flux measures.

- Engineering Enthalpy Rise Hot Channel Factor: $F_{\Delta H}^{E}$ accounts for flow conditions and tolerances on the hot channel. It is composed of different coefficients, accounting for fuel rod variation in enrichment, fuel rod variations in geometric dimensions, non uniform flow distribution at the core inlet, redistribution between channels, and thermal diffusion exchange between adjacent channels. Several of these effects are considered separately in other lot channel factors (for example the inlet flow maldistribution factor, or the subchannel flow area factor) so that only the effect of rod-to-rod variation in enrichment is considered explicitly in this coefficient. On the basis of the CRBRP studies (Table s 8 and 9) the fissile content uncertainty results in a local fission rate bounding uncertainty of $+/-3 \%$, for which a rectangular distribution can be assumed with a standard deviation of $1.73 \%$. For preliminary analysis this coefficient is applied by increasing the heat flux of the rods in the hot assembly by $3 \%$. It might be worth pointing out that the $5.2 \%$ factor given in Table 9 for the CRBRP is simply the $3 \sigma$ limit for the distribution defined above.

- Physics Calculation Methods and Control Rods Effect: Uncertainties due to physics calculational methods and control rod effects are applied directly as multipliers to the radial power profile peaking factors. In agreement with CRBRP a $4 \%$ uncertainty is assumed. 


\section{- Other Miscellaneous Coefficients}

- Subchannel Flow Area: Lacking an analysis of the effects of rod bundle dimensional tolerances and fuel rod bowing during operation, the same uncertainty factor used for the CRBRP (Table 9) will be used. This coefficient will be applied by reducing the flow area of all the subchannels in the hot assembly by $1.9 \%$ (for the CRBRP a direct correspondence between the hot channel factor for coolant $\Delta \mathrm{T}$ and the reduction in flow area in the hot assembly can be assumed). This factor will have to be defined on the basis of admissible tolerances on the moderator box, fuel rods, and guide thimbles.

- Coolant Properties: This factor was considered in the CRBRP to account for differences in coolant properties between different sources. For the SCWR, the ASME/STIM steam tables will be used, and no uncertainty allowance will be considered for the range of parameters (temperatures up to $800^{\circ} \mathrm{C}$ ). We assume that the ASME data are sufficiently corroborated not to require the definition of uncertainty factors. This might prove to be an overly optimistic assumption, especially considering the high temperatures that the cladding may reach, but based on our preliminary information, no uncertainty factor is defined pending further investigations.

- Heat Transfer Coefficient: This is a critical area, and the definition of appropriate correlations for heat transfer on the rod surface is essential. Given the definition of the cladding temperature as the main thermal design parameter, a complete and detailed understanding of the heat transfer phenomena in supercritical water will be necessary. For the time being, and has discussed in Section 3.2.2, two correlations have been selected for preliminary analyses. These correlations have however been defined for flow inside a tube, and the effects of the bundle geometry, shape of the flow channels (due to the presence of the moderator boxes), cold wall factors, and mixing grids are unknown and have to be assessed. Since it is difficult to anticipate the effect of these different features lacking experimental data, a large uncertainty exists concerning the heat transfer coefficients. However, introducing a large uncertainty factor in the design would exceedingly penalize the project. Since it is expected that (a) better correlations will be available following experimental activities and (b) the above mentioned effects should lead to improvements in the heat transfer coefficient, in the following study no uncertainty will be considered for heat transfer correlations (thus assuming that the calculated heat transfer coefficient is overly conservative).

- Cladding Conductivity and Thickness: An uncertainty of $+/-5 \%$ on the cladding conductivity was assumed in the CRBRP. This factor is supposed to account both for the effect of uncertainties in property database and for the cladding thickness tolerances. This factor will be applied for the SCWR to the cladding conductivity for the purpose of calculating cladding midwall temperature and fuel temperature.

- Thermal Diffusion Coefficient: Thermal mixing between different channels is represented in several correlations and subchannel analysis code in terms of a Thermal Diffusion Coefficient. A conservative estimate of the TDC that will be used for this analysis is TDC $=0.038$.

Table 10 summarizes the hot channel factors that will be used for preliminary analysis on the SCWR using a direct treatment of the uncertainties. 
Table 10. Hot Channel Factors and Uncertainties for SCWR analysis using the Direct Method

\begin{tabular}{|c|c|c|}
\hline Hot Channel Factors and Uncertainties & Value & Application in a Direct Method \\
\hline \multicolumn{3}{|c|}{ Best Estimate Peaking Factors } \\
\hline Radial Power Peaking Factor & 1.25 & Applied to the hot channel heat flux \\
\hline Local Power Peaking Factor & 1.16 & Applied to the hot rod heat flux \\
\hline Axial Power Peaking Factor & 1.55 & Chopped cosine \\
\hline \multicolumn{3}{|c|}{ Plant Operating Parameter } \\
\hline Reactor Power Level & $2 \%$ & Power multiplied by $102 \%$ \\
\hline System Pressure & $200 \mathrm{KPa}$ & System pressure reduced by $200 \mathrm{Kpa}$ \\
\hline Core Inlet Temperature & $2.22 \mathrm{C}$ & Inlet Temperature increased by $2.2 \mathrm{C}$ \\
\hline Primary Coolant Flow Rate & $5 \%$ & Flow Rate reduced by $5 \%$ \\
\hline Core Bypass Flow & $6 \%$ & Flow Rate reduced by $6 \%$ \\
\hline Inlet Flow Maldistribution & $5 \%$ & Flow Rate in the hot assembly reduced by $5 \%$ \\
\hline \multicolumn{3}{|c|}{ Nuclear Hot Channel Factors } \\
\hline Engineering Enthalpy Rise Hot Channel Factor & $3 \%$ & Heat Flux in hot channel increased by $3 \%$ \\
\hline Physics Calculational Methods & $4 \%$ & Radial Peaking Factor increased by $4 \%$ \\
\hline \multicolumn{3}{|c|}{ Miscellaneous Coefficients } \\
\hline Subchannel Flow Area & $1.9 \%$ & Reduce flow area in the hot channel by $1.9 \%$ \\
\hline Coolant Properties uncertainty & --- & --- \\
\hline Heat Transfer Correlation uncertainty & --- & --- \\
\hline Cladding Conductivity and Thickness & $5 \%$ & Decrease Cladding Conductivity by $5 \%$ \\
\hline TDC & 0.038 & $\begin{array}{l}\text { Used } 0.038 \text { for correlations and subchannel analysis } \\
\text { codes }\end{array}$ \\
\hline
\end{tabular}

\subsection{Temperature And Densities Profiles In The Average And Hot Channels For Different System Configurations}

The procedure adopted in this study to analyze the SCWR thermathydraulic behavior has been divided into several steps of increasing detail and complexity, to be better able to understand the physical behavior of the SCWR system.

First, an analysis of the temperatures and density profiles in the average and hot channels for different possible system configurations was completed. Important parameters for this analysis are the core inlet and outlet temperatures and the option of canned assemblies versus an open lattice. The results are not influenced by the specific channel geometry (rod diameter, pitch, and moderation ratios) or by heat transfer correlations. The aim of this first phase is to analyze some characteristic of the system, highlight potential areas of concerns regarding the feasibility of the system and to provide density profiles to the neutronic design group. 
To develop this analyses a simplified code (SCWAT, SuperCritical Water Analysis Tool) has been developed. This code will be used for further preliminary analysis on the SCWR and will be expanded in future investigations. At this stage of the investigation only a simplified core analysis module (hot + nominal, average channel) and a correlation testing module (used for the analyses of section 1.4) have been developed. The hot channel has been simply calculated by applying to the average best estimate channel (calculated using nominal value for all parameters and considering no allowance for uncertainties) the hot channel factors discussed in the previous section in a direct way. (Note that the simplified code used is not a subchannel analysis code, and therefore gives no allowance for crossflow between channels.) The average channel calculations provide a sufficient database of information for our preliminary neutronic tasks, while the hot channel analyses were required to better understand the physical feasibility of the proposed design points. Please note that, as above mentioned, the average channel conditions are calculated with best estimate design values, neglecting uncertainties, and thus the term 'average channel' is used with a meaning different from the one often used in core design where it represents the average values for the fuel bundle studied, considering the uncertainty factors AND the hot channel factors in the correct way through a subchannel analysis code.

Since the aim of this activity was simply the evaluation of the temperature, enthalpy, and density profiles in the core, no further data are needed except for the hot channel factors, the system pressure, and the core inlet and outlet temperatures. As discussed in Section 3.1, two different main cases have been studied. Based on the results of the analysis, other options were then considered for each case.

\begin{tabular}{|l|l|l|}
\hline & CASE \#1 & \multicolumn{1}{c|}{ CASE \#2 } \\
\hline Core Outlet Temperature & $510^{\circ} \mathrm{C}$ & $510^{\circ} \mathrm{C}$ \\
\hline Core Inlet Temperature & $280^{\circ} \mathrm{C}$ & $450^{\circ} \mathrm{C}$ \\
\hline Core Inlet Pressure & $25 \mathrm{MPa}$ & $25 \mathrm{MPa}$ \\
\hline $\begin{array}{l}\text { Radial Power Profile Peaking Factor } \\
\text { (Hot Rod) }\end{array}$ & $1.45\left(1.25^{*} 1.16\right)$ & $1.45\left(1.25^{*} 1.16\right)$ \\
\hline Axial Power Profile & $\begin{array}{l}\text { Chopped Cosine, } \\
\text { Peaking factor } 1.55\end{array}$ & $\begin{array}{l}\text { Chopped Cosine, } \\
\text { Peaking factor } 1.55\end{array}$ \\
\hline
\end{tabular}

\subsubsection{Case \#1 Direct/Indirect Cycle, Thermal Core, Inlet Core Temperature $280^{\circ} \mathrm{C}$}

The first case to be considered is a direct/indirect cycle with a core inlet temperature of $280^{\circ} \mathrm{C}$ and a core outlet temperature of $510^{\circ} \mathrm{C}$. This set of parameters is analogous to the Japanese/European reference design points and is the obvious choice for a direct cycle with no recirculation loops.

The main concern of this solution (from a core thermat hydraulic design point of view) is the huge enthalpy rise in the core. Figure 45 shows the enthalpy rise along the core for an advanced PWR (AP1000), the ABWR and this configuration. As is evident from Figure 45, the proposed

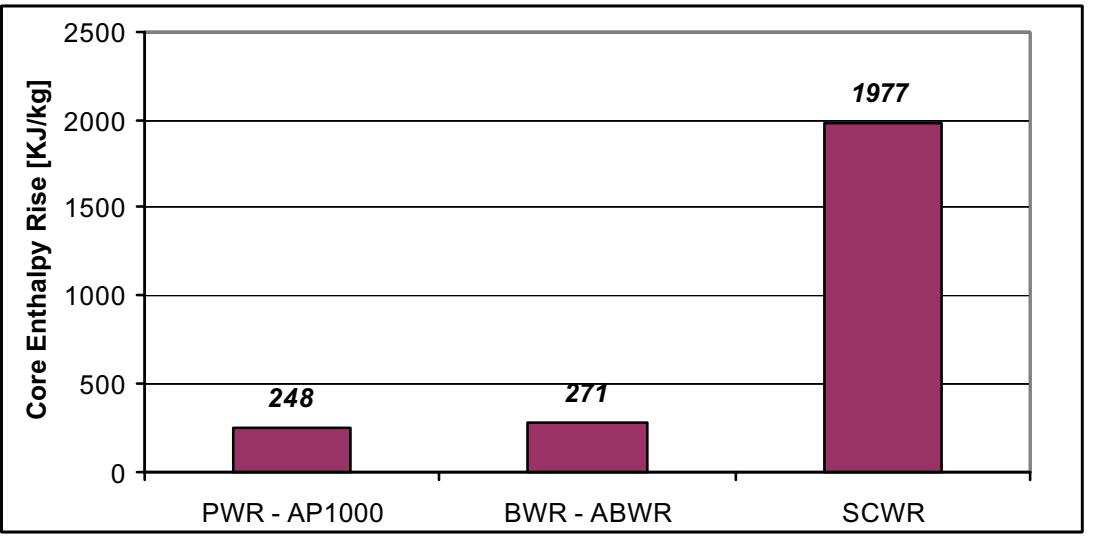

Figure 45. Core enthalpy rise for different reactor concepts. 
configuration for the SCWR has an enthalpy rise that is an order of magnitude larger than PWR/BWR systems. This peculiarity will present significant concerns both from the point of view of thermat hydraulic design and from the point of view of system operation and control.

Two different cases (open lattice and canned assemblies) have been considered, and the results (temperature and density profiles along the channel) are given in Figures 46 to 50 . It must be stressed that for the case of canned assemblies a perfect flow distribution (i.e. the flow into each assembly exactly matches the radial peaking factor so that all channels behave like the average channel) has been assumed. Only the mat distribution uncertainty has been accounted for the hot channel. This is an extremely optimistic assumption, since it is equivalent to assuming no power shifts in the radial profile during the life of the plant. This case is however interesting as it allows us to evaluate the effect of the hot channel factors in the system when the radial peaking factors are eliminated.

Based on these results some considerations may be drawn:

\section{- Thermal Hydraulic Core} Design. As Figure 48 shows, even for the case with canned assemblies and ideal orificing, the hot channel factors are sufficient to give a difference of more than

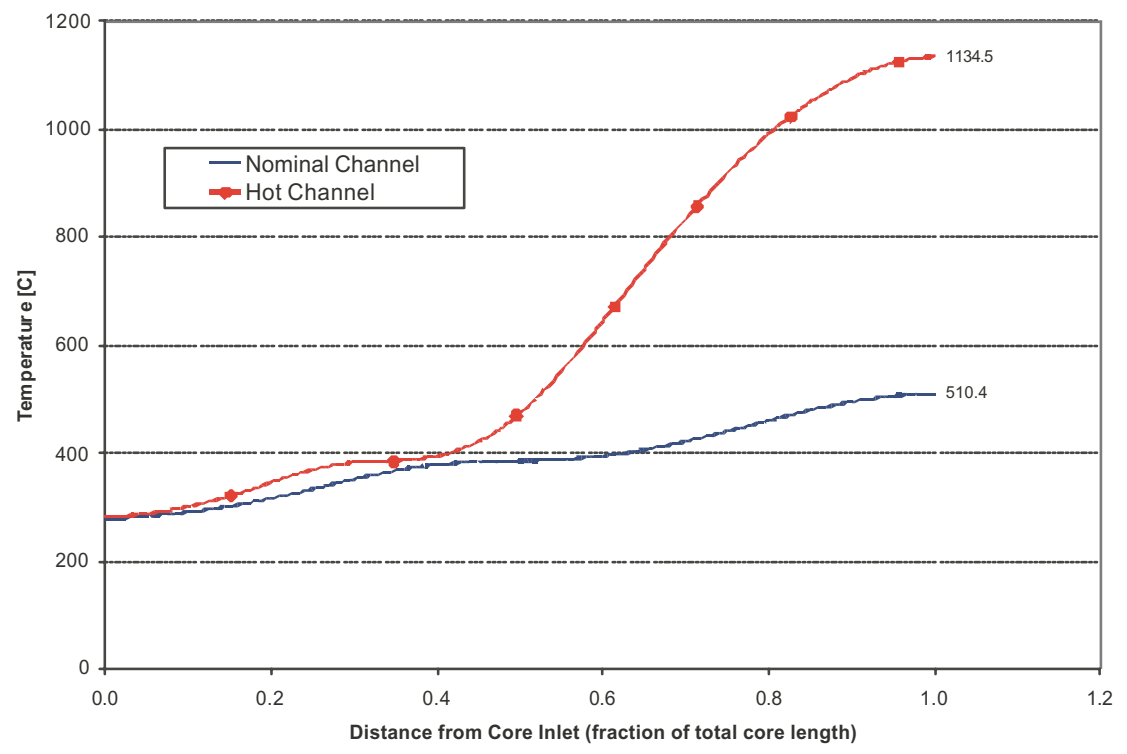

Figure 46. Temperature profiles in the average and hot channel for different radial power peaking factors. (Open lattice)

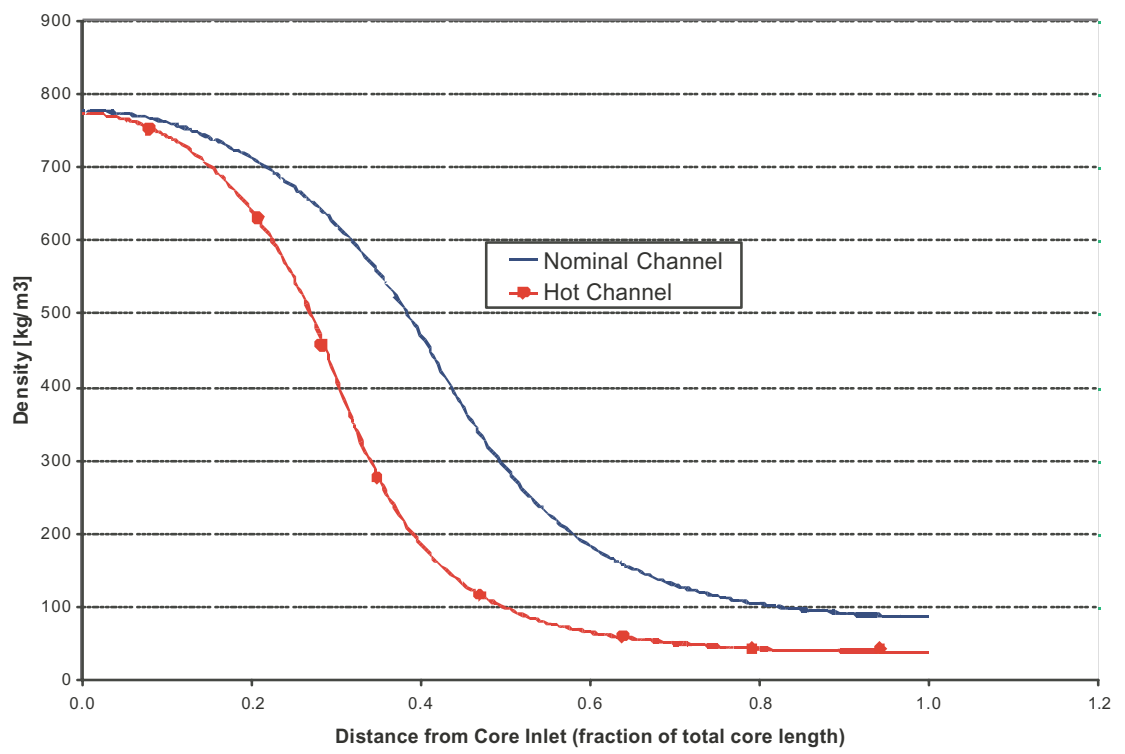

Figure 47. Coolant density in the average and hot channel, no water $\mathrm{rod} / \mathrm{tube}$ assumed. (Open lattice) $190^{\circ} \mathrm{C}$ between the nominal and hot channel. This huge difference is due to the enthalpy rise in the core: given the fact that all perturbations affect the enthalpy rise in the channel, even small hot channel factors lead to huge difference in enthalpy and therefore in temperature, given the relatively low $\mathrm{Cp}$ at the high core outlet temperatures. This effect is clearly shown in Figure 50: the enthalpy rise in the nominal channel is $1974 \mathrm{KJ} / \mathrm{kg}$, while the enthalpy rise for the hot channel is $2553 \mathrm{KJ} / \mathrm{kg}$. The effect of the 
hot channel factors is therefore to increase the enthalpy rise by $30 \%$. For other nuclear systems (like both PWRs and LMFBRs) this would roughly translate in an equivalent effect on the temperature rise, but for the SCWR, due to the transition through the pseudo-critical region, there is no linear relationship between temperature and enthalpy and the hot channel factor effects on the temperature are significantly larger: the temperature rise in the nominal channel is $230^{\circ} \mathrm{C}$, while the same temperature rise in the hot channel becomes $420^{\circ} \mathrm{C}$, with an increase in the temperature rise of more than $83 \%$. And, this increase assumes an ideal orificing that exactly matches the radial peaking factor at all times during the lifetime.

Since the design criteria discussed before must be verified for both the average channel and hot channel, an effective core thermathydraulic design will require significant reductions in core outlet temperatures. The case of an open lattice shows an unacceptable core outlet temperature

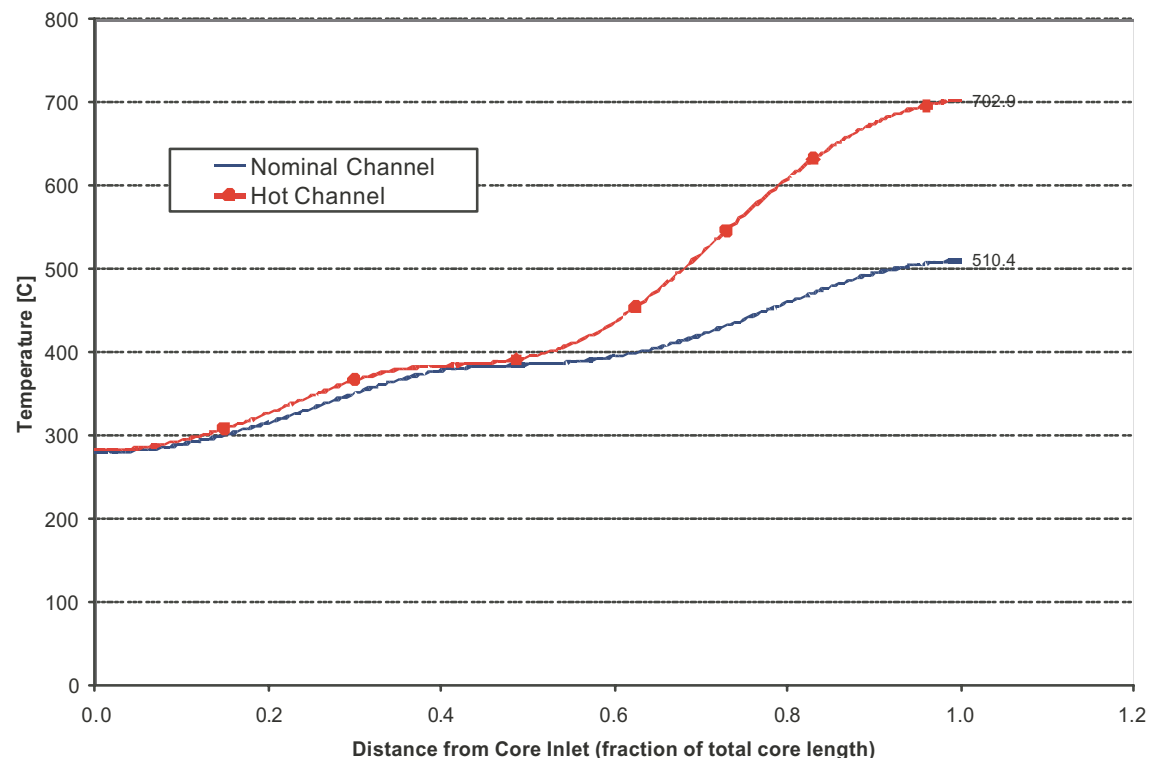

Figure 48. Temperature profiles in the average and hot channel for different radial power peaking factors. (Canned assemblies)

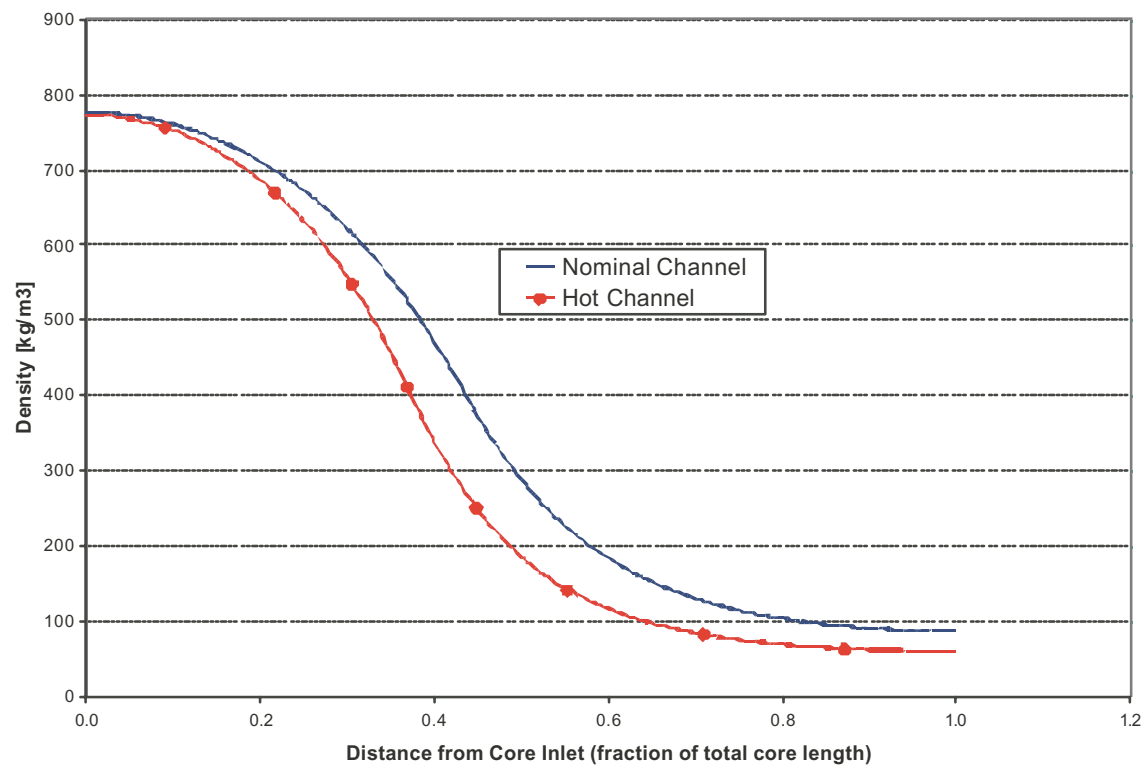

Figure 49. Coolant density in the ave rage and hot channel, no water rod/tube assumed. (Canned assemblies)

(Figure 46) in the hot channel for any value of the radial power profile: in any case the outlet temperature is above the design criterion for the cladding material (Criterion No.1 in Section 3.1.2). Even the canned assembly case (Figure 48) gives an unacceptable core outlet temperature above the cladding limit temperature. Given these results, the feasibility of an open lattice core is extremely doubtful, and even if a canned assembly's design is adopted, a significant reduction in core outlet temperature will be required, unless significantly lower hot channel coefficients are considered. Also, given the large effect of the hot channel factors, a statistical treatment of these uncertainty 
coefficients is recommend, even though it will be significantly more time-consuming than the conservative treatment of the uncertainties used in this study.

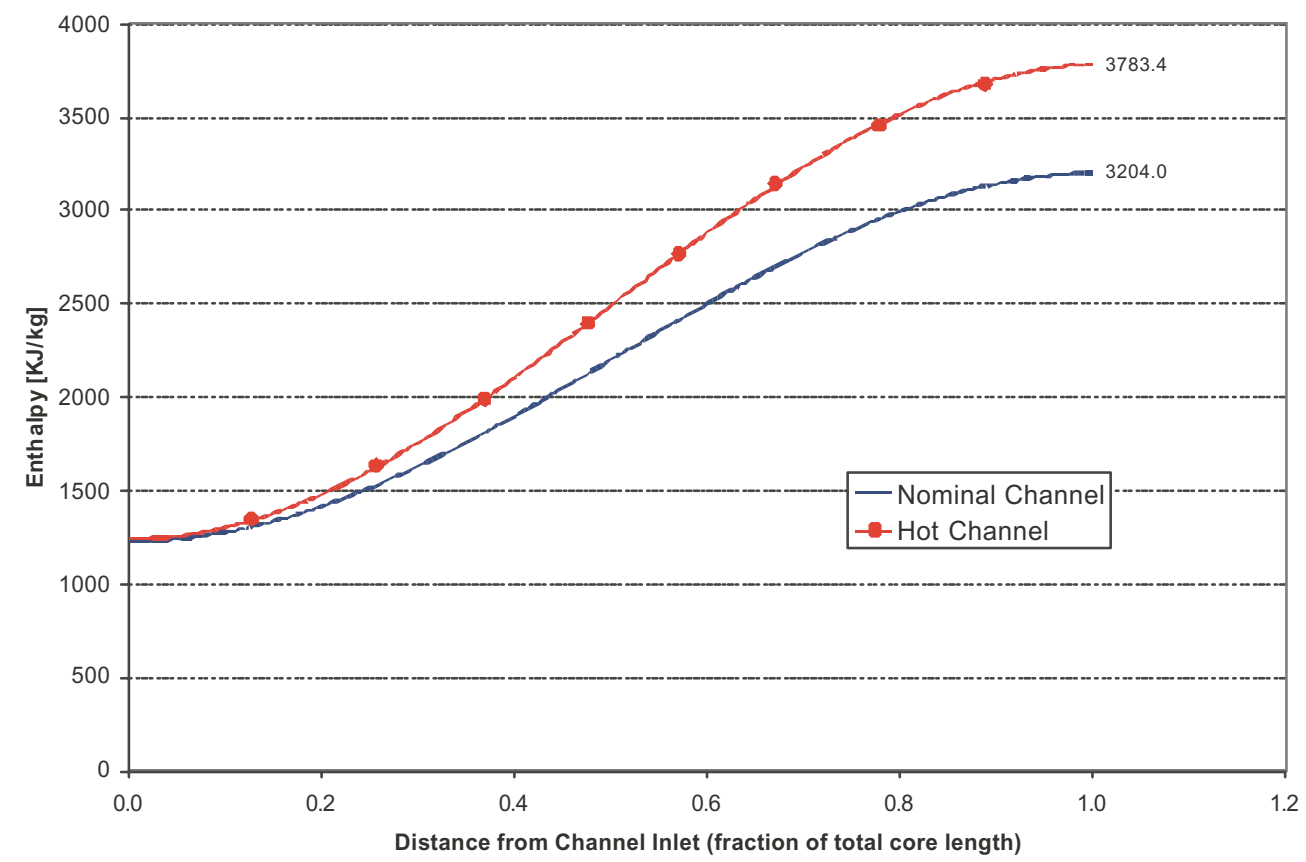

Figure 50. Coolant enthalpy in the average and hot channel, no water rod/tube assumed. (Canned assemblies)

- System Control A large reduction in core outlet temperature will not by itself solve the issue of the large enthalpy rise: for a temperature reduction from $510^{\circ} \mathrm{C}$ to $450^{\circ} \mathrm{C}$ the enthalpy rise will change only from 1974 to $1720 \mathrm{KJ} / \mathrm{kg}$. This enthalpy rise will make the control and operation of the system problematic at best. For example, for a change in flow rate of $5 \%$ the core outlet temperature will rise by $20-30^{\circ} \mathrm{C}$. For an analogous change in a PWR flow rate, the exit temperature will change only by $1^{\circ} \mathrm{C}$. This will significantly reduce the area of admissible core operation, require extremely rapid controls, and lead to increased trip frequencies.

Note also that a strong point in support of the SCWR/Direct Cycle has been that "It greatly simplifies the BWR RPV by eliminating recirculation pumps, steam separators and driers". Actually, the same results could be obtained by designing a BWR for a once through cycle with superheated steam. However, this is prevented by CHF (dryout) concerns that would require very low power densities, but it must also be considered that the BWR recirculating loop is a very important safety feature of the BWR system. Since only a limited part of the core flow rate (for the ABWR around 14-15\%) is actually send to the turbine, a large water inventory is maintained in the recirculation loop of the BWR, and therefore even following a Loss of Feedwater, a large water inventory is available to remove decay heat.

No such possibility is available for the once-through SCWR system: on a loss of feedwater, no coolant will be available to the core to remove decay heat. Feedwater will thus have to be maintained through the system, and the injection system will have to be much faster than in BWRs (and at a much higher pressure). This will make the design of a passive direct cycle SCWR problematic, and this will be discussed further in the design relative tasks. As will be discussed further in more appropriate documents, it is doubtful that the elimination of the BWR recirculation system and the adoption of a once-through system will overall be a strong advantage of the SCWR in direct cycle. Quite naturally, this concern and 
the huge enthalpy rise in the core are strictly connected and are both due to the adoption of a oncethrough direct cycle.

This safety concern coupled with the previously discussed issues (controllability, average to hot channel differences) connected to the huge enthalpy rise in the core, are very serious issues to be considered before the feasibility of a once-through system can be demonstrated. In conclusion, the proposed reference temperatures do not allow for a feasible core design. The following options can be considered:

Option 1: maintain an open lattice. An open lattice will require a large reduction in the peak temperature. Also, a subchannel analysis code will have to be developed to study the effective temperature/density profiles in the lattice to verify the beneficial effects of cross flow. Even with a significant reduction in average outlet temperature, the large differences between the hot and average channel will create significant concerns regarding the possibility of designing a core with these conditions. Control and Operation will be extremely complex as previously discussed. The feasibility of this solution is extremely doubtful.

Option 2: adopt canned assemblies. Canned assemblies will allow the adoption of higher temperatures, differences between hot and average channel will be smaller, development of subchannel analysis code can be postponed. However, the core enthalpy rise will still be very large, thus leading to the same control issues. Moreover, the possibility of designing for a perfect orificing will have to be assessed based on the radial peaking factor evolution during the fuel cycle. Moreover, the very large difference in density between core inlet and outlet (a factor of 2-3 larger than in BWR) will lead to significant parallel channel instability issues that will have to be addressed. Even in this case, the average core outlet temperature will have to be significantly reduced to be compatible with the cladding temperature criterion: a SCWR with a core outlet temperature of $510^{\circ} \mathrm{C}$ does not look feasible with the given requirements for the cladding temperature, and a reduction at least to $450^{\circ} \mathrm{C}$ is suggested. A statistical treatment of the uncertainties should be adopted as soon as possible, given the large effect of the hot channel factors on the design of the system. The penalty for the SCWR associated with the use of conservative, direct methods is larger than compared to PWRs, and therefore a statistical method should be used for all further investigations.

One important thing is however to be considered: all the preceding analyses assumed a more or less complete lack of thermathydraulic and neutronic design interaction. While this is a good assumption for PWRs, the same is not true for the SCWR: given the large changes in enthalpy above the critical temperature, and the effect that the changes in density will have on the design, it will be necessary to develop any further analyses by coupling the neutronic and thermathydraulic design. This will naturally not solve any problems connected to the large core enthalpy rise, but should at least help achieve a more flat radial power distribution and strong damping factors for any hot-channel factor. However, the neutronic-thermal hydraulic coupling is limited by the adoption of a solid moderator (the same effect would be obtained with water rods) that tends to limit the effect of the lower densities at high temperature, by providing for an always available source of moderating atoms.

\subsubsection{Case \#2 Indirect Cycle and Inlet Core Temperature of $450^{\circ} \mathrm{C}$}

In an indirect cycle approach, the selection of the core inlet temperature is more open. This may allow for a reduction in the core enthalpy rise and thus the issues discussed in the previous section. In particular, two different scenarios can be anticipated: 
Thermal Core: Increasing the core inlet temperature moves the large density shift associated with the transition around the pseudo-critical temperature even nearer to the core inlet than in the cases discussed above. This will have the positive effect of making the density more uniform along the channel, but on the other way will require an even more important introduction of some sort of moderating material (either in the form of solid moderator rods, or with a water tube solution). Our study of this solution will be postponed until a neutronic study has been performed and some preliminary feasibility issues have been addressed.

Fast Core : On the other hand, operating the system in indirect cycle completely in the supercritical region should make the adoption of a fast spectrum solution more easily achievable without requiring very small pitch to diameter ratios in the core. This solution will also result in a very small core enthalpy rise. Issues connected to this solution are:

1. Given the very low densities, operating at low enthalpies rise will require very high flow velocities. For example, operating with the same enthalpy rise as in a PWR will require the velocities in the SCWR core to be about 8 times larger than in PWRs.

2. A system like the proposed one will have a very low water inventory in the primary system, thus creating safety concerns that are more similar to the ones for a high pressure gas reactor than for a LWR.

3. Since the system will be very similar to a gas reactor, the natural question becomes "why would a SCWR design with its very high pressures and corrosive coolant be more interesting than a gas reactor?" The answer is not clear, and it looks that this solution holds little interest compared to a gas cooled reactor design.

All in all, this solution has significant feasibility (high velocities, cost) and safety (extremely low inventory, very high pressure) issues. Even if these can be solved, the prospects for competitive power generation with this solution look dim (comparison with a gas reactor).

Figures 51 and 52 show the temperature and density profiles for this solution in an open lattice (no or ificing). The discontinuities in the temperature and density profiles are due to the steam table implemented in the code: only properties for discrete values of the pressure $(22,23,25$, and 26 $\mathrm{MPa})$ have been generated. Therefore, there is a significant change in properties at the transition between the different pressure "regions" that impact the numerical solution. Given the limited interest for this high temperature, high velocity solution no effort has been devoted at this time to

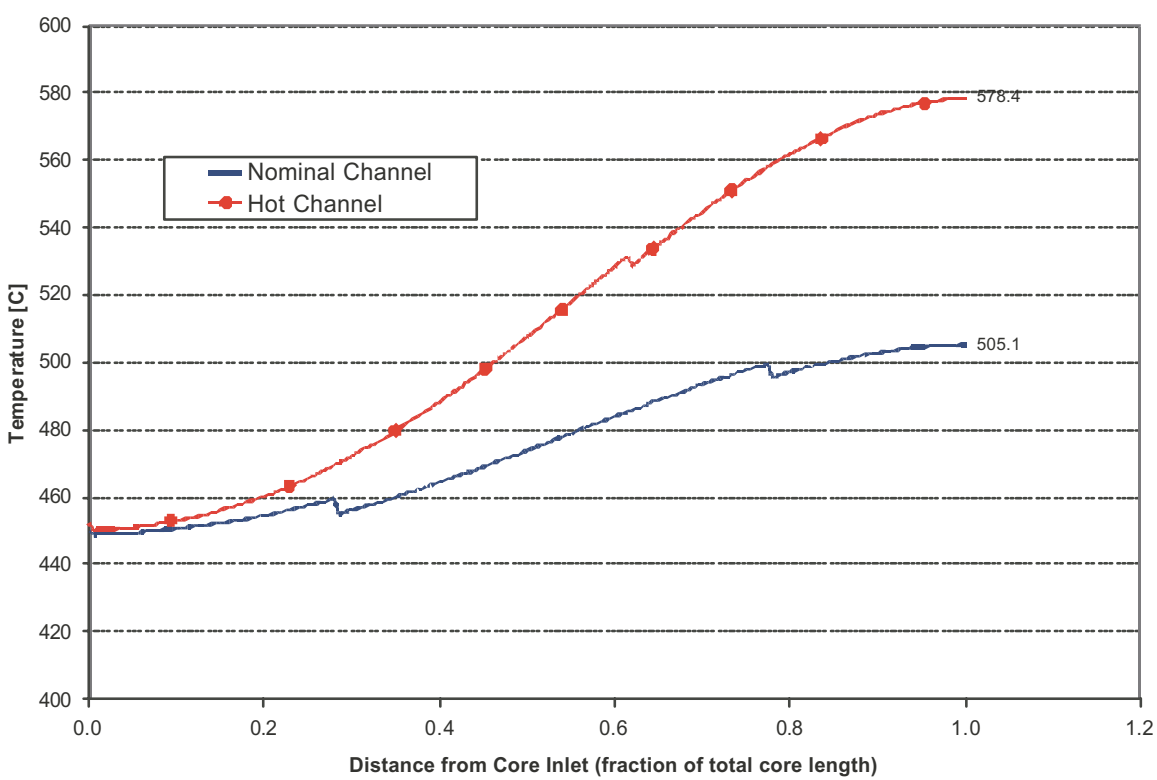

Figure 51. Temperature profiles in the average and hot channel for different radial power peaking factors, with no water rod/tube for moderation, an open lattice and a core inlet temperature of $450^{\circ} \mathrm{C}$. 
develop a more complete steam table for the SCWAT code.

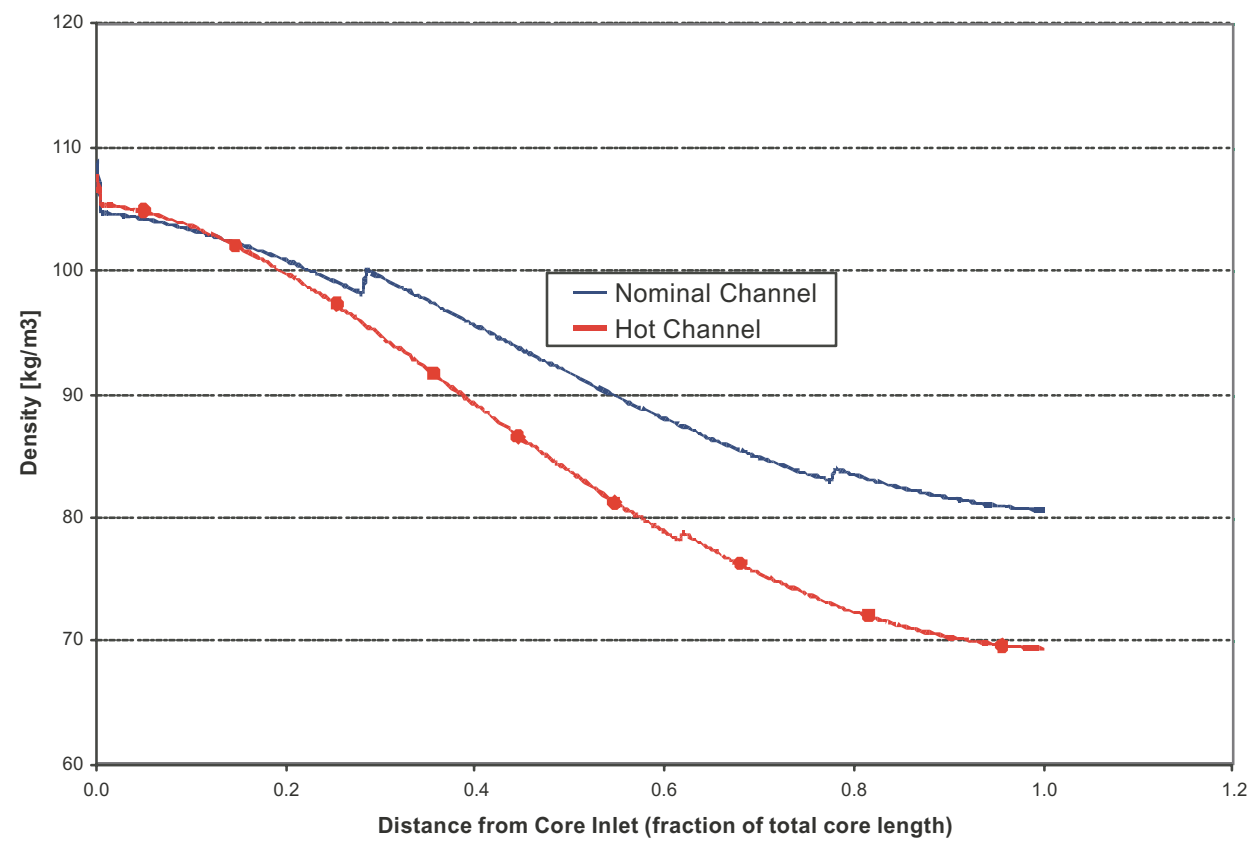

Figure 52. Coolant Density in the average and hot channel with no water rod/tube for moderation, an open lattice, and a core inlet temperature of $450^{\circ} \mathrm{C}$.

\subsection{RELAP5 Code Improvements for Supercritical Applications (INEEL)}

The RELAP5-3D (INEEL 2002) computer program is being improved for analysis of supercritical light water reactors. Our first quarterly (MacDonald et al. 2002) described modifications that allowed the code to simulate slow transients for a wide range of supercritical conditions. Blowdown transients have now been simulated and are described below.

A series of 85 blowdown calculations were performed based on the geometry of the Edwards pipe experiment (Edwards and O'Brien 1970). This experiment simulated a pipe pressurized with water that was blown down to the atmosphere through a large, fast-opening hole in one end of the pipe. Although the experiment was performed at subcritical conditions, the initial pressure was changed to $25 \mathrm{MPa}$ for this evaluation. The initial temperature varied from $500 \mathrm{~K}$ to $800 \mathrm{~K}$. Eight of these 85 problems encountered water property failures and did not run to completion with the existing code. The failures generally occurred near the pseudo-critical temperature point.

Several code updates were implemented to correct the code execution failures. One change was to modify the interfacial heat transfer coefficient for vapor near the critical point. Changes were also made to the extrapolations for metastable states near the critical point. Modifications were also made to the transport properties of thermal conductivity and viscosity to eliminate discontinuities as the temperature changed from supercritical to subcritical. The modified transport properties were based on the $4^{\text {th }}$ edition of the 1967 ASME steam tables (Meyer et al. 1979). The combined code modifications now allow all 85 modified Edwards pipe blowdown calculations to run to completion. Figures 53 and 54 show the pressure and break mass flow rate for the case with initial conditions of $25 \mathrm{MPa}$ and $647 \mathrm{~K}$. 
An existing pressurized water reactor model, known as typpwr from the RELAP53D assessment library (Carlson et al. 1990), was modified so that the initial conditions were supercritical on the primary side of the reactor. The modified model had an initial pressure of $25 \mathrm{MPa}$ and initial temperatures ranging from $583 \mathrm{~K}$ to $704 \mathrm{~K}$ on the primary side. The modified model was run successfully using the modified code through a loss-of-coolant accident (LOCA) initiated by a small break. Figures 55 and 56 show the primary system pressure and break mass flow rate for this small-break LOCA calculation.

The modified code can now represent transients that pass near the critical point. Although the code ran successfully near the critical point, at times it ran slowly. This problem is currently being investigated.

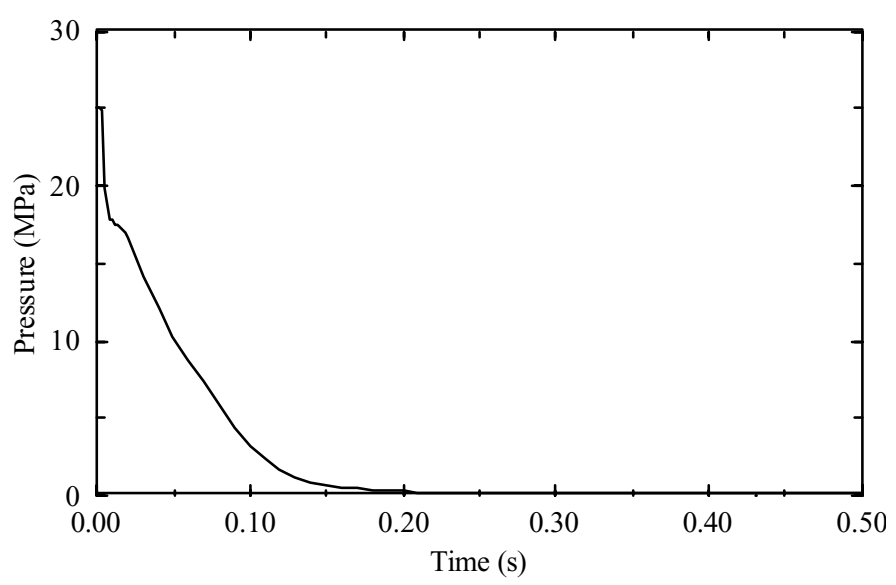

Figure 53. Pressure during a blowdown of Edwards pipe.

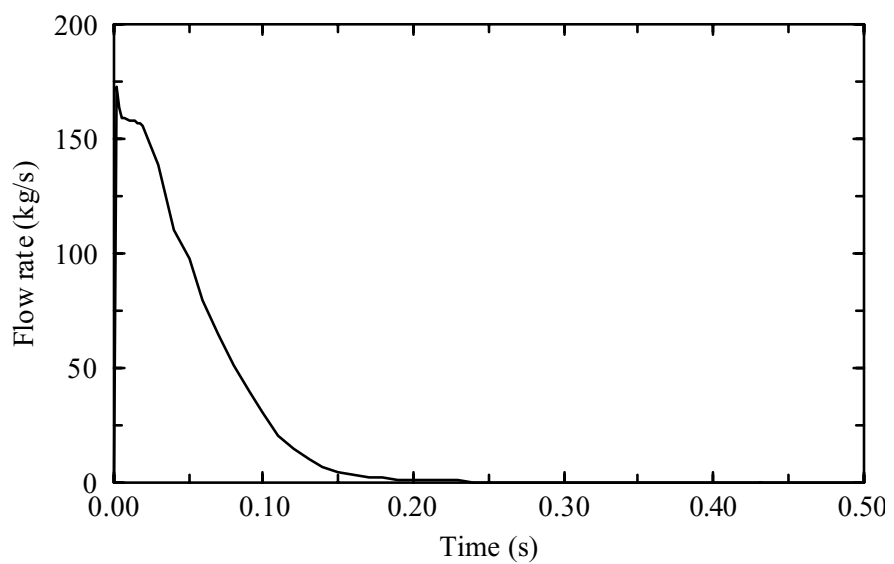

Figure 54. Break flow rate during a blowdown of Edwards pipe.

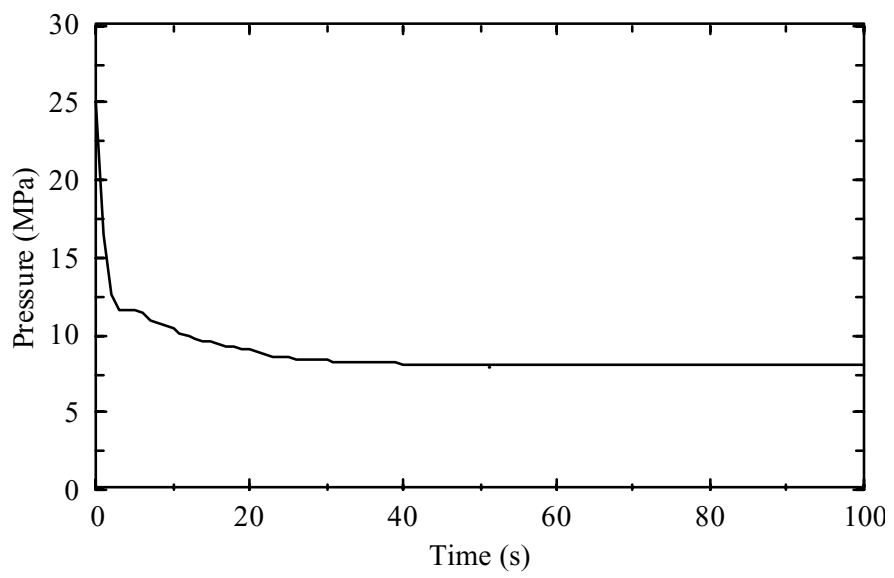

Figure 55. Primary system pressure during a smallbreak LOCA. 


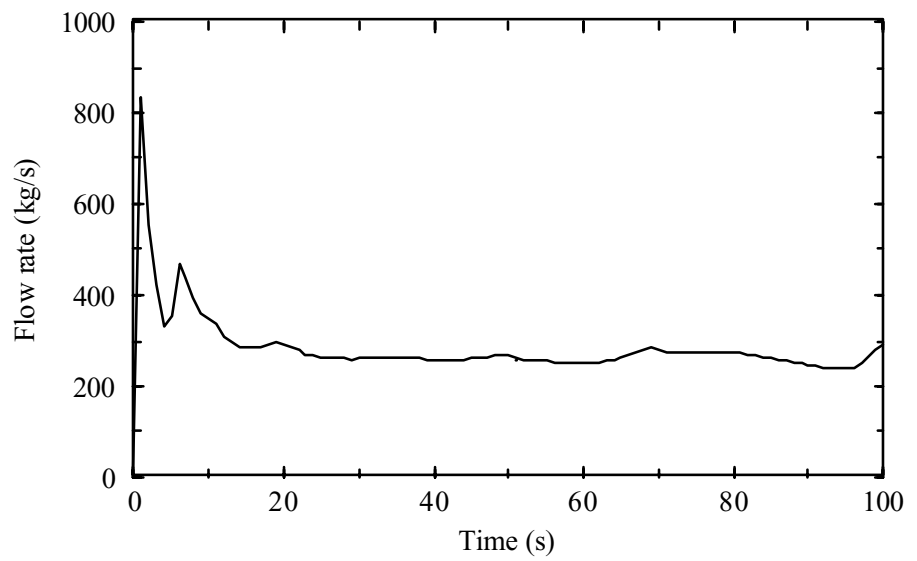

Figure 56. Break flow rate during a small-break LOCA. 


\section{References}

- Allegheny Technologies, private communication, July 2002.

- Allvac, "Alloy 718 Technica http://www.allvac.com/pages/Nickel/UNSN07718.htm, 2002.

- ANSI, American National Standard Institute N18.2, "Nuclear Safety Criteria for the Design of Stationary PWR Plants," 1973

- Apley, W. J., Tritium Target Development Project Executive Summary Topical Report, PNL8142, September 1992

- ASM International, Metals Handbook, Vol.1, 1990.

- ASME, "ASME Boiler and Pressure Vessel Code," Sec III, Div. 1, Subsec. NB, Class 1 Components, 1974 ed., American Society of Mechanical Engineers (July 1974a).

- ASME Code Case 1592, "ASME Boiler and Pressure Vessel Code," Sec. III, American Society of Mechanical Engineers (1974b).

- Beaumont, M.D., et al., "Properties of Fuel and Core Component Material," WCAP-9224 (Nonproprietary), July 1978.

- Beck, R. L., W. M. Mueller, "Zirconium Hydrides and Hafnium Hydrides", in Metal Hydrides, Academic Press, pp.241-335, 1968.

- Bishop, A.A., R.O. Sandberg, L.S. Tong, "Forced Convection Heat Transfer to Water near Critical Temperature and Supercritical pressures", WCAP-2056-P, Part-III-B, February 1964

- Blackledge, J. P., "Chemistry of Metal Hydrides as Related to Their Applications in Nuclear Techonlogy", in Metal Hydrides, Academic Press, pp.119-164, 1968.

- Carelli, M. D., and Bach, C. W., (1979), "Predicted Steady State ThermatHydraulic Performance of the Fuel and Blanket Assemblies in the CRBRP Heterogeneous Core," Clinch River Breeder Reactor Plant Report, WARD-D-0210, Westinghouse Electric Corporation

- Carelli, M. D., and Spencer, D. R., (1976), "CRBRP Assemblies Hot Channel Factors Preliminary Analysis," Clinch River Breeder Reactor Plant Report, WARD-D-0050, Westinghouse Electric Corporation

- Carelli, M. D., and Rosenthal, P. W., Rymer, W. R., (1985), "Final Predicted Steady State ThermalHydraulic Performance of the CRBR Fuel and Blanket Assemblies," Clinch River Breeder Reactor Plant Report, WARD-D-0324, Westinghouse Electric Corporation

- Carlson, K. E., R. A. Riemke, S. Z. Rouhani, R. W. Shumway, W. L. Weaver, 1990, "RELAP5/MOD3 Code Manual Volume III: Developmental Assessment Problems," NUREG/CR-5535, EGG-2596 (Draft), Volume III, June.

- Cheng, X., T. Schulenberg, “ Heat Transfer at Supercritical Pressures - Literature Review and Application to an HPLWR", FZKA-6609, Forschungszentrum Karlsruhe, 2001

- Cheng, X., et al., "ThermatHydraulics of a Supercritical Pressure Light Water Reactor," IKET, 2002.

- Cheng, X., et al., "ThermatHydraulic Analysis of Supercritical Light Water Reactors", Proceedings of the International Congress on Advanced Nuclear Power Plants (ICAPP), Hollywood, Florida, June 9-13, 2002.

- Cheng, X., T.Schulenberg, "Design Analysis of Core Assemblies for Supercritical Steam Conditions," Forschungszentrum Karlsruhe, 2002

- Chelemer, H., L.H. Boman, D.R. Sharp, “Improved Thermal Design Procedure”, WCAP-8568, nonproprietary, July 1975

- Dobashi, K., Y. Oka, S. Koshizuka, "Core and Plant Design of the Power Reactor Cooled and Moderated by Supercritical Light Water”, 2000. 
- Dobashi, K., Y. Oka, S. Koshizuka, “Conceptual Design of a High Temperature Power Reactor Cooled and Moderated by Supercritical Light Water", ICONE-6, May 10-15, 1998.

- Dynamic Metal Forming, private communication, July 2002.

- Edwards, A. R. and T. P. O'Brien, 1970, "Studies of Phenomena Connected with the Depressurization of Water Reactors," Journal of the British Nuclear Energy Society, 9, pp. 125135.

- EG\&G Mound Applied Technologies, Guide to Good Practices at DOE Tritium Facilities, October 1989.

- Elliott, R. P., Constitution of Binary Alloys, First Supplement, pp.679-681, McGraw-Hill, 1965.

- Friedland, A.J., S. Ray, "Revised Thermal Design Procedure," WCAP-11397-A, nonproprietary, April 1989

- Friedland, A. J., (1980), "CRBRP Core Assemblies Hot Channel Factors Preliminary Analysis," CRBRP-ARD-0050, U.S. Department of Energy, Technical Information Center

- Graham, J, L.E. Strawbridge, P. Bradbury, "Safety of the Clinch River Plant", Nuclear Engineering International, 19, 221, 854 (1974)

- Gross, S., "The Problem of Hydrogen Embrittlement in Nickel Hydorgen Cells", Proceedings of the $25^{\text {th }}$ Intersociety Energy Conversion Engineering, IECEC-90, Vol.3, pp.33-38, Reno, Nevada, August 12-17, 1990.

- Hattori, T., H. Anada, K. Abe, and M. Harada, "Study of Fuel Cladding Materials for SupercriticalPressure, Light-Water-Cooled Reactor", Proceedings of the $1^{\text {st }}$ International Symposium on Supercritical Water-Cooled Reactors Design and Technology, The University of Tokyo, November 6-9, 2000.

- Harvey, A.H., et al., "NIST/ASME Steam Properties", NIST Standard Reference Database 10 Version 2.11, 1996

- He, J., et al., "Effect of Hydrogen on Deformation of Inconel 718", Materials Transactions, JIM, Vol.35, No.10, pp.689-694, 1994.

- Huang, J., et al., "Estimation of Hydrogen Redistribution in Zirconium Hydride under Temperature Gradient", Journal of Nuclear Science and Technology, Vol.37, No.10, pp.887-892, 2000.

- Huffine, C. L., "Fabrication of Hydrides", in Metal Hydrides, Academic Press, pp.675-747, 1968.

- Ishiwatari, Y., et al., "Safety Analysis of a High Temperature Supercritical Pressure Light Water Cooled and Moderated Reactor", Proceedings of the International Congress on Advanced Nuclear Power Plants (ICAPP), Hollywood, Florida, June 9-13, 2002.

- INEEL, 2002, “RELAP5-3D Code Manual”, INEEL-EXT-98-00834, Revision 2.0, July.

- Kondo T., Y. Watanabe, Y. S. Yi, and A. Hishinuma, "An Evaluation of Potential Material Coolant Compatibility for Applications in Advanced Fusion Reactors", J. of Nuc. Mat., p. 2083 (1998).

- Koshizuka, S., Y. Oka, "Computational Analysis of Deterioration Phenomena and Thermat Hydraulic Design of SCR", Proceedings of the It International Symposium on Supercritical Water-Cooled Reactors Design and Technology, The University of Tokyo, November 6-9, 2000.

- Lanning, D. D., D. L. Baldwin, and R. J. Guenther, Final Report on the WC-1 Light-Water Reactor Target Rod Irrradiation Test and Postirradiation Examinations, PNL-8133, Vol. 1, August, 1992.

- Lenhart, S., et al., "Hydrogen Environment Embrittlement of Inconel Alloy 718 Pressure Vessels in $\mathrm{Ni} / \mathrm{H}_{2}$ Cells", Proceedings of the $27^{\text {th }}$ Intersociety Energy Conversion Engineering, IECEC-92, Vol.1, pp.233-237, San Diego, August 3-7, 1992.

- MacDonald, P., et al., 2002, "Feasibility Study of Supercritical Light Water Cooled Fast Reactors for Actinide Burning and Electric Power Production," Nuclear Energy Research Initiative Project 
2001-001, Progress Report for Year 1, Quarter 1 (September 01 - December 01), INEEL/EXT02-00107.

- MacDonald, P., et al., 'Feasibility Study of Supercritical Light Water Cooled Fast Reactors for Actinide Burning and Electric Power Production, Progress Report for Year 1, Quarter 2 (January through March 2002)", INEEL/EXT-02-00107, June 2002

- Marschman S. C., et al., Tritium Permeation Scoping Experiments, PNL-7843, October 1991.

- Meyer, C. A., R. G. McClintock, G. J. Silvestri, and R. C. Spencer, Jr., 1979, "1967 ASME Steam Tables - - Thermodynamic and Transport Properties of Steam", $4^{\text {th }}$ edition, New York: The American Society of Mechanical Engineers.

- Mueller, W. M., "Hydrides in Nucle ar Reactor Applications", in Metal Hydrides, Academic Press, pp.21-50, 1968a.

- Mueller, W. M., “Titanium Hydrides”, in Metal Hydrides, Academic Press, pp.336-383, 1968b.

- Mukohara, T., Y. Oka, S. Koshizuka, "Subchannel Analysis of Supercritical Water Cooled Reactors," SCR-2000, Nov. 6-8, 2000, Tokyo

- Mukohara, T., S. Koshizuka, Y. Oka, "Subchannel Analysis of Supercritical Water Cooled Reactors", Proceedings of SCR-2000, Nov 6-8, 2000, Tokyo, Japan

- Namba, T., et al., "Surface Processes of Hydrogen Transport in Fusion Reactor Materials", Journal of Nuclear Materials, Vol.128-129, pp.646-651, 1984.

- Oka, Y., S. Koshizuka, "Design Concept of Once-Through Cycle Supercritical-Pressure Light Water Cooled Reactors", Proceedings of the $I^{\text {st }}$ International Symposium on Supercritical WaterCooled Reactors Design and Technology, The University of Tokyo, November 6-9, 2000.

- Okano, Y., et al., "Design of Water Rod Cores of a Direct Cycle Supercritical-Pressure Light Water Reactor", Annuals of Nuclear Energy, Vol.21, No.10, pp.601-611, 1994.

- Olander, D. R., Fundamental Aspects of Nuclear Reactor Fuel Elements, Report TID-26711-P1, Technical Information Center, DOE, 1976.

- Paetz, P., K. Lucke, "Uber die Dichteanderung von Zirkonhydrid bei der Bestrahlung mit Schnellen Neutronen", Journal of Nuclear Materials, Vol.43, pp.13-27, 1972.

- Park, C. S., G. P. Sharp-Bette, Advanced Engineering Economics, p.48, John Wiley \& Sons, 1990.

- Pinchuk, P. G., et al., "Nature and Thermal Stability of Radiation-Induced Defects in Zirconium Hydride", Atomnaya Energiya, Vol.40, No.4, pp.289-292, 1976.

- Primakov, N. G., et al. "Nonuniform Swelling and Hydrogen Redistribution in Zirconium Hydride under Neutron Irradiation", International Journal of Hydrogen Energy, Vol.24, pp.805$811,1999$.

- Shcherbak, V. I., et al., "Radiation-induced Swelling of Zirconium Hydride", Atomnaya Energiya, Vol.71, No.2, pp.178-180, 1991.

- Siegel, B., G. G. Libowitz, "the Covalent Hydrides and Hydrides of the Groups V to VIII Transition Metals", in Metal Hydrides, Academic Press, pp.545-674, 1968.

- Simnad, M. T., "The U-ZrHx Alloy: Its Properties and Use in TRIGA Fuel", Nuclear Engineering and Design, Vol.64, pp.403-422, 1981.

- Tang, Y.S., R.D. Coffield, R.A. Markley, "Thermal Analysis of Liquid Metal Fast Breeder Reactors", American Nuclear Society, 1978.

- Todreas, N. E., M. S. Kazimi, Nuclear Systems I. Thermal Hydraulic Fundamentals, Chapter 8, Hemisphere Publishing Corporation, 1990.

- USERDA, "Guidelines and Procedures for Design of Nuclear Systems and Components at Elevated Temperatures," RDT Standard, RDT F9-5T, Reactor Development and Technology Division, U.S. Energy Research and Development Administration (1974a) 
- USERDA, "Supplementary Criteria and Requirements for RDT Reactor Plant Protection Systems," RDT Standard, RDT C-16-1T, Reactor Development and Technology Division, U.S. Energy Research and Development Administration (1974b)

- USERDA, "Requirements for Construction of Nuclear Components at Elevated Temperatures," RDT Standard, RDT F9-4T (Suppl. To ASME Code Cases 1592,1593,1594,1595,1596), Reactor Development and Technology Division, U.S. Energy Research and Development Administration (1976)

- USNRC, "Standard Review Plan for the Review of Safety Analysis Reports for Nuclear Power Plan,” NUREG-0800, U.S. Nuclear Regulatory Commission, February 2002 update to April 1996 version.

- USNRC, 10 CFR Part 50, Appendix A, General Design Criterion 10

- Van Houten, R., "Selected Engineering and Fabrication Aspects of Nuclear Metal Hydrides (Li, Ti, Zr and Y)", Nuclear Engineering and Design, Vol.31, pp.434-448, 1974.

- Viswanathan, R., W. T. Bakker, "Materials for Boilers in Ultra Supercritical Power Plants", Proceedings of the 2000 International Joint Power Generation Conference, Miami Beach, July 23-36, 2000.

- Wang, W., D.R. Olander, "Thermodynamics of the HZZr System", Journal of the American Ceramic Society, Vol.78(12), pp.3323-3328, 1995.

- Yamagata, K., et al., "Forced Convection Heat Transfer to supercritical water flowing in tubes", Int. Journal of Heat Mass Transfer, Vol. 15 (1972), pp2575-2593

- Yamanaka, S. et al., "Thermal and Mechanical Properties of Zirconium Hydride", Journal of Alloys and Compounds, Vol.293-295, pp.23-29, 1999.

- Yamanaka, S. et al., "Thermal Properties of Zirconium Hydride", Journal of Nuclear Materials, Vol.294, pp.94-98, 2001. 


\section{Project Schedule}

\begin{tabular}{lll}
\hline Task & Activity & Description \\
Task 1 & $\begin{array}{l}\text { Fuel-cycle Neutronic Analysis and Reactor Core Design } \\
\text { (INEEL) }\end{array}$ \\
& 1.1 & Reactivity Swing Analysis \\
1.2 & Actinide Discharge and Isotopic Evaluation \\
1.3 & Reactivity Coefficient Calculations \\
1.4 & Peaking Factors and Reactor Control
\end{tabular}

Task 2 Fuel Cladding and Structural Material Corrosion and Stress Corrosion Cracking Studies (University of Michigan, MIT)

2.1 Identification of Most Promising Materials (MIT)

2.2 Design and Construction of an Out-of-pile Supercritical Water Test Facility (U-Mich)

2.3 Corrosion and Stress Corrosion Cracking Behavior of Candidate Materials (U-Mich)

2.4 Radiation Stability of Candidate Alloys (U-Mich)

2.5 Modeling of Corrosion and stress Corrosion Cracking in Supercritical Water (U-Mich)

Task 3 Plant Engineering and Reactor Safety Analysis (Westinghouse and INEEL)

3.1 Conceptual Design of the Reactor Coolant System (Westinghouse)

3.2 Definition of the Thermal/Mechanical Design Limits

Core Thermal-hydraulic Design (Westinghous

3.4 Evaluation of Coupled Thermal-

3.5 Plant Configuration and Operation (Westinghouse)

3.6 Establish the Conceptual Design of Required Safety Systems and Define their Performance Parameters (Westinghouse)

3.7 Analysis of Anticipated Transients and Potential Accidents (INEEL)

3.8 Conceptual Layout of Reactor Containment, Fuel Handling, and Auxiliary Buildings (Westinghouse)

3.9 Economic Analysis (Westinghouse)

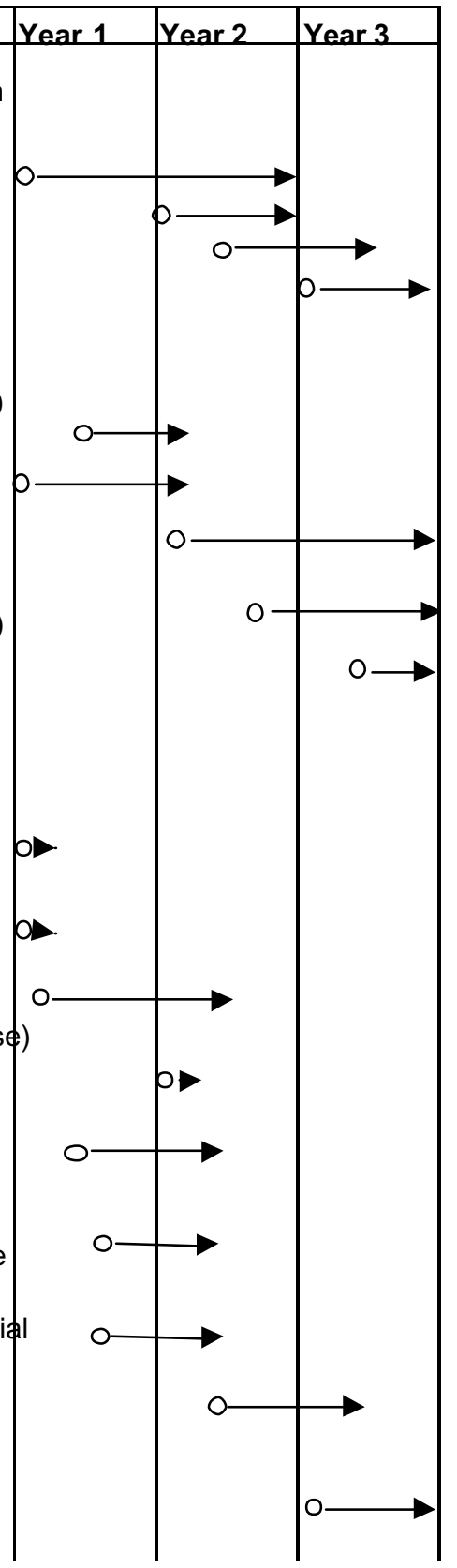




\section{INEEL}

\section{Budget and Actual Costs for Year 1}

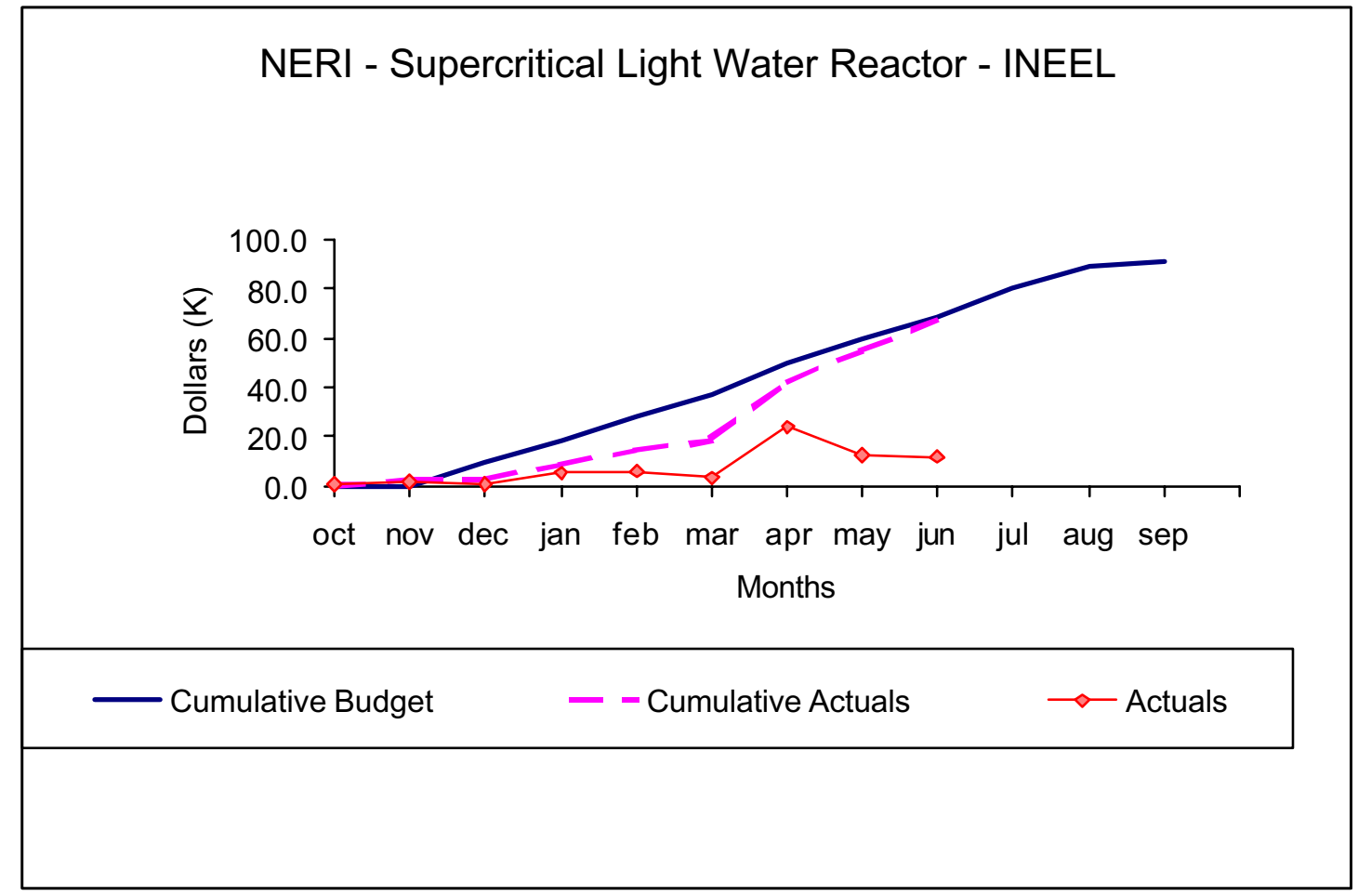

\section{MIT}

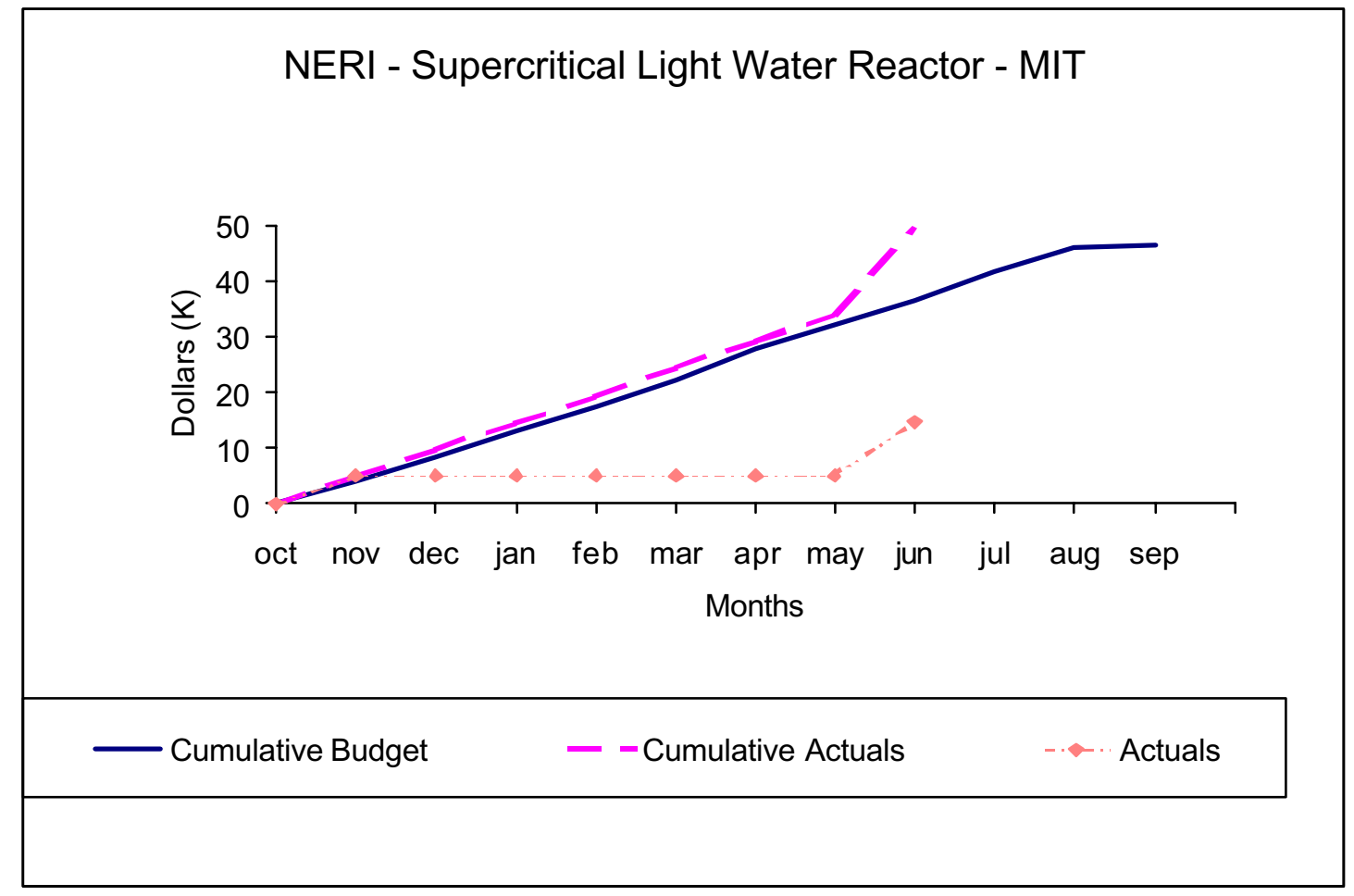




\section{University of Michigan}

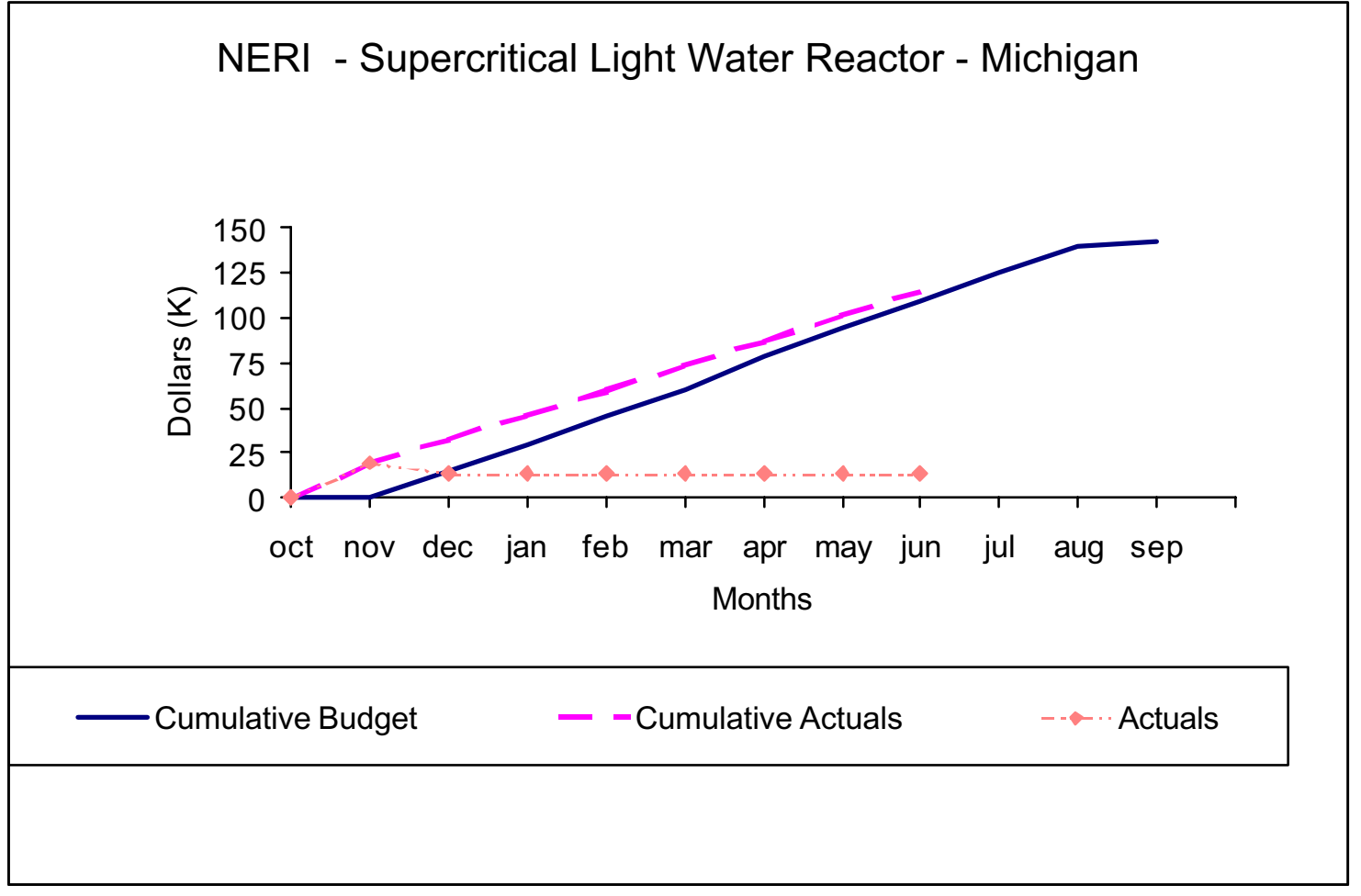

\section{Westinghouse Electric Co.}

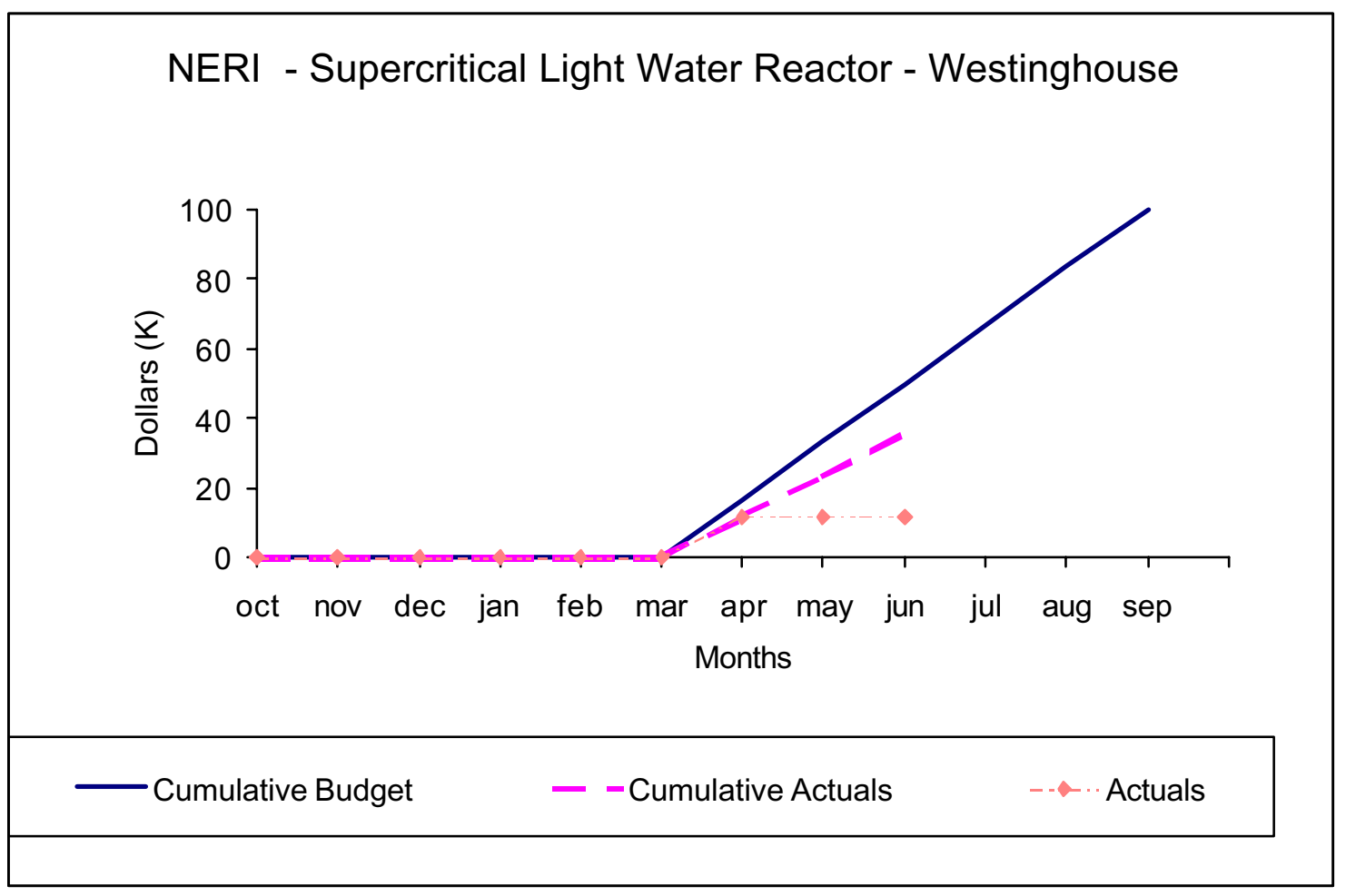




\section{Appendix A - Thermal-hydraulics of the SCWR Core with Moderator Boxes}

In this appendix simple calculations are presented to support the thermal feasibility of the core geometry used for the neutronic analysis of Section 2. The geometry is that of Figure 4. Table A.I reports the main input data for the calculations. Note that with the assumed pressure and inlet/outlet temperatures the thermal efficiency of the system is estimated to be about $42.5 \%$ [Oka and Koshizuka 2000], which is deemed acceptable. In Table A.I the radial power depression is defined as the ratio of the lowest-to-average fuel-assembly power, and its importance will become apparent later in the analysis. It is assumed that the flow rate in the fuel assemblies is adjusted by means of orifices to maintain the average outlet temperature of $450^{\circ} \mathrm{C}$ throughout the core. Note that the average power density is comparable with that of a PWR (i.e., $105 \mathrm{~kW} / \mathrm{L}$ ) and is much higher than that of a BWR (i.e., $54 \mathrm{~kW} / \mathrm{L}$ ).

Table A.I. Input data for the thermal calculations.

\begin{tabular}{|l|l|}
\hline \multicolumn{1}{|c|}{ Parameter } & \multicolumn{1}{c|}{ Value } \\
\hline Fuel & $\mathrm{UO}_{2}, 95 \% \mathrm{TD}$ \\
\hline Pin OD & $9.6 \mathrm{~mm}$ \\
\hline Cladding Thickness & $0.57 \mathrm{~mm}$ \\
\hline Cladding Material & Alloy 718 (high-Ni alloy) \\
\hline Fuel Pin Pitch & $11.616 \mathrm{~mm}$ \\
\hline Pitch-to-Diameter Ratio & 1.21 \\
\hline Moderator Box Side Length & $23.232 \mathrm{~mm}$ \\
\hline Moderator Box Thickness & $0.57 \mathrm{~mm}$ \\
\hline Cell Hydraulic Diameter & $5.133 \mathrm{~mm}$ \\
\hline Cell Flow Area & $312.74 \mathrm{~mm}$ \\
\hline Active Fuel Length & $4.27 \mathrm{~m}(14 \mathrm{ft})$ \\
\hline Core Inlet/Outlet Temperature & $280 / 450^{\circ} \mathrm{C}$ \\
\hline Operating Pressure & $25 \mathrm{MPa}$ \\
\hline Average Fuel Pin Power & $100 \mathrm{~kW}$ \\
\hline Average Power Density & $96.4 \mathrm{~kW} / \mathrm{L}$ \\
\hline Average Linear Heat Generation & $23.4 \mathrm{~kW} / \mathrm{m}$ \\
\hline Radial Power Peaking & 1.3 \\
\hline Radial Power Depression & 0.6 \\
\hline Axial Power Peaking & $1.57(=\pi / 2$ from cosine profile) \\
\hline Peak Linear Heat Generation & $47.8 \mathrm{~kW} / \mathrm{m}$ \\
\hline
\end{tabular}

Two constraints are used in the analysis. First, the peak cladding temperature in the core should remain below $620^{\circ} \mathrm{C}$ at $100 \%$ power. It was shown by Hattori et al. [2000] that the mechanical and corrosion properties of Alloy 718 at this temperature are compatible with long-term operation in a supercriticalwater environment. This conclusion is also confirmed by Viswanathan and Bakker [2000] for high-Ni alloys in general. The second constraint is that the fuel centerline temperature remain below the melting point of irradiated $\mathrm{UO}_{2}$ at $112 \%$ power. The melting point for irradiated $\mathrm{UO}_{2}$ is $2600^{\circ} \mathrm{C}$, recommended by Todreas and Kazimi [1990].

To calculate the cladding temperature, we make use of the following equations: 


$$
\begin{array}{ll}
\dot{\mathrm{m}} \frac{\mathrm{dh}}{\mathrm{dz}}=\mathrm{q}^{\prime}(\mathrm{z}) & \text { (energy conservation) } \\
\mathrm{q}^{\prime \prime}=\mathrm{H}\left(\mathrm{T}_{\mathrm{w}}-\mathrm{T}_{\mathrm{b}}\right) & \text { (Newton's law of cooling) }
\end{array}
$$

where $\dot{m}$ is the fuel assembly flow rate, $h$ is the coolant enthalpy, $q^{\prime}$ is the fuel assembly linear heat generation rate with a cosine axial profile, $\mathrm{q}^{\prime \prime}$ is the heat flux at the fuel pin surface (calculated from q' by means of obvious geometric considerations), $\mathrm{H}$ is the heat transfer coefficient, $\mathrm{T}_{\mathrm{w}}$ is the wall temperature and $\mathrm{T}_{\mathrm{b}}$ is the bulk temperature. The heat transfer coefficient is calculated with the Oka-Koshizuka's (OK) correlation [Koshizuka and Oka 2000], which was specifically developed for SCWR applications, accounts for the deterioration and enhancement of heat transfer phenomena characteristic of supercritical fluids, and was validated with experimental data for supercritical water. The O-K correlation consists of the following equations:

$$
\begin{aligned}
& \mathrm{Nu}=0.015 \operatorname{Re}^{0.85} \operatorname{Pr}^{\mathrm{y}} \\
& \mathrm{y}=0.69-\frac{81000}{\mathrm{DHF}}+\mathrm{f}_{\mathrm{c}} \mathrm{q}^{\prime \prime} \\
& \mathrm{f}_{\mathrm{c}}=\left\{\begin{array}{lc}
2.9 \times 10^{-8}+0.11 / \mathrm{DHF} & 0 \leq \mathrm{h} \leq 1500 \mathrm{~kJ} / \mathrm{kg} \\
-8.7 \times 10^{-8}-0.65 / \mathrm{DHF} & 1500 \leq \mathrm{h} \leq 3300 \mathrm{~kJ} / \mathrm{kg} \\
-9.7 \times 10^{-7}+1.3 / \mathrm{DHF} & 3330 \leq \mathrm{h} \leq 4000 \mathrm{~kJ} / \mathrm{kg}
\end{array}\right.
\end{aligned}
$$

$$
\mathrm{DHF}=200 \cdot \mathrm{G}^{1.2}
$$

where DHF is the deterioration heat transfer flux in $\mathrm{W} / \mathrm{m}^{2}$ and $\mathrm{G}$ is the mass flux in $\mathrm{kg} / \mathrm{m}^{2} \mathrm{~s}$. Use of the O$\mathrm{K}$ correlation is recommended for the following range of the parameters: $\mathrm{G}=1.00-1.75 \mathrm{Mg} / \mathrm{m}^{2} \mathrm{~s}, \mathrm{q}^{\prime \prime}=0.0-$ $1.8 \mathrm{MW} / \mathrm{m}^{2}$ and $\mathrm{T}_{\mathrm{b}}=20-550^{\circ} \mathrm{C}$.

The axial coolant and cladding temperature profiles for the peak-power fuel assembly (1.3 peaking) are illustrated in Figure A.1. It can be seen that the peak cladding temperature constraint is met with a large margin. However, the most severe temperature conditions for the cladding occur in the fuel assembly of lowest power, which in our case is also that of lowest flow rate. This is because the heat flux at which the heat transfer coefficient drops is proportional to the coolant flow with an exponent greater than unity (see equation A.6). Figure A.2 shows the axial coolant and cladding temperature profiles for the lowest-power fuel assembly (0.6 power depression). The cladding temperature is indeed higher than in the peak-power fuel assembly, nevertheless the $620^{\circ} \mathrm{C}$ constraint is still met with a margin of about $13^{\circ} \mathrm{C}$.

To calculate the fuel centerline temperature at $112 \%$ power, we shall assume that the peak cladding temperature at this power level is $840^{\circ} \mathrm{C}$ in accordance with the transient limit specified by Ishiwatari et al. [2002] for their SCWR design with high-Ni alloy fuel cladding. The peak linear heat generation rate at $112 \%$ power is $47.8 \times 1.12=53.5 \mathrm{~kW} / \mathrm{m}$. The thermal conductivity of Alloy 718 at the temperatures of interest is about $20 \mathrm{~W} / \mathrm{m} \cdot \mathrm{K}$ [Allvac 2002]. Then, the temperature drop across the cladding is $54^{\circ} \mathrm{C}$. Assuming a cold gap conductance of $2 \times 10^{4} \mathrm{~W} / \mathrm{m}^{2} \mathrm{~K}$ [Todreas and Kazimi 1990], the temperature drop across the gap is about $50^{\circ} \mathrm{C}$. Therefore, the fuel surface temperature is $944^{\circ} \mathrm{C}$. The value of the thermal conductivity integral of the fuel is $53.5 /(4 \pi)=4.26 \mathrm{~kW} / \mathrm{m}$. Using the thermal conductivity data for $95 \%$ $\mathrm{TD} \mathrm{UO}_{2}$ fuel from Todreas and Kazimi [1990] combined with a surface temperature of $944^{\circ} \mathrm{C}$, the centerline temperature is estimated to be about $2570^{\circ} \mathrm{C}$, which meets the no-fuel-melting constraint. 


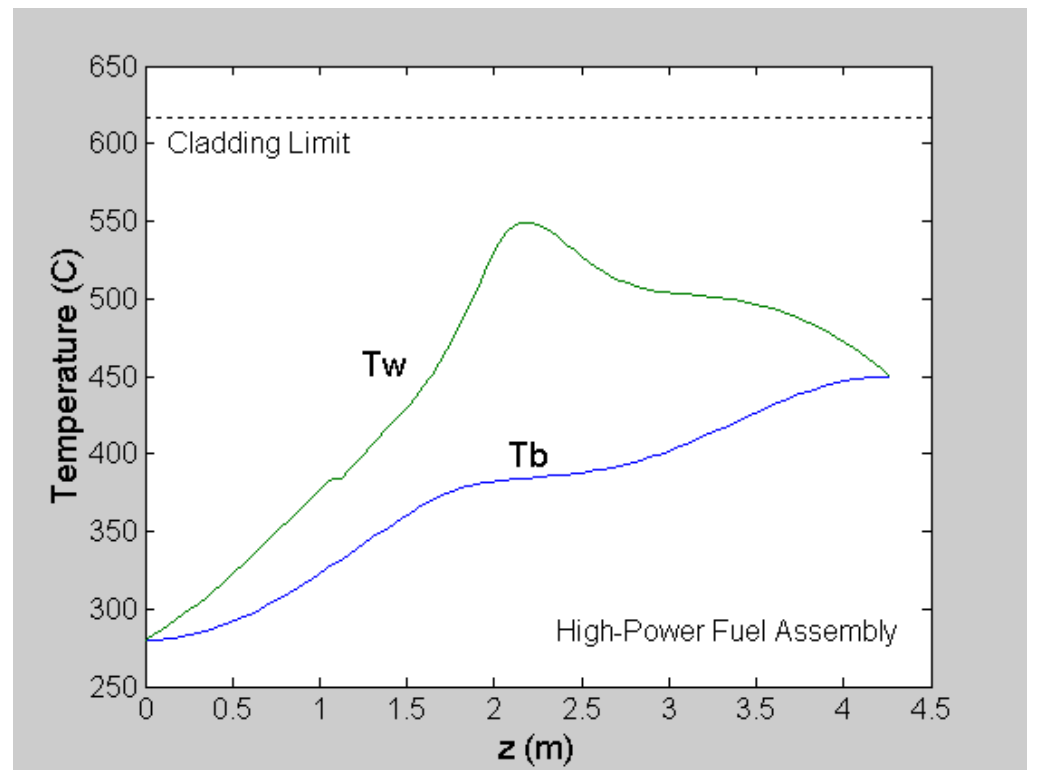

Figure A.1. Temperature profiles in the fuel assembly of highest power.

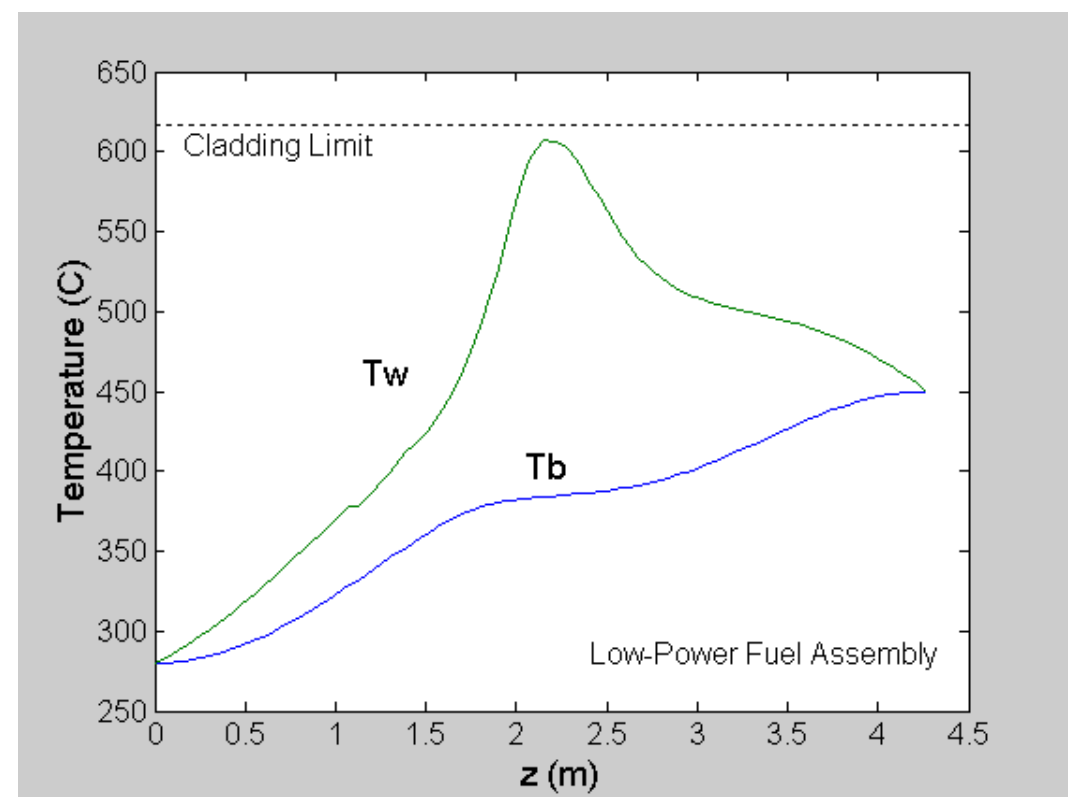

Figure A.2. Temperature profiles in the fuel assembly of lowest power.

Finally, it is important to estimate the maximum operating temperatures of the $\mathrm{ZrH}_{\mathrm{x}}$ moderator, which are used in the feasibility study of Section 3. A temperature distribution exists within the moderator because of neutron and gamma heating. For the purpose of this calculation we shall assume that all fast neutron and gamma energy (or about $10.3 \%$ of the total energy released by a fission event [Todreas and Kazimi 1990]) is deposited in the moderator. This is a very conservative assumption especially with regard to the gamma energy deposition, which will in fact mostly occur in the heavy and high atomic number uranium fuel.

Considering that there are 5 fuel pins for each moderator box and that the peak linear heat generation rate in the fuel pin is $47.8 \mathrm{~kW} / \mathrm{m}$, it is possible to estimate the peak linear heat generation rate in the moderating box as $47.8 \times 5 \times 0.103=24.6 \mathrm{~kW} / \mathrm{m}$. Then the heat flux at the moderator box outer surface is 
about $265 \mathrm{~kW} / \mathrm{m}^{2}$. For this value of the heat flux the O-K correlation yields a heat transfer coefficient of about $12 \mathrm{~kW} / \mathrm{m}^{2} \mathrm{~K}$, so the temperature at the moderator box outer surface is $450+265 / 12 \sim 470^{\circ} \mathrm{C}$. The thermal conductivity of Alloy 718 at the temperatures of interest is $15 \mathrm{~W} / \mathrm{m} \cdot \mathrm{K}$ [Allvac 2002]. Then the temperature drop across the moderator box wall is about $10^{\circ} \mathrm{C}$. Allowing for an additional $10^{\circ} \mathrm{C}$ contactresistance drop between the moderator box wall and the $\mathrm{ZrH}_{\mathrm{x}}$, the moderator surface temperature becomes $490^{\circ} \mathrm{C}$. Assuming a $\mathrm{ZrH}_{\mathrm{x}}$ thermal conductivity of $15 \mathrm{~W} / \mathrm{m} \cdot \mathrm{K}$ (see Section 3.1) and approximating the square box with a cylinder, the temperature drop within the $\mathrm{ZrH}_{\mathrm{x}}$ is $24600 /(4 \pi \times 15) \sim 130^{\circ} \mathrm{C}$, resulting in a peak centerline $\mathrm{ZrH}_{\mathrm{x}}$ temperature of $620^{\circ} \mathrm{C}$. 


\section{Appendix B: Nomenclature}

$\mathrm{Cp}$
$\mathrm{Dh}$
$\mathrm{G}$
$\mathrm{H}$
$\mathrm{Ht}$
$\mathrm{L}$
$\mathrm{Nu}$
$\mathrm{P}$
$\mathrm{P} / \mathrm{D}$
$\mathrm{Pr}$
$\mathrm{Q}$
$\mathrm{Re}$
$\mathrm{T}$

$\lambda$
$\mu$
$\rho$
$\Delta \mathrm{h}$

\section{Subscripts}

B

W

In

Out

Acronyms
ABWR
Bishop
BWR
CHF
DHF
DNB
FFP
LMFBR
MNCTR
Ratio
MDNBR
MDHFR
OK
PWR
SCWR
SRP

Heat Capacity [KJ/kg C]

Hydraulic Diameter [m]

Mass Velocity $\left[\mathrm{kg} / \mathrm{m}^{2} \mathrm{~s}\right]$

Specific Enthalpy [KJ/kg]

Heat Transfer coefficient $\left[\mathrm{KW} / \mathrm{m}^{2} \mathrm{C}\right]$

Channel Length

Nusselt Number

Pressure [MPa]

Pitch-over-Diameter Ratio

Prandtl Number

Heat Flux $\left[\mathrm{W} / \mathrm{m}^{2}\right]$

Reynolds Number

Temperature [C]

Conductivity [W/m C]

Viscosity [Pa-s]

Density $\left[\mathrm{kg} / \mathrm{m}^{3}\right]$

Enthalpy difference $[\mathrm{KJ} / \mathrm{kg}]$

Bulk temperature properties

Wall temperature properties

Core Inlet value

Core Outlet value

Advanced BWR

Bishop correlation

Boiling Water Reactor

Critical Heat Flux

Deterioration Heat Flux

Departure from Nucleate Boiling

Fossil Fuel Plant

Liquid Metal Fast Breeder Reactor

Minimum Nominal Cladding Temperature

Minimum DNB Ratio

Minimum DHF Ratio

Oka-Koshizuka correlation

Pressurized Water Reactor

SuperCritical Water Reactor

Standard Review Plan (NUREG-0800) 


\section{Feasibility Study of Supercritical Light Water Cooled Fast Reactors for Actinide Burning and Electric Power Production}

Nuclear Energy Research Initiative Project 2001-001

\section{Progress Report for Work Through June 2002}

$3^{\text {rd }}$ Quarterly Report

Principal Investigators:

Philip MacDonald, Dr. Jacopo Buongiorno, Cliff Davis, and Dr. Kevan Weaver

Telephone: 208-526-9634

Fax: 208-526-2930

Email: pem@inel.gov

Collaborating Organizations:

Massachusetts Institute of Technology

Principal Investigators: Professor Ron Latanision and Dr. Bryce Mitton

University of Michigan

Principal Investigator: Professor Gary Was

Westinghouse Electric Company

Principal Investigators: Drs. Luca Oriani, Mario Carelli, and Dmitry Paramonov, and Lawrence Conway 